\title{
Fitogeografía de la costa del Pacífico de Norteamérica
}

\author{
por \\ Manuel Peinado Lorca ${ }^{1}$, Miguel Ángel Macías Rodríguez², Juan Luis Aguirre Martínez 3 \\ \& José Delgadillo Rodríguez ${ }^{4}$
}

\begin{abstract}
${ }^{1}$ Departamento de Biología Vegetal, Universidad de Alcalá, E-28871 Alcalá de Henares, España; manuel.lorca@uah.es. ${ }^{2}$ Departamento de Ciencias Ambientales, CUCBA, Universidad de Guadalajara, Jalisco, México, mmacias@cucba.udg.mx.

Cátedra de Medio Ambiente, Universidad de Alcalá, E-28871 Alcalá de Henares, España; juanl.aguirre@uah.es.

${ }^{4}$ Herbario BCMEX, P.O. Box 189003-064, Coronado, California, USA; jdelga.jose@gmail.com.
\end{abstract}

\section{Resumen}

Peinado Lorca, M., Macías Rodríguez, M.Á., Aguirre Martínez, J.L. \& Delgadillo Rodríguez, J. 2009. Fitogeografía de la costa del Pacífico de Norteamérica. Anales Jard. Bot. Madrid 66(2): 151-194.

Este estudio fue diseñado para analizar la variación florística a lo largo de la costa del Pacífico entre Cook Inlet, Alaska $\left(61^{\circ} 30^{\prime} \mathrm{N}\right)$ hasta el extremo sur de la península de Baja California, México $\left(23^{\circ} 02^{\prime} \mathrm{N}\right)$, utilizando para ello los datos correspondientes a 965 inventarios fitosociológicos (que incluyen 686 plantas vasculares) obtenidos en el muestreo de 279 localidades costeras. Mediante un método de clasificación por agrupamientos (Average Linkage Clustering), y usando el índice de similitud de Sørensen como medida de la diversidad florística entre aquéllos, los datos de campo fueron relacionados con las cuatro regiones biogeográficas descritas en el área de estudio: Boreal-Norteamericana, Rocosiana, Californiana y Xerofítico-Mexicana. De acuerdo con sus respectivos patrones de distribución, los táxones registrados (géneros y especies) fueron agrupados en elementos florísticos. Los elementos florísticos, junto con la comparación entre los principales tipos de vegetación costera, sirvieron como criterios para realizar una clasificación fitogeográfica más detallada del área de estudio, en la que se han diferenciado ocho provincias florísticas. Las diferencias fitogeográficas actuales están condicionadas por ciertos acontecimientos paleoclimáticos y paleogeográficos que se discuten en este artículo. Las provincias boreales y templadas presentan porcentajes muy elevados de elementos de amplia distribución, cuyo origen hay que situar en la geoflora Boreotropical o Artoterciaria que dominó el hemisferio norte durante el Terciario. Las provincias florísticamente más diversas son las que se sitúan en la región Californiana, debido a que albergan elementos de las geofloras Artoterciaria y Madroterciaria. La flora tropical de la península de Baja California se caracteriza por un elevado número de táxones relacionados con la flora neotropical, especialmente con la de Sudamérica.

Palabras clave: Biodiversidad, Biogeografía, elemento florístico, Geofloras, Paleobiogeografía, provincias florísticas.

\begin{abstract}
Peinado Lorca, M., Macías Rodríguez, M.Á., Aguirre Martínez, J.L. \& Delgadillo Rodríguez, J. 2009. Phytogeography of the Pacific Coast of North America. Anales Jard. Bot. Madrid 66(2): 151-194 (in Spanish).

This study was designed to explore floristic variation along the Pacific coast from Cook Inlet, Alaska $\left(61^{\circ} 30^{\prime} \mathrm{N}\right)$, to the southern tip of Baja California, Mexico, at $23^{\circ} 02^{\prime} \mathrm{N}$. Data corresponding to 965 phytosociological relevés (including 686 vascular plants) obtained by sampling 279 coastal sites were examined. Using an objective classification system (Average Linkage Clustering) and Sørensen's index, floristic data acquired in fieldwork were related to the biogeographical regions of the study area. According to the worldwide distribution pattern of genera and species, the registered taxa were grouped into phytogeographical elements. These elements, along with the climatic classification of the sites and comparisons among the main coastal vegetation types, gave rise to a phytogeographical classification of the study area in which four regions (North American Boreal, Rocky Mountain, Californian and Xerophytic-Mexican) and eight floristic provinces were distinguished. Each province is characterized by its climate, changes in phytogeographic elements, the presence of endemic genera or species, and by its characteristic vegetation types. Floristic differences among provinces are related to palaeoclimatic and palaeogeographical events. The boreal and temperate provinces show high percentages of broadly distributed elements, whose origins can be found in the Boreotropical or Arctotertiary geoflora that dominated the Northern Hemisphere during the Tertiary. The floristically richest provinces are the three that occupy the Mediterranean zone, since these provinces harbour elements of the Arctotertiary and Madrotertiary geofloras. The flora of tropical Baja California is characterised by a high number of taxa related to Neotropical flora, especially to those showing links with South America.
\end{abstract}

Keywords: Biodiversity, Biogeography, floristic element, floristic provinces, Geoflora, Palaeobiogeography. 


\section{Introducción}

Desde los trabajos pioneros de Humboldt, y basándose en las restricciones en la distribución de la mayoría de las especies, los fitogeógrafos han agrupado las plantas de acuerdo con las similitudes en sus patrones de distribución, lo que constituye un criterio esencial en la clasificación biogeográfica (Hagen, 1986). Hay tres enfoques principales para la clasificación biogeográfica basada en la distribución de las plantas: los dos primeros (por semejanzas florísticas y por unidades fitocoronómicas) tienen una base exclusivamente florística, mientras que el tercero integra también otros componentes bióticos y abióticos. Con el primer enfoque los táxones dentro de una determinada zona se reúnen en grupos florísticos de similar distribución geográfica, que han sido llamados "areal types" (Whittaker \& Niering, 1964), "floristic groups" (Gleason \& Cronquist, 1964), "geographical elements" (Stott, 1981) o "phytogeographical elements" (Qian, 1999).

El objetivo del segundo enfoque, denominado " $\mathrm{Fi}$ tocoronomía" por Takhtajan (1986), es investigar la variación espacial en la composición florística dentro de una zona determinada, clasificándola dentro de un sistema jerárquico cuyas categorías fundamentales son reinos, regiones y provincias, a las que se caracteriza a través de sus táxones endémicos, en lugar de hacerlo por los compartidos. En otras palabras, mientras que el método de los elementos florísticos se basa explícitamente en especies compartidas, es decir, en la similitud, el método de Takhtajan está basado en la exclusividad. Aunque ambos métodos no son en absoluto excluyentes, por lo general han sido utilizados por unos $\mathrm{u}$ otros fitogeógrafos para sus clasificaciones, como ha ocurrido con las clasificaciones a escala continental de Qian (1999), basada en elementos fitogeográficos, y la de Thorne (1993), que sigue la clasificación fitocoronómica de Norteamérica elaborada por Takhtajan en colaboración con Cronquist (Takhtajan, 1986).

Una tercera aproximación a la clasificación fitogeográfica puede ser llamada "integradora”, puesto que en la misma se concitan aspectos fisiográficos y geológicos, clima, flora y vegetación. Esta metodología tiene una larga tradición en Norteamérica, desde Merriam y su concepto de "región biótica", en el cual integra también el componente faunístico (Merriam, 1890, 1898). El sistema fue usado por Dice (1943) en el primer mapa de provincias bióticas de Norteamérica y ha sido el empleado en clasificaciones más recientes tanto de Baja California (Peinado \& al., 1994a) como de Norteamérica (Daubenmire, 1978; Brown \& al., 1998; Rivas-Martínez \& al., 1999). Con la excepción del uso de la fauna como criterio de clasificación, la división en provincias que se presenta en este artículo intenta seguir el criterio de Dice de considerar las provincias como áreas discretas que, además de compartir flora, vegetación y fauna, poseen características fisiográficas y climáticas comunes, un criterio también seguido, con algunas modificaciones, en las clasificaciones continentales de Bailey (1995) y Brown \& al. (1998).

A pesar de algunos excelentes trabajos regionales y la disponibilidad de buenas floras territoriales, hasta la fecha los cambios florísticos en la vegetación costera del Pacífico de Norteamérica no han sido definidos con precisión. En un estudio preliminar de las dunas del Pacífico, Cooper (1936) fue el primero en describir la distribución de 53 plantas representativas de playas y dunas desde el sureste de Alaska hasta el norte de Baja California. Casi 40 años después, Macdonald \& Barbour (1974), Breckon \& Barbour (1974) y Barbour \& al. (1975) publicaron la única síntesis florística conocida de las playas arenosas y marismas del Pacífico norteamericano, pero sus trabajos no incluyen especies de hábitats adyacentes tales como dunas, acantilados, playas pedregosas y otros ambientes costeros. Aunque algunos estudios regionales o locales (Kumler, 1969; Wiedemann, 1966; Williams \& Potter, 1972; Johnson, 1977; Barbour \& Johnson, 1988; Klinka \& al., 1995; Grewell \& al., 2007; Pickart \& Barbour, 2007) han establecido la distribución y ecología de las plantas que aparecen en otros hábitats costeros, hasta la fecha no se ha abordado una síntesis fitogeográfica completa de la costa pacífica septentrional.

En algunas de nuestras publicaciones previas, hemos relacionado la vegetación clímax del oeste de Norteamérica con la variación bioclimática (Peinado \& al., 1997a), establecimos los límites de los zonobiomas del Pacífico usando la vegetación zonal y azonal como indicadoras (Peinado \& al., 1994a, 1997b, 2007), identificamos las similitudes climáticas que producen idénticos modelos de zonación en los halobiomas de California, Baja California, y del Mediterráneo europeo (Peinado \& al., 1995a), así como los patrones zonales que asemejan a los manglares norteamericanos con otros tropicales (Peinado \& al., 1995c). El presente estudio, que se sitúa entre los objetivos de la tesis doctoral de uno de los autores del presente trabajo (M.Á. Macías), fue diseñado para investigar la variación florística a lo largo de la costa del Pacífico norteamericano, desde Alaska hasta Baja California. Analizando el clima, la variación florística latitudinal, los grupos florísticos, el componente endémico y la vegetación, realizamos una propuesta de clasificación fitogeográfica del área de estudio que trata de definir con mayor precisión algunas unidades fitogeográficas esbozadas con anterioridad a escala regional o continental. 
La clasificación fitogeográfica está principalmente basada en el análisis florístico de los tipos de vegetación azonal costera. La vegetación azonal es aquella que está influenciada en mayor medida por el suelo que por el clima, lo que incluye típicos ejemplos de biomas litorales tales como litobiomas, psammobiomas, halobiomas y anfibiomas (Walter, 1985).

\section{Material y métodos}

\section{Área de estudio}

Situada a lo largo de unos 7000 kilómetros del litoral occidental del océano Pacífico, el área de estudio se extiende desde Cook Inlet, Alaska (613ㅇN), hasta el extremo sur de la península de Baja California, en los $23^{\circ} 02^{\prime} \mathrm{N}$ (Fig. 1). En longitud, el área alcanza su límite occidental en la isla de Kodiak (152 $\left.{ }^{\circ} 34^{\prime} \mathrm{W}\right)$, mientras la localidad muestreada más oriental fue Bahía de las Palmas (109'34'W), en Baja California Sur (Fig. 2). Toda esa franja litoral está delimitada al oeste por el más potente sistema fisiográfico de Norteamérica, el Pacific Border System (Brouillet \& Whetstone, 1993).

A lo largo de la zona de estudio se distinguen cuatro macroclimas (Boreal, Templado, Mediterráneo y Tropical), que corresponden a otros tantos zonobiomas (Peinado \& al., 2007), cuyos límites coinciden aproximadamente con los de las cuatro regiones biogeográficas definidas en el área de estudio. El zonobioma Boreal está incluido en la región Boreal-Norteamericana de Rivas-Martínez \& al. (1999), dentro de la cual, de acuerdo con Dice (1943), se distinguen sendas provincias: Hudsoniana (boreal continental) y Sitchense (boreal oceánica). El zonobioma Templado se extiende a lo largo de la franja oceánica de la región Rocosiana (Rocky Mountains region de Takhtajan, 1986), la denominada provincia Oregoniana (Dice, 1943). El zonobioma Mediterráneo corresponde a la región Californiana (Raven, 1988), dentro de la cual se han definido las provincias Californiano Septentrional, Californiano Meridional y Martirense (Peinado \& al., 1994b). La zona tropical corresponde a la región Xerofítico-Mexicana (Rzedowski, 1978), que en la zona de estudio fue dividida en dos provincias: Bajocaliforniana y Sanlucana (Peinado \& al., 1994b). El mapa de la Fig. 1 está basado en la clasificación en provincias bióticas de Dice (1943) con las modificaciones surgidas de este artículo.

\section{Métodos}

Como preparación para los trabajos de campo se seleccionaron 300 localidades a lo largo de la costa del Pacífico, incluyendo las islas Kodiak y Vancouver. Las localidades fueron seleccionadas mediante el conocimiento previo de las mismas derivado de la bibliografía, eligiendo aquellas sobre las que existía constancia de la existencia de una vegetación bien conservada; se seleccionaron también localidades situadas en zonas de especial protección como parques nacionales, estatales o reservas de vida silvestre, en el supuesto de que la vegetación situada en las mismas estaría en un estado más próximo al natural. Como puede verse en la Fig. 2, hay un gran tramo costero, el situado entre el sur de Alaska y la isla de Vancouver, en el que el número de localidades visitadas es muy reducido, lo que se debe tanto a la presencia de grandes glaciares desprovistos de vegetación como a la inaccesibilidad del mismo. Por el contrario, las localidades muestreadas se concentran en algunos tramos costeros, como en el extremo sur de la península de Baja California; tal concentración se produce por la existencia, en esas zonas, de ecosistemas costeros muy extensos y especialmente bien preservados.

Una vez seleccionadas, las localidades fueron asignadas a un determinado zonobioma o zonoecotono de acuerdo con nuestra propuesta anterior (Peinado \& al., 2007). Con ello, cada localidad también resultó inicialmente adscrita a una determinada región biogeográfica.

El objetivo de los trabajos de campo, realizados entre abril de 2004 y agosto de 2008, fue tomar inventarios de plantas vasculares en cada localidad, valorando la importancia de cada planta en su respectivo hábitat. Para ello, en cada localidad se delimitaron subjetivamente comunidades en función de la fisionomía de la vegetación y de las especies dominantes como indicadoras de las condiciones ecológicas. Para evaluar la abundancia y dominancia de las plantas vasculares en sus respectivas comunidades, en cada una de ellas se seleccionó un cuadrado de muestreo basado en el concepto de área minima para comunidades florísticamente uniformes (Westhoff \& van der Maarel, 1973); en cada uno de esos cuadrados se tomó un inventario fitosociológico según el método de Braun-Blanquet (1979). Este método es de gran utilidad para la toma rápida y eficaz de datos de campo en zonas cuya flora es bien conocida (Westhoff \& van der Maarel, 1973: 701), y se está utilizando cada vez más en Norteamérica (Keeler-Wolf, 2007). Se tomaron 965 inventarios en 279 localidades (Fig. 2; para la ubicación exacta de esas localidades véase el Apéndice 2). En los inventarios se registraron un total de 381 géneros y 686 táxones infragenéricos. La nomenclatura de estos últimos sigue a USDA (2008), excepto para los táxones de Baja California (Wiggins, 1980) y para las especies de los géneros Agave (Gentry, 1978), Helianthus (Heiser \& al., 1966), e Isocoma (Nesom, 1991). La nomenclatura de los géneros sigue a Wielgorskaya (1995). El material recolectado se conserva en el herbario BCMEX. 


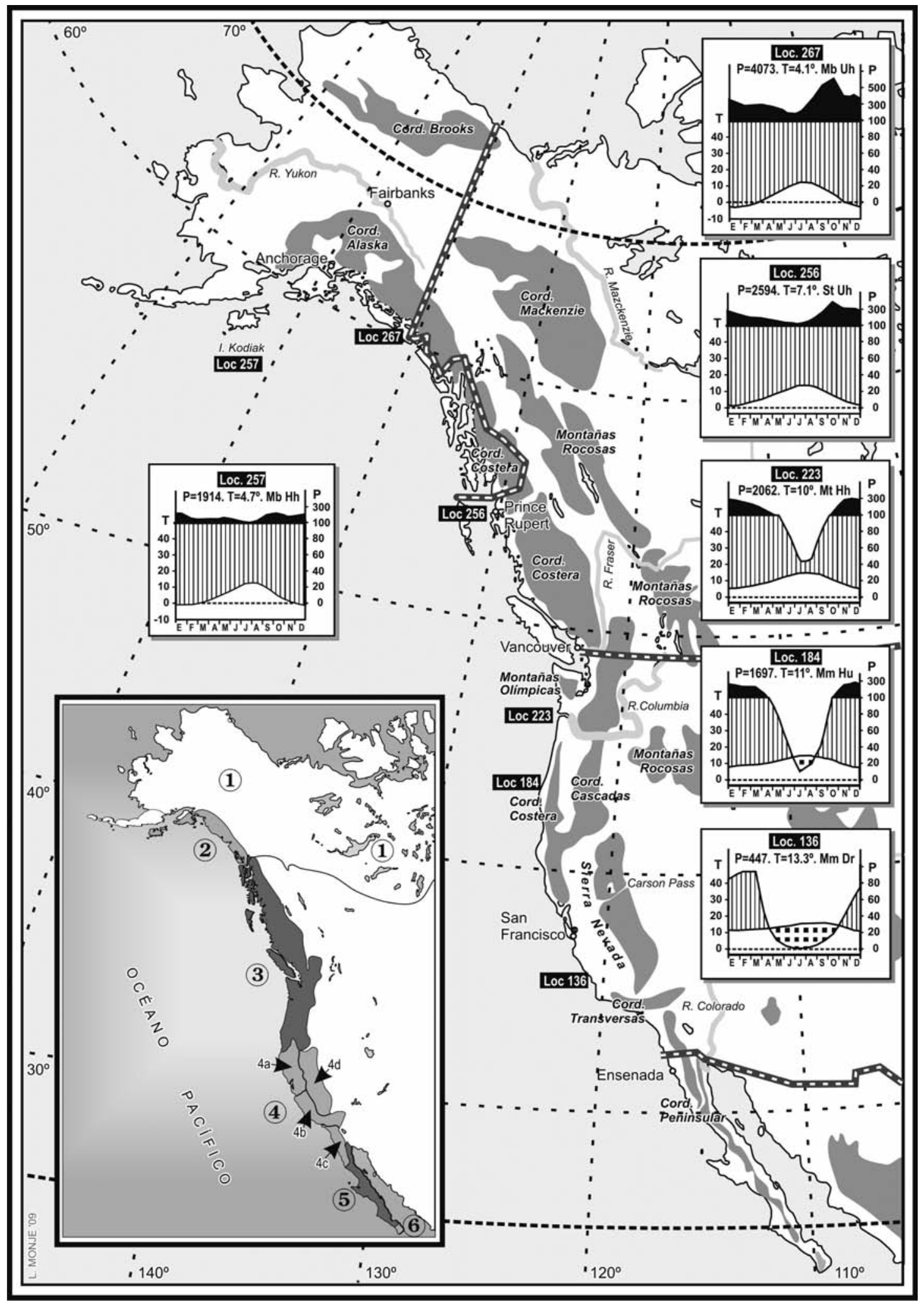

Fig. 1. Esquema fisiográfico de la cuenca del Pacífico norteamericano, con climatogramas de seis localidades muestreadas (véase el Apéndice 2). En el recuadro inferior izquierdo se muestran las unidades fitogeográficas de dicha cuenca adaptadas de Dice (1943): 1, provincia Hudsoniana. 2, provincia Sitchense. 3, provincia Oregoniana. 4, región Californiana (provincias: 4a, Californiana Septentrional; 4b, Californiana Meridional; 4c, Martirense; 4d, Nevadense). 5, provincia Bajocaliforniana. 6, provincia Sanlucana. Abreviaturas de los climogramas: Ombrotipos: Hh, Hiperhúmedo; Hu, Húmedo; Se, Seco; Uh, Ultrahiperhúmedo. Termotipos: Mb, Mesoboreal; Mm, Mesomediterráneo; Mt, Mesotemplado; St, Supratemplado. P, Precipitación anual (mm). Termotipos y ombrotipos según Rivas-Martínez (2007). 
El siguiente paso fue recopilar la información disponible sobre el área de distribución de los táxones registrados en los inventarios. Para ello, se utilizaron fuentes bibliográficas (Cooper, 1936; Peck, 1941; Hultén, 1968; Calder \& Taylor, 1968; Munz \& Keck, 1973; Macdonald \& Barbour, 1974; Breckon \& Barbour, 1974; Barbour \& al., 1975; Good, 1974; Johnson, 1977; Abrams \& Ferris, 1980; Wiggins, 1980; Barbour \& Johnson, 1988; Hickman, 1993; MacKinnon \& al., 1994; Pojar \& MacKinnon, 1994; Klinka \& al., 1995; Wielgorskaya, 1995; Mabberley, 2002; Flora of Norteamerica Editorial Committee, 1993-2008), junto con los mapas de distribución obtenidos de las bases de datos Klinkenberg y USDA. Según su distribución mundial, cada uno de los táxones registrados fue asignado a uno de los 17 elementos fitogeográficos que se presentan en la Tabla 1 (véase también el Apéndice 1 para la adscripción de un determinado taxon a su correspondiente elemento).

Con los datos obtenidos en el campo, se construyó una matriz de doble entrada (localidades y especies), en la cual los valores de abundancia/dominancia de la escala de Braun-Blanquet fueron transformados en una escala binaria de presencia (valor 1) o ausencia (valor 0 ). Esta matriz fue utilizada para clasificar los datos utilizando el software SPSS 13.0 y el método de clústeres o agrupamientos ALC (Average Linkage Clustering), basado en las distancias Euclídeas al cuadrado y delimitando los agrupamientos en función de las principales discontinuidades. El ALC es uno de los métodos más usados para clasificar datos numerosos y heterogéneos (Digby \& Kempton, 1987; Kent \& Coker, 1992). Obtenidos grupos relativamente homogéneos, las diferencias en la diversidad entre ellos fueron posteriormente valoradas utilizando matrices elaboradas con el índice de similitud de Sørensen (SI), que fue calculado como

$$
S I=2 c /(a+b)
$$

siendo $C$ el número de táxones compartidos por cada par de agrupamientos comparados; y $a$ y $b$, el número de táxones en cada uno de ellos (Sørensen, 1948). La elaboración manual de las matrices de Sørensen a partir de la comparación por pares de los grupos obtenidos en el ALC, aunque muy laboriosa, permite detectar las especies características y diferenciales de dichos grupos, lo que resulta de gran utilidad para elaborar las tablas sintéticas de porcentajes que se presentan en el apartado de resultados. Por otro lado, el método de $S \varnothing$ rensen resalta más las presencias que las ausencias de especies (Legendre \& Legendre, 1983), lo que es de importancia en la clasificación biogeográfica integrada cuando está basada en la vegetación azonal, cuyas especies tienden a tener áreas de distribución muy extensas y sus comunidades son relativamente pobres en especies características o diferenciales. Por último, el método de Sørensen ha sido muy usado en análisis biogeográficos de Norteamérica, desde los trabajos pioneros de Dice (1945) hasta la clasificación de Qian (1999).

Tabla 1. Áreas de distribución de los elementos fitogeográficos definidos en este artículo. Las abreviaturas son las empleadas en texto y tablas.

\begin{tabular}{|l|l|l|}
\hline & \multicolumn{1}{|c|}{ Elementos fitogeográficos } & \multicolumn{1}{c|}{ Área de distribución } \\
\hline AAT & Anfiatlántico Tropical & Zonas tropicales de las costas atlánticas afroamericanas. \\
APT & Anfipacífico Tropical & Zonas tropicales de las costas pacíficas de Asia y América. \\
BAJ & Bajocaliforniano & Provincias tropicales Bajocaliforniana y Sanlucana (1). \\
BOR & Boreo-Pacífico Occidental & Costas boreales de Alaska y British Columbia. \\
CAL & Californiano & Región Californiana (1). \\
COS & Cosmopolita & Cosmopolita y subcosmopolita. \\
DIS & Disyunto & Discontinua sobre dos o más regiones fitogeográficas (2). \\
HOL & Holártico & Reino Holártico (3). \\
INT & Introducido & Alóctono en el area de estudio. \\
MAD & Madreano & Región Madreana (3). \\
NAE & Norteamericano-Asiático Oriental & Zonas boreotempladas de las costas pacíficas de Asia y América. \\
NAS & Norte-Suramericano & Norteamérica y Suramérica (excluyendo las plantas NEO). \\
NEO & Neotropical & Reino Neotropical. \\
NOA & Norteamericano & Norteamérica, incluyendo Groenlandia y México. \\
OES & Norteamericano Occidental & Oeste de las Rocosas. \\
PAC & Pacifico & Costa del Pacifico norteamericano. \\
PAN & Pantropical & Pantropical. \\
SON & Sonorense & Provincia Sonorense (4). \\
TEM & Templado-Pacífico Occidental & Costas templadas entre Oregon y British Columbia. \\
\hline
\end{tabular}

(1) Véase la Fig. 1. (2) Elemento aplicado sólo para géneros y excluyendo los géneros incluidos en los elementos NAE, NAS, NEO y PAN. (3) Sensu Takhtajan (1986). (4) Sensu Takhtajan (I.c.), pero excluyendo los táxones del elemento BAJ. 


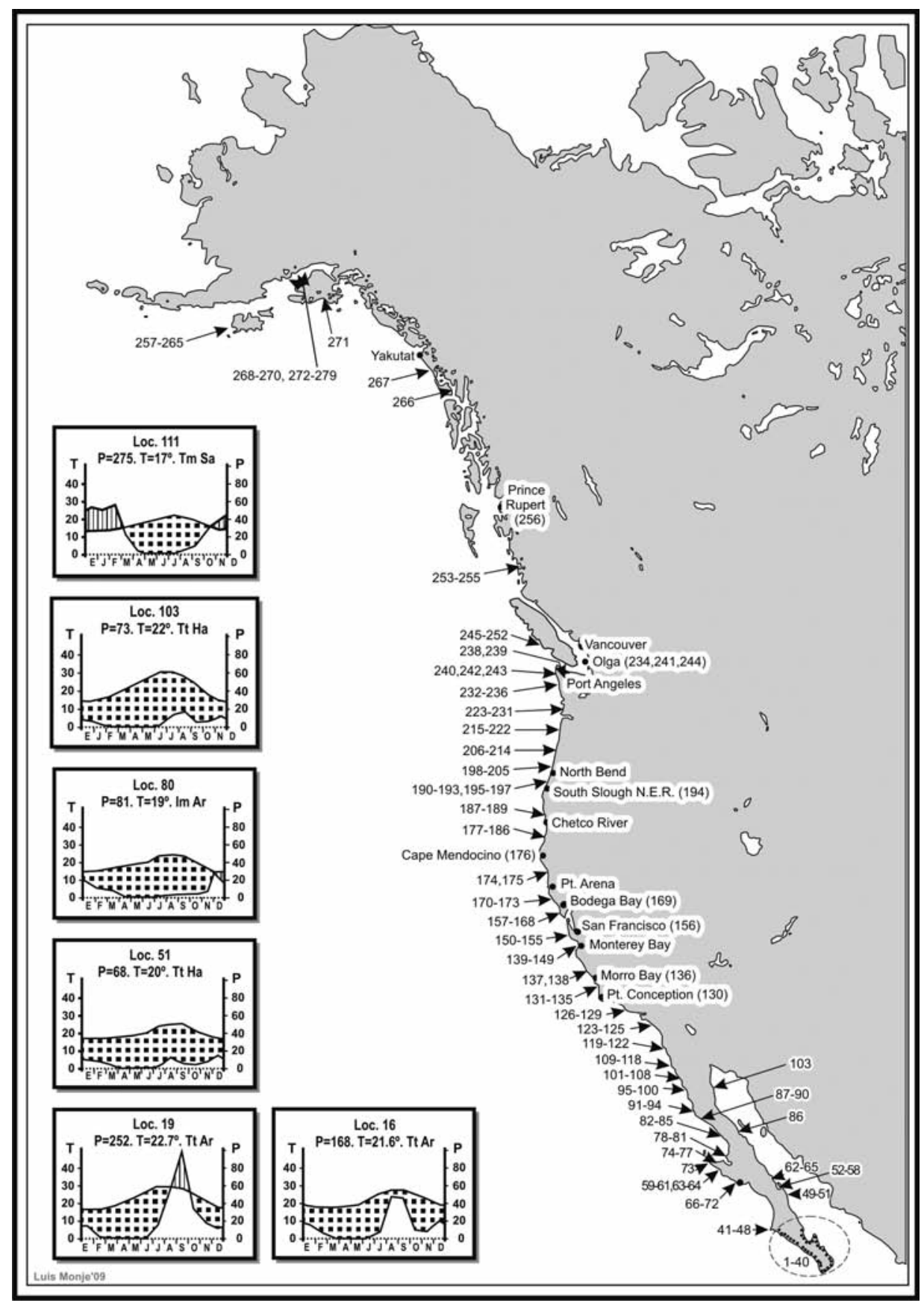

Fig. 2. Localidades muestreadas (véase el Apéndice 2) y climatogramas de seis de ellos. Abreviaturas de los climatogramas: Ombrotipos: Ar, Árido; Ha, Hiperárido; Sa, Semiárido. Termotipos: Tm, Termomediterráneo; Tt, Termotropical. P, Precipitación anual (mm). (Termotipos y ombrotipos según Rivas-Martínez, 2007).

\section{Resultados y discusión}

\section{Resultados de la clasificación}

La Fig. 3 muestra los agrupamientos obtenidos usando la matriz de 279 localidades, que se distribuyeron en seis agrupamientos iniciales. De acuerdo con la localización geográfica de las localidades y su asignación a una región biogeográfica, cuatro de los grupos corresponden a otras tantas regiones $\mathrm{BOR}$, BorealNorteamérica; ROC, Rocosiana; CAL, Californiana; XER, Xerofítico-Mexicana) y dos grupos a las zonas de transición o zonoecotonos (TRA-1 y TRA-2). A su vez, los cuatro grupos regionales se dividieron en subgrupos. Para determinar la composición florística de estos grupos y subgrupos, se construyó una tabla 
sintética que incluyó los 686 táxones infragenéricos junto con los porcentajes de presencia en cada grupo y subgrupo. Los datos totales y porcentuales por elementos fitogeográficos se muestran en las Tablas 2 y 3 ; los datos de esa tabla para los 260 táxones más significativos se presentan en las Tablas 4-7 y 11-14, mientras que los índices de similitud entre pares de grupos y subgrupos se resumen en las Tablas 8-10. En el Apéndice 1 se presenta el listado completo de los táxones registrados agrupados por elementos.

El subgrupo XER-1 incluyó los inventarios procedentes de las localidades más septentrionales de la región Xerofitico-Mexicana. XER-2 reunió a los tomados en las localidades con manglares (Avicennia germinans, Laguncularia racemosa, Maytenus phyllanthoides y Rhizophora mangle), mientras que en los subgrupos XER-3 y XER-4 se incluyeron los procedentes del extremo meridional del área de estudio, la región de El Cabo de la península de Baja California. Ambos subgrupos meridionales presentan los porcentajes más bajos de plantas de los elementos Madreano y Californiano, lo que subraya su mayor distancia con la flora septentrional. Por el contrario, los porcentajes de táxones de relaciones tropicales son los más elevados de todos los grupos. En ambos subgrupos el número de las especies endémicas del elemento Bajocaliforniano alcanza las proporciones más altas, lo que sugiere su mayor aislamiento con respecto a otros subgrupos xerofítico-mexicanos.

Setenta y tres localidades de las inicialmente adscritas a la región Californiana $(77,7 \%)$ resultaron incluidas en el grupo CAL; y diez, en TRA-2. El grupo CAL se subdividió en siete subgrupos (Tabla 5). La mayor parte de las localidades con halobiomas y anfibiomas se agruparon en el subgrupo CAL-1. El subgrupo CAL-2 incluyó 19 localidades situadas entre el centro y el norte de California, desde la bahía de Monterey hasta la frontera entre California y Oregón. Este sugbrupo muestra claras similitudes florísticas con el subgrupo CAL-3, pero en este último -que incluye los inventarios tomados en los sistemas dunares de la bahía de Monterey-faltan los táxones típicos de playas y saladares (Abronia latifolia, Ammopbila arenaria, Leymus mollis subsp. mollis, Sarcocornia pacifica y Spartina foliosa), mientras que dominan los caméfitos y nanofanerófitos de dunas semifijas: Artemisia californica, A. pycnocephala, Baccharis pilularis, Corethrogyne filaginifolia var. californica, Eriogonum parvifolium y Eriopbyllum stoechadifolium.

El subgrupo CAL-4 reunió 5 localidades en las cuales coexisten dos especies formadoras de dunas pioneras, Abronia maritima y A. latifolia, una superposición de áreas de dos especies con el mismo biotipo e idénticos requerimientos ecológicos (Purer, 1936),

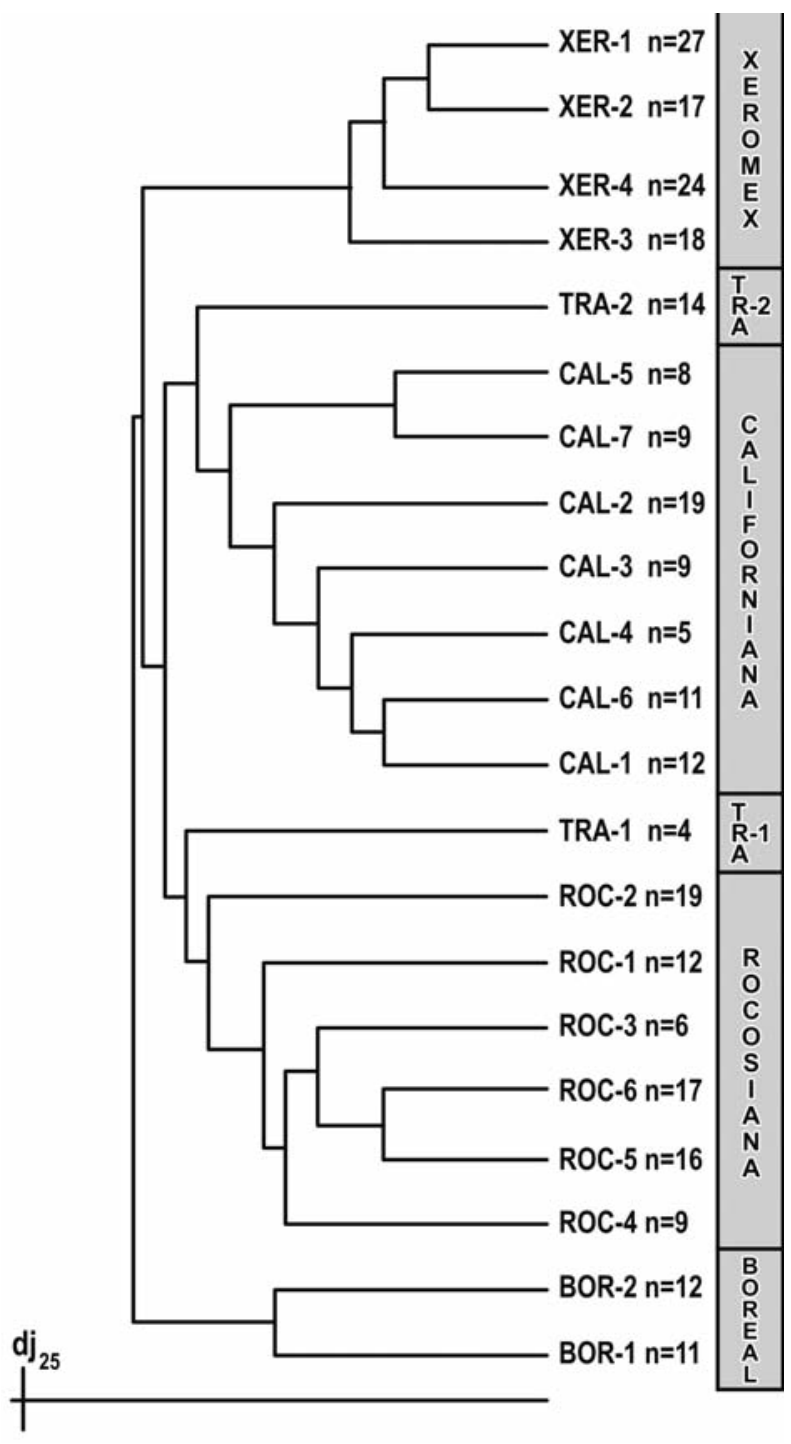

Fig. 3. Dendrograma obtenido por ALC de 965 inventarios tomados en 279 localidades ( $n$ ).

que en toda la costa del Pacífico sólo se presenta en algunas playas del centro de California. En los inventarios de esas localidades faltan los arbustos propios de las dunas primarias y secundarias, mientras que presentan altos porcentajes de plantas pioneras de playas como Camissonia cheiranthifolia subsp. cheiranthifolia, Ambrosia chamissonis y Cakile maritima.

El subgrupo CAL-5 reunió ocho localidades situadas alrededor de Point Conception, en donde se encuentran las únicas localidades dunares bien conservadas del sur de California: Guadalupe, Nipomo, Pismo Beach y Oso Flaco. El elevado número de especies por localidad refleja la alta diversidad de hábitats, entre los que destacan las saucedas edafófilas con mirtos (Myrica californica, Salix lasiolepis), extensos matorrales de 


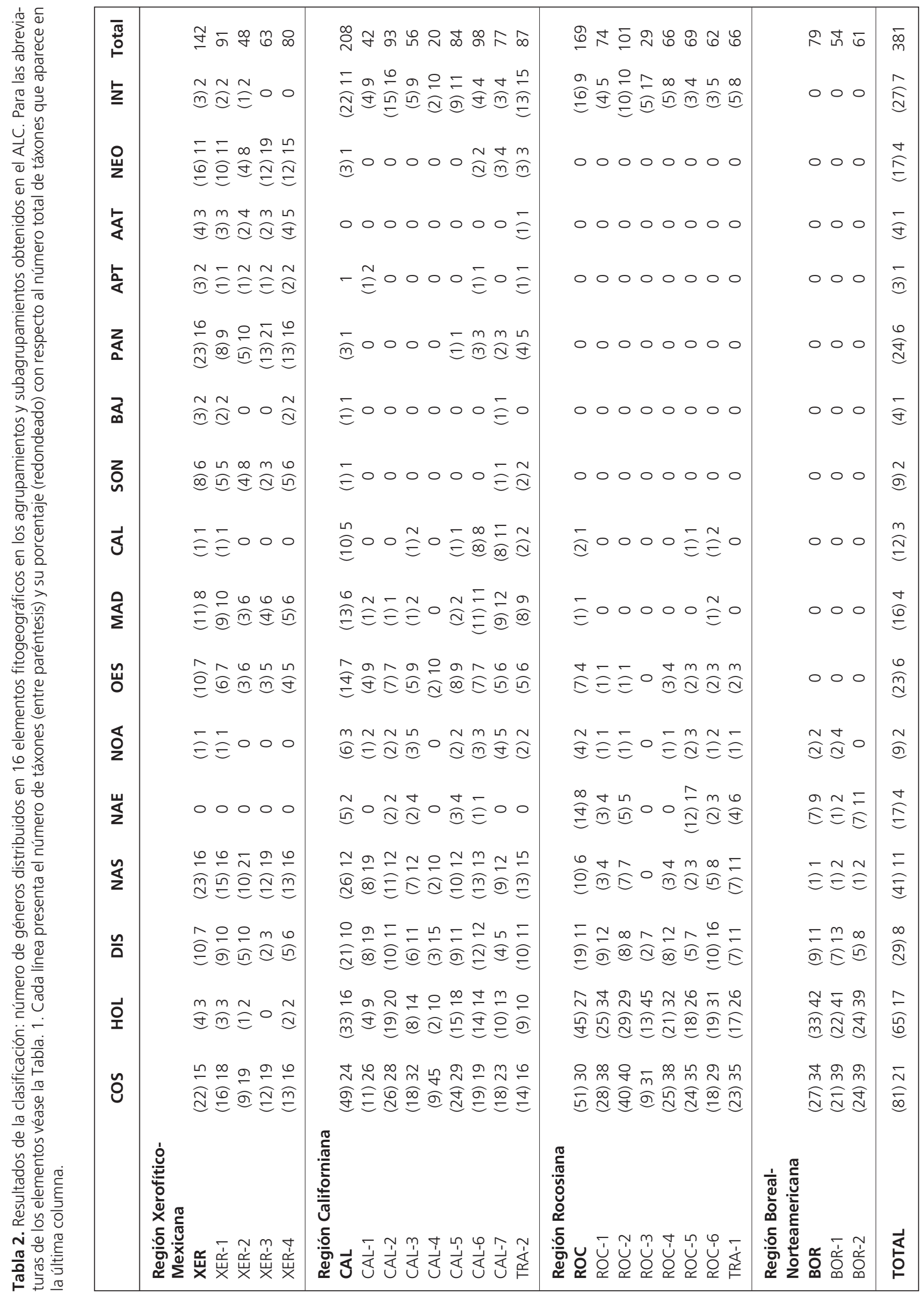




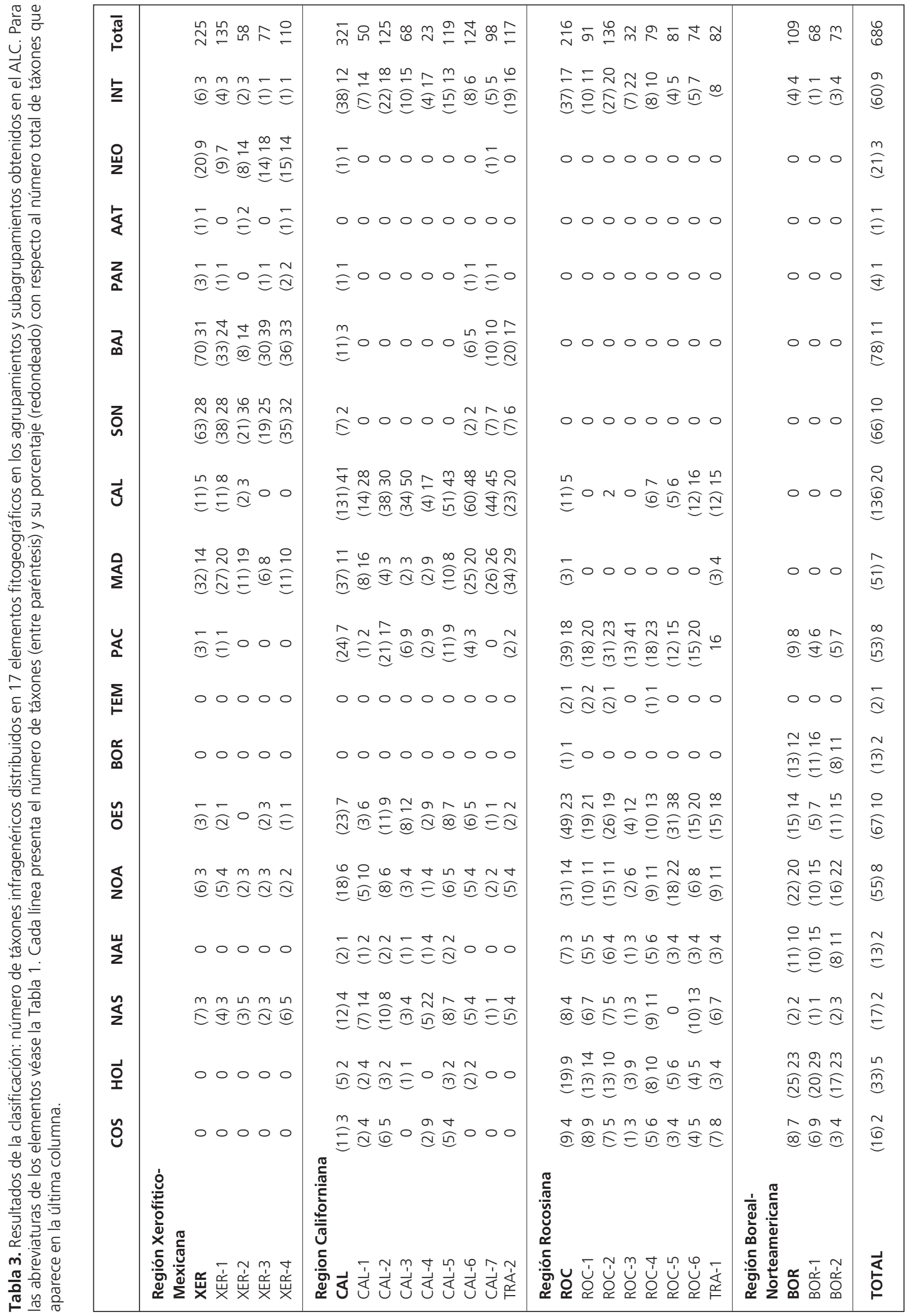


Tabla 4. Resultados de la clasificación por ALC: diferencias florísticas más significativas entre las localidades de la región XerofíticoMexicana (subgrupos XER-1 a XER-4) y las de la zona de transición entre ésta y la región Californiana (subgrupo TRA-2). Las cifras son porcentajes redondeados de presencia.

\begin{tabular}{|c|c|c|c|c|c|}
\hline Subgrupos & 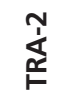 & 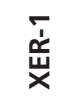 & 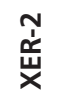 & 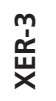 & 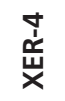 \\
\hline Número de especies & 117 & 135 & 58 & 78 & 111 \\
\hline Número de localidades & 14 & 27 & 17 & 18 & 24 \\
\hline Media de especies por localidad & 29 & 22 & 16 & 26 & 17 \\
\hline \multicolumn{6}{|c|}{ Plantas de distribución californiana meridional } \\
\hline Lotus scoparius var. scoparius & 7 & - & - & - & - \\
\hline Nassella lepida & 7 & - & - & - & - \\
\hline Dudleya lanceolata & 29 & - & - & - & - \\
\hline Viguiera laciniata & 14 & - & - & - & - \\
\hline Agave shawii subsp. shawii & 14 & - & - & - & - \\
\hline Opuntia littoralis & 14 & - & - & - & - \\
\hline Rhus integrifolia & 14 & - & - & - & - \\
\hline Encelia californica var. californica & 21 & - & - & - & - \\
\hline Mirabilis californica & 43 & - & - & - & - \\
\hline Rosa minutifolia & 21 & - & - & - & - \\
\hline Bergerocactus emoryi & 21 & - & - & - & - \\
\hline Amblyopappus pusillus & 79 & - & - & - & - \\
\hline Dudleya cultrata & 86 & - & - & - & - \\
\hline \multicolumn{6}{|c|}{ Plantas de distribución californiana y tropical } \\
\hline Sarcocornia pacifica & 21 & 26 & 47 & - & 4 \\
\hline Spartina foliosa & 21 & 19 & 35 & - & - \\
\hline Frankenia salina & 21 & 19 & - & - & - \\
\hline Suaeda esteroa & 21 & 19 & 6 & - & - \\
\hline Arthrocnemum subterminale & 21 & 19 & 41 & - & 13 \\
\hline Batis maritima & 21 & 26 & 88 & - & 25 \\
\hline Monanthochloe littoralis & 43 & 26 & 41 & - & 25 \\
\hline Limonium californicum & 7 & - & - & - & - \\
\hline \multicolumn{6}{|c|}{ Plantas de distribución californiana-meridional y tropical } \\
\hline Abronia maritima & 64 & 44 & 12 & 22 & 50 \\
\hline Stenocereus gummosus & 43 & 11 & 12 & 33 & 13 \\
\hline Croton californicus & 7 & 4 & - & 56 & 17 \\
\hline Mammillaria dioica & 50 & 7 & 6 & - & - \\
\hline Simmondsia chinensis & 21 & - & - & 33 & - \\
\hline Isocoma menziesii var. vernonioides & 57 & 4 & - & - & - \\
\hline Lycium brevipes & 93 & 48 & - & - & - \\
\hline Euphorbia misera & 71 & 56 & - & - & - \\
\hline Dudleya attenuata subsp. orcuttii & 7 & 4 & - & - & - \\
\hline Isocoma menziesii var. menziesii & 64 & 4 & 6 & - & - \\
\hline Helianthus niveus subsp. niveus & 93 & 7 & - & - & - \\
\hline Echinocereus maritimus & 21 & 4 & - & - & - \\
\hline Ambrosia chenopodifolia & 21 & 11 & - & - & - \\
\hline Opuntia prolifera & 21 & 7 & - & - & - \\
\hline Mesembryanthemum crystallinum & 100 & 44 & - & - & - \\
\hline Atriplex canescens subsp. canescens & 50 & 41 & - & - & - \\
\hline Atriplex julacea & 79 & 89 & 6 & - & - \\
\hline Frankenia palmeri & 50 & 100 & 6 & - & - \\
\hline
\end{tabular}


Tabla 4. (Continuación).

\begin{tabular}{|c|c|c|c|c|c|}
\hline Subgrupos & 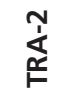 & $\begin{array}{l}\overline{\dot{q}} \\
\overrightarrow{\breve{x}}\end{array}$ & 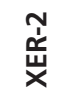 & 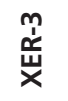 & 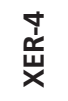 \\
\hline Número de especies & 117 & 135 & 58 & 78 & 111 \\
\hline Número de localidades & 14 & 27 & 17 & 18 & 24 \\
\hline Media de especies por localidad & 29 & 22 & 16 & 26 & 17 \\
\hline Lycium andersonii & - & 7 & 47 & - & 4 \\
\hline Camissonia cheiranthifolia subsp. suffruticosa & 43 & 4 & - & - & - \\
\hline Suaeda taxifolia & 43 & 37 & - & - & 13 \\
\hline Camissonia crassifolia & 29 & 70 & - & - & - \\
\hline Astragalus anemophilus & 50 & 4 & - & - & - \\
\hline \multicolumn{6}{|l|}{ Plantas de distribución xerofítico-mexicana } \\
\hline Ambrosia ambrosioides & - & 67 & 88 & 72 & 100 \\
\hline Cenchrus palmeri & - & 30 & 88 & 67 & 96 \\
\hline Hymenoclea pentalepis & - & 67 & 88 & 78 & 100 \\
\hline Allenrolfea occidentalis & - & 74 & 88 & 11 & 33 \\
\hline Hyptis emoryi & - & 67 & 88 & 17 & 92 \\
\hline Fouquieria diguetii & - & 37 & 35 & - & 4 \\
\hline Atriplex magdalenae & - & 7 & - & - & 33 \\
\hline Plantas termotropicales & - & - & - & - & - \\
\hline Maytenus phyllanthoides & - & - & 88 & 78 & 63 \\
\hline Opuntia cholla & - & - & 18 & 61 & 8 \\
\hline Bursera microphylla & - & - & 29 & 11 & 8 \\
\hline Sporobolus virginicus & - & - & 12 & 89 & 29 \\
\hline Ipomoea pes-caprae subsp. brasiliensis & - & - & 6 & 94 & 4 \\
\hline Sesuvium verrucosum & - & - & 41 & 11 & 13 \\
\hline Laguncularia racemosa & - & - & 100 & - & 4 \\
\hline Rhizophora mangle & - & - & 100 & - & 8 \\
\hline Avicennia germinans & - & - & 100 & - & 13 \\
\hline \multicolumn{6}{|l|}{ Elementos sanlucanos } \\
\hline Oenothera drummondii var. thalassaphila & - & - & - & 94 & 4 \\
\hline Setaria palmeri & - & - & - & 94 & 100 \\
\hline Cyrtocarpa edulis & - & - & - & 78 & 25 \\
\hline Euphorbia leucophylla & - & - & - & 100 & 29 \\
\hline Jouvea pilosa & - & - & - & 100 & 33 \\
\hline Lycium fremontii var. congestum & - & - & - & 50 & 33 \\
\hline Proboscidea althaefolia & - & - & - & 94 & 25 \\
\hline Antigonon leptopus & - & - & - & 61 & 4 \\
\hline Asclepias subulata & - & - & - & 72 & 4 \\
\hline Froelichia interrupta & - & - & - & 72 & 4 \\
\hline Jatropha cordata & - & - & - & 44 & 4 \\
\hline Portulaca pilosa & - & - & - & 56 & 4 \\
\hline Drymaria holosteoides var. crassifolia & - & - & - & 39 & 4 \\
\hline Bursera cerasifolia & - & - & - & 28 & 4 \\
\hline Dalea divaricata subsp. anthonyi & - & - & - & 83 & - \\
\hline Cardiospermum corindum & - & - & - & 33 & - \\
\hline Castela peninsularis & - & - & - & 33 & - \\
\hline Porophyllum porphyreum & - & - & - & 39 & - \\
\hline Physalis glabra & - & - & - & 39 & - \\
\hline Scaevola plumieri & - & - & - & 39 & - \\
\hline
\end{tabular}


Tabla 5. Resultados de la clasificación por ALC: diferencias florísticas más significativas entre las localidades de la región Californiana (subgrupos CAL-1 a CAL-7) y las de la zona de transición californiano-rocosiana (subgrupo TRA-1). Las cifras son los porcentajes redondeados de presencia.

\begin{tabular}{|c|c|c|c|c|c|c|c|c|}
\hline Subgrupos & $\frac{5}{5}$ & 永 & $\stackrel{m}{1}$ & $\stackrel{+}{⿺}$ & 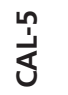 & $\stackrel{\varphi}{\stackrel{1}{8}}$ & 交 & $\begin{array}{l}\underset{\Sigma}{\Sigma} \\
\underset{F}{F}\end{array}$ \\
\hline Número de especies & 50 & 125 & 68 & 23 & 120 & 147 & 98 & 82 \\
\hline Número de localidades & 12 & 19 & 9 & 5 & 8 & 11 & 9 & 4 \\
\hline Media de especies por localidad & 14 & 23 & 18 & 8 & 34 & 21 & 29 & 35 \\
\hline \multicolumn{9}{|l|}{ Plantas de distribución boreo-templada } \\
\hline Carex lyngbyei & - & - & - & - & - & - & - & 25 \\
\hline Picea sitchensis & - & - & - & - & - & - & - & 25 \\
\hline Deschampsia cespitosa subsp. beringensis & - & - & - & - & - & - & - & 25 \\
\hline Festuca rubra subsp. rubra & - & - & - & - & - & - & - & 25 \\
\hline Sarcocornia perennis & - & - & - & - & - & - & - & 50 \\
\hline \multicolumn{9}{|c|}{ Plantas de distribución rocosiana y californiana septentrional } \\
\hline Baccharis pilularis & 8 & 58 & 67 & - & 88 & 27 & - & 100 \\
\hline Ammophila arenaria & 8 & 63 & - & - & 38 & 18 & - & 100 \\
\hline Calystegia soldanella & 17 & 16 & - & 60 & 13 & - & - & 100 \\
\hline Armeria maritima subsp. californica & - & 32 & 33 & - & 13 & - & - & 75 \\
\hline Carex obnupta & - & 16 & - & - & 13 & - & - & 50 \\
\hline Juncus falcatus & - & 11 & - & - & 13 & - & - & 50 \\
\hline Polygonum paronychia & - & 37 & - & - & 13 & - & - & 75 \\
\hline Carex pansa & - & - & 22 & - & 63 & - & - & 50 \\
\hline Polystichum munitum & - & - & 11 & - & - & - & - & 50 \\
\hline Salix hookeriana & - & 11 & - & - & - & - & - & 50 \\
\hline Pinus contorta var. contorta & - & - & - & - & - & - & - & 25 \\
\hline Tanacetum camphoratum & - & - & - & - & - & - & - & 75 \\
\hline Cardionema ramosissimum & - & 11 & - & - & - & - & - & 50 \\
\hline Phacelia argentea & - & - & 11 & - & - & - & - & 50 \\
\hline Myrica californica & - & - & - & - & 75 & 18 & - & - \\
\hline Lonicera involucrata var. involucrata & - & - & - & - & - & - & - & 50 \\
\hline Alnus rubra & - & - & - & - & - & - & - & 50 \\
\hline Spiranthes romanzoffiana & - & - & - & - & - & - & - & 50 \\
\hline Veronica scutellata & - & - & - & - & - & - & - & 25 \\
\hline \multicolumn{9}{|l|}{ Plantas de distribución californiana septentrional } \\
\hline Camissonia cheiranthifolia subsp. cheiranthifolia & 8 & 58 & 22 & 100 & 38 & - & - & 100 \\
\hline Artemisia pycnocephala & 8 & 58 & 33 & - & 13 & - & - & 100 \\
\hline Salix lasiolepis & - & 5 & 11 & 40 & 100 & - & - & 25 \\
\hline Erigeron glaucus & - & 58 & 89 & - & 25 & - & - & 50 \\
\hline Eriogonum latifolium & - & 68 & 22 & - & 13 & - & - & 75 \\
\hline Ericameria ericoides & 8 & 32 & 11 & - & 75 & - & - & - \\
\hline Lupinus arboreus & - & 16 & 11 & - & 38 & - & - & 25 \\
\hline Eriophyllum stoechadifolium & - & 74 & 89 & - & 63 & - & - & - \\
\hline Eriogonum parvifolium & - & 11 & 89 & - & 75 & - & - & - \\
\hline Corethrogyne californica var. californica & - & 11 & 67 & - & 88 & - & - & - \\
\hline Toxicodendron diversilobum & - & - & 33 & - & 63 & 9 & - & - \\
\hline Grindelia hirsutula var. maritima & - & 11 & 44 & - & - & - & - & - \\
\hline \multicolumn{9}{|l|}{ Plantas de distribución californiana meridional } \\
\hline Lotus scoparius var. scoparius & - & - & - & - & 50 & 36 & 78 & - \\
\hline Nassella lepida & - & - & - & - & 25 & 9 & 78 & - \\
\hline Dudleya lanceolata & - & - & - & - & 13 & 18 & 89 & - \\
\hline Lupinus chamissonis & - & - & - & 20 & 63 & - & - & - \\
\hline Dudleya caespitosa & - & - & - & - & 50 & 9 & - & - \\
\hline Viguiera laciniata & - & - & - & - & - & 18 & 78 & - \\
\hline Agave shawii subsp. shawii & - & - & - & - & - & 55 & 100 & - \\
\hline Opuntia littoralis & - & - & - & - & - & 45 & 44 & - \\
\hline Rhus integrifolia & - & - & - & - & - & 64 & 78 & - \\
\hline Encelia californica var. californica & - & - & - & - & - & 27 & 56 & - \\
\hline Mirabilis californica & - & - & - & - & - & 9 & 44 & - \\
\hline Rosa minutifolia & - & - & - & - & - & 9 & 56 & - \\
\hline Bergerocactus emoryi & - & - & - & - & - & 36 & 100 & - \\
\hline
\end{tabular}


Tabla 5. (Continuación).

\begin{tabular}{|c|c|c|c|c|c|c|c|c|}
\hline Subgrupos & 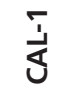 & స̃ & $\stackrel{m}{\stackrel{n}{ك}}$ & $\frac{+}{d}$ & 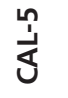 & $\stackrel{\varphi}{\stackrel{1}{4}}$ & 今 & 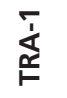 \\
\hline Número de especies & 50 & 125 & 68 & 23 & 120 & 147 & 98 & 82 \\
\hline Número de localidades & 12 & 19 & 9 & 5 & 8 & 11 & 9 & 4 \\
\hline Media de especies por localidad & 14 & 23 & 18 & 8 & 34 & 21 & 29 & 35 \\
\hline Cneoridium dumosum & - & - & - & - & - & 36 & 44 & - \\
\hline Eriogonum fasciculatum var. fasciculatum & - & - & - & - & - & 36 & 78 & - \\
\hline Malosma laurina & - & - & - & - & - & 18 & 44 & - \\
\hline Acalypha californica & - & - & - & - & - & 18 & 44 & - \\
\hline Erigeron blochmaniae & - & - & - & - & 50 & - & - & - \\
\hline Senecio blochmaniae & - & - & - & - & 63 & - & - & - \\
\hline Conicosia pugioniformis & - & - & - & - & 50 & - & - & - \\
\hline Amblyopappus pusillus & - & - & - & - & - & - & 22 & - \\
\hline Achnatherum diegoense & - & - & - & - & - & - & 44 & - \\
\hline Dudleya campanulata & - & - & - & - & - & - & 44 & - \\
\hline \multicolumn{9}{|c|}{ Plantas de distribución californiana y xerofítico-mexicana } \\
\hline Sarcocornia pacifica & 100 & 42 & - & 20 & 25 & 9 & - & - \\
\hline Spartina foliosa & 75 & 32 & - & - & 25 & 18 & - & 50 \\
\hline Frankenia salina & 92 & 16 & - & - & 25 & 18 & - & - \\
\hline Limonium californicum & 58 & 16 & - & - & 25 & - & - & 50 \\
\hline Suaeda esteroa & 58 & - & - & - & 13 & 18 & - & - \\
\hline Arthrocnemum subterminale & 58 & - & - & - & - & 18 & - & - \\
\hline Batis maritima & 50 & - & - & - & - & 18 & - & - \\
\hline Monanthochloe littoralis & 58 & - & - & - & - & 18 & - & - \\
\hline \multicolumn{9}{|c|}{$\begin{array}{l}\text { Plantas de distribución californiano-meridional } \\
\text { y xerofítico-mexicana }\end{array}$} \\
\hline Abronia maritima & - & - & - & 40 & 25 & 18 & 11 & - \\
\hline Stenocereus gummosus & - & - & - & - & - & 9 & 44 & - \\
\hline Croton californicus & - & - & - & - & 50 & 9 & - & - \\
\hline Mammillaria dioica & - & - & - & - & - & 18 & 89 & - \\
\hline Simmondsia chinensis & - & - & - & - & - & 18 & 89 & - \\
\hline Lycium brevipes & - & - & - & - & - & 27 & 11 & - \\
\hline Euphorbia misera & - & - & - & - & - & 9 & 78 & - \\
\hline Dudleya attenuata subsp. orcuttii & - & - & - & - & - & 18 & 44 & - \\
\hline Isocoma menziesii var. menziesii & - & - & - & - & - & 18 & 11 & - \\
\hline Helianthus niveus subsp. niveus & - & - & - & - & - & 9 & 11 & - \\
\hline Echinocereus maritimus & - & - & - & - & - & 18 & 44 & - \\
\hline Ambrosia chenopodifolia & - & - & - & - & - & 9 & 44 & - \\
\hline Opuntia prolifera & - & - & - & - & - & 9 & 67 & - \\
\hline Mesembryanthemum crystallinum & - & - & - & - & - & 18 & 11 & - \\
\hline Atriplex canescens subsp. canescens & - & - & - & - & - & 18 & 11 & - \\
\hline Isocoma menziesii var. vernonioides & - & - & - & - & - & 18 & - & - \\
\hline Atriplex julacea & - & - & - & - & - & - & 11 & - \\
\hline Frankenia palmeri & - & - & - & - & - & - & 11 & - \\
\hline Lycium andersonii & - & - & - & - & - & - & 22 & - \\
\hline Camissonia cheiranthifolia subsp. suffruticosa & - & - & - & - & - & 18 & - & - \\
\hline \multicolumn{9}{|l|}{ Plantas de amplia distribución costera } \\
\hline Cakile maritima & 25 & 74 & 22 & 80 & 25 & 27 & 11 & 50 \\
\hline Ambrosia chamissonis & 17 & 74 & 44 & 80 & 88 & 9 & 11 & 75 \\
\hline Distichlis spicata & 75 & 37 & 33 & 20 & 50 & 18 & - & 50 \\
\hline Argentina egedii subsp. egedii & 8 & - & - & 20 & 25 & 9 & - & 25 \\
\hline Achillea millefolium & - & 74 & 67 & - & 88 & 9 & - & 75 \\
\hline Abronia latifolia & 8 & 63 & - & 60 & 38 & - & - & 50 \\
\hline Artemisia californica & 8 & - & 67 & - & 25 & 36 & 100 & - \\
\hline Leymus mollis subsp. mollis & - & 42 & - & - & 13 & 9 & - & 25 \\
\hline Cuscuta salina & 75 & - & - & 20 & - & 18 & - & 50 \\
\hline Fragaria chiloensis subsp. pacifica & - & 42 & - & - & 38 & 18 & - & 75 \\
\hline Juncus lesueurii & - & 26 & - & 20 & 50 & - & - & 100 \\
\hline Jaumea carnosa & 75 & - & - & - & 25 & 18 & - & 50 \\
\hline Triglochin maritimum & 42 & - & - & - & - & - & - & 50 \\
\hline
\end{tabular}


dunas semifijas ricos en endemismos californianos (Eriogonum parvifolium, Ericameria ericoides, C. filaginifolia var. californica, Lupinus chamissonis, y los endemismos locales Erigeron blochmaniae, Monardella crispay Senecio blochmaniae), y los nanojuncales de arenas húmedas dominados por Juncus leuseurii y Carex pan$s a$. La diversidad de hábitats existente en esos complejos sistemas dunares explica el gran número de géneros que este subgrupo meridional comparte con los septentrionales CAL-2 y CAL-3, e incluso con los subgrupos ROC-3, ROC-4 y ROC-6, lo que justifica que los índices de similitud entre estos grupos superen valores de 0,5 (Tablas 9, 10).

Los subgrupos CAL-6 y CAL-7 reunieron los inventarios de las localidades más meridionales de California y los del extremo noroccidental de Baja California. En ambos subgrupos abundan las plantas de distribución meridional y las de hojas y tallos crasos que dominan el matorral costero de suculentas, una formación vicariante de los tabaibales inframediterráneos canarios (Peinado \& al., 1995b. Los porcentajes de estas plantas meridionales son más elevados en el subgrupo CAL-7, que reúne las localidades más sureñas, desde Tijuana a Punta Colonet, en Baja California. El subgrupo CAL-6 incluyó los inventarios tomados en localidades algo más septentrionales; la diferencia florística con CAL-7 estriba en que en CAL-6 hay algunos inventarios de saladares y en los de dunas se incluyen los de las poblaciones más meridionales de Ammophila arenaria y Baccharis pilularis, dos plantas que no crecen en las costas de Baja California. A diferencia de lo que ocurre en otros subgrupos CAL, en los dos meridionales aparecen géneros de origen tropical tales como Agave, Batis, Croton, Justicia, Myrtillocactus y Stenocereus. Además, ambos subgrupos presentan también los mayores porcentajes de géneros endémicos pertenecientes a los elementos Madreano y Californiano.

Las localidades situadas entre los $29^{\circ} 30^{\prime} \mathrm{N}$ y los $30^{\circ} 47^{\prime} \mathrm{N}$-diez de la zona Mediterránea y cuatro de la Tropical-se unieron en el grupo TRA-2 (Tabla 4), en el que se observa una disminución en el porcentaje de las plantas del matorral costero de suculentas y en el número de géneros endémicos madreanos y californianos, un elevado porcentaje de endemismos locales como Dudleya cultrata y Astragalus anemophilus, la presencia diferencial de matorrales dunares con Euphorbia misera, Helianthus niveus, Lycium brevipes y L. californicum. TRA-2 también presenta elementos de distribución esencialmente tropical como Atriplex julacea, $\mathrm{Ca}$ missonia crassifolia o Pachycereus schottii, que se suman a los ya existentes en los subgrupos mediterráneos más meridionales.
El grupo ROC (Tabla 6) incluyó 69 de las 70 localidades situadas en Oregón, Washington y British Columbia (es decir, en la región Rocosiana), y diez localidades del noroeste de California. Una localidad del sur de Oregón y tres del norte de California se reunieron en el grupo TRA-1. El grupo ROC se subdividió en seis subgrupos. El subgrupo ROC-1 reunió localidades con saladares y humedales. Se trata de un grupo fuertemente cohesionado por los elevados porcentajes de especies típicamente halófilas o subhalófilas como Sarcocornia pacifica, Distichlis spicata, Jaumea carnosa o Triglochin maritimum. Algunas de esas plantas se presentan también en el subgrupo halófilo mediterráneo CAL-1, pero en este último faltan especies de distribución boreotemplada como Carex lyngbyei, Deschampsia cespitosa subsp. beringensis, Festuca rubra, Glaux maritima y Plantago maritima var. juncoides, mientras que se presentan algunas plantas (Frankenia salina, Limonium californicum, Spartina foliosa, entre otras) inexistentes en el subgrupo ROC-1. Además, Sarcocornia pacifica sustituye a $S$. perennis (taxon boreotemplado) en los subgrupos halófilos mediterráneos.

Los sistemas de grandes dunas costeras rocosianas presentan una elevada variabilidad de hábitats dentro de los complejos zonales y sucesionales que comienzan en comunidades herbáceas pioneras y conducen hasta bosques de dunas estabilizadas dominados por coníferas (Kumler, 1969; Wiedemann, 1966; Franklin \& Dyrness, 1985; Klinka \& al., 1995). El resto de los subgrupos rocosianos refleja esos complejos dunares. El subgrupo ROC-2, que presentó el mayor número de especies por localidad, incluyó 19 localidades distribuidas entre Oregón y British Columbia, que tienen en común el poseer sistemas dunares complejos en los que se incluyen bosques de Picea sitchensis y Pinus contorta var. contorta, altifruticedas húmedas de Salix bookeriana y Myrica californica, pastizales de depresiones húmedas y de áreas de deflación dominados por juncáceas y ciperáceas (Juncus falcatus, Carex obnupta, C. pansa y C. lyngbyei), y comunidades de playas (Cakile edentula) y de dunas primarias (Ammophila arenaria, Leymus mollis subsp. mollis, Latbyrus japonicus var. japonicus).

El subgrupo ROC-3 reunió seis localidades en las que los porcentajes más elevados corresponden a bosques de dunas (Picea sitchensis y P. contorta var. contorta son los árboles dominantes) y a plantas de playas (Cakile edentula) y dunas primarias (Leymus mollis subsp. mollis, Ammophila arenaria, Lathyrus japonicus). Se trata de localidades con bosques maduros que contactan directamente con la vegetación de playas, sin que haya grandes sistemas dunares, lo que trae 
Tabla 6. Resultados de la clasificación por ALC: diferencias florísticas más significativas entre las localidades de la región Rocosiana (subgrupos ROC). Las cifras son porcentajes redondeados de presencia.

\begin{tabular}{|c|c|c|c|c|c|c|}
\hline $\begin{array}{l}\text { Subgrupos } \\
\text { Número de especies }\end{array}$ & $\begin{array}{l}\text { ப் } \\
\text { ¿̛ } \\
91\end{array}$ & 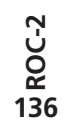 & 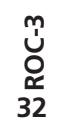 & $\begin{array}{l}\text { U্ } \\
\text { ঠ̊ } \\
80 \\
80\end{array}$ & $\begin{array}{l}\text { Ů } \\
\text { Ơ } \\
81 \\
81\end{array}$ & 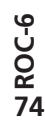 \\
\hline Número de localidades & 12 & 19 & 6 & 9 & 16 & 17 \\
\hline Media de especies por localidad & 21 & 37 & 12 & 18 & 11 & 6 \\
\hline \multicolumn{7}{|l|}{ Plantas de distribución boreo-templada } \\
\hline Carex lyngbyei & 67 & 42 & - & 67 & 13 & 12 \\
\hline Picea sitchensis & 67 & 84 & 83 & 78 & 75 & - \\
\hline Lathyrus japonicus var. maritimus & 50 & 95 & 67 & 11 & - & 29 \\
\hline Deschampsia cespitosa subsp. beringensis & 83 & 42 & - & 56 & 13 & - \\
\hline Festuca rubra subsp. rubra & 17 & 63 & - & 22 & - & 6 \\
\hline Hordeum brachyantherum subsp. brachyantherum & 25 & 16 & 17 & - & 6 & - \\
\hline Honkenya peploides subsp. major & 8 & 26 & - & 11 & - & 29 \\
\hline Plantago maritima v. juncoides & 83 & 32 & - & 11 & - & - \\
\hline \multicolumn{7}{|l|}{ Plantas de distribución rocosiana } \\
\hline Gaultheria shallon & 50 & 79 & 100 & 67 & 50 & 18 \\
\hline Vaccinium ovatum & 42 & 74 & 100 & 44 & 44 & - \\
\hline Cakile edentula subsp. edentula & 8 & 68 & 33 & 11 & - & 12 \\
\hline Arctostaphylos uva-ursi & 8 & 42 & 50 & 33 & 13 & - \\
\hline Sarcocornia perennis & 100 & 32 & - & 11 & - & 18 \\
\hline Anaphalis margaritacea & 25 & 37 & 83 & 11 & - & - \\
\hline Glaux maritima & 67 & 26 & - & - & 6 & - \\
\hline Cytisus scoparius & - & 53 & 50 & - & 19 & - \\
\hline Tsuga heterophylla & 8 & 5 & - & - & 44 & - \\
\hline Hypochaeris radicata & - & 89 & - & 22 & - & - \\
\hline Lupinus littoralis & - & 74 & 17 & - & - & - \\
\hline Poa confinis & - & 42 & - & - & - & - \\
\hline \multicolumn{7}{|c|}{ Plantas de distribución rocosiana y californiano-septentrional } \\
\hline Polystichum munitum & 17 & 42 & 17 & 22 & 63 & 6 \\
\hline Lonicera involucrata var. involucrata & 33 & 58 & 50 & 78 & 13 & 12 \\
\hline Salix hookeriana & 33 & 74 & 17 & 78 & - & 6 \\
\hline Pinus contorta var. contorta & 17 & 74 & 67 & 44 & 6 & - \\
\hline Alnus rubra & 17 & 16 & - & 22 & 38 & 12 \\
\hline Ammophila arenaria & - & 89 & 50 & 44 & - & 18 \\
\hline Carex obnupta & 17 & 89 & - & 44 & - & 6 \\
\hline Tanacetum camphoratum & 8 & 53 & 17 & 11 & - & - \\
\hline Myrica californica & 33 & 58 & 67 & 44 & - & - \\
\hline Baccharis pilularis & - & 21 & - & 11 & - & 18 \\
\hline Carexpansa & - & 42 & 17 & 11 & - & - \\
\hline Juncus falcatus & - & 74 & - & 22 & - & - \\
\hline Spiranthes romanzoffiana & - & 32 & - & 22 & - & - \\
\hline Veronica scutellata & - & 42 & - & 22 & - & - \\
\hline Armeria maritima subsp. californica & - & 26 & - & - & - & 6 \\
\hline Polygonum paronychia & - & 53 & - & - & - & 6 \\
\hline Cardionema ramosissimum & - & 58 & - & - & - & - \\
\hline Phacelia argentea & - & - & - & - & - & 6 \\
\hline Calystegia soldanella & - & - & - & 11 & - & - \\
\hline \multicolumn{7}{|l|}{ Plantas de amplia distribución costera } \\
\hline Leymus mollis subsp. mollis & 58 & 74 & 83 & 22 & - & 41 \\
\hline Cakile maritima & - & 53 & 17 & 11 & - & 18 \\
\hline Distichlis spicata & 92 & 32 & - & 11 & - & 6 \\
\hline Ambrosia chamissonis & 8 & 5 & - & 11 & - & 6 \\
\hline Fragaria chiloensis subsp. pacifica & 25 & 84 & - & 22 & - & 6 \\
\hline Argentina egedii subsp. egedii & 50 & 89 & - & 89 & - & - \\
\hline Cuscuta salina & 42 & 21 & - & 11 & - & - \\
\hline Triglochin maritimum & 83 & 47 & - & 44 & - & - \\
\hline Juncus lesueurii & - & 89 & 17 & 22 & - & - \\
\hline Achillea millefolium & 25 & 47 & - & - & - & 12 \\
\hline Abronia latifolia & - & 11 & - & 11 & - & 6 \\
\hline Jaumea carnosa & 83 & 37 & - & - & - & - \\
\hline
\end{tabular}


como consecuencia la falta de las plantas que caracterizan a los subgrupos ROC-1 y ROC-2.

El subgrupo ROC-4 agrupó nueve inventarios cuya composición florística es similar a ROC-2, pero hay diferencias de porcentaje significativas en la vegetación de playas y dunas, y en la ausencia de plantas de las áreas de deflación (faltan, por ejemplo, Armeria maritima subsp. californica, Cardionema ramosissimum, Lupinus littoralis, Poa macrantha y Polygonum paronychia), lo que pone de manifiesto la menor extensión y menor diversidad de hábitats de los sistemas dunares del grupo ROC-4 con respecto a ROC-2.

El subgrupo ROC-5 reunió localidades en las que la vegetación está más próxima a la etapa final de la sucesión dunar, que en Oregón está constituida por bosques maduros de Picea sitchensis acompañado de Pseudotsuga menziesii var. menziesii, Tsuga heterophylla y Thuja plicata (Kumler, 1969; Wiedemann, 1966). Los elevados porcentajes de especies nemorales tales como Gaultheria shallon, Polystichum munitum y Vaccinium ovatum son indicadores de este subgrupo en el que, por el contrario, faltan las plantas herbáceas de los complejos dunares que caracterizan los siguientes grupos.

El subgrupo ROC-6 es el que presentó el número de táxones por localidad más bajo (6). Agrupó nueve localidades de California y otras ocho distribuidas desde Oregón a British Columbia. Los porcentajes más altos fueron los alcanzados por Leymus mollis subsp. mollis y Lathyrus japonicus var. japonicus, lo que indica que se trata de localidades que presentan únicamente vegetación de playas, en las que no existen sistemas de dunas con los bosques de Picea sitchensis, Pinus contorta y otras comunidades psammófilas que caracterizan el resto de los subgrupos TEM.

En resumen, el grupo ROC es un grupo florístico homogéneo, que agrupa las localidades templadas situadas entre el sur de Oregón y British Columbia, a las que se añaden algunas localidades del noroeste de $\mathrm{Ca}$ lifornia, que pueden considerarse dentro de una transición climática templado-mediterránea. En el amplio rango latitudinal sobre el que se extienden las localidades del grupo TEM, no hay diferencias fitogeográficas significativas: los subgrupos separados por el ALC indican diferencias zonales o sucesionales y no de distribución geográfica.

El grupo TRA-1 reunió las tres localidades más septentrionales de California y una del sur de Oregón. Las cuatro localidades parecen estar ligadas por sus altas proporciones de Salix hookeriana, que forma densas altifruticedas en depresiones húmedas, y por algunos hemicriptófitos propios de pastizales psammófilos (Carex obnuta, Juncus falcatus, Tanacetum camphoratum). En ambos casos, se trata de plantas que forman comunidades muy extendidas en los complejos dunares templados, pero cuyo límite meridional se encuentra en la zona de clima mediterráneo del noroeste de California.

El grupo BOR incluyó las 23 localidades boreales inventariadas en Alaska, que resultaron distribuidas en dos subgrupos: BOR-1, que agrupó las localidades situadas alrededor de Cook Inlet, es decir, en la zona boreal continental, y BOR-2, que reunió las localidades bajo clima boreal oceánico. Las diferencias florísticas entre ambos grupos se resumen en la Tabla 7.

\section{Elementos fitogeográficos}

El 21,3\% del total de géneros en el área de estudio son de distribución cosmopolita, un porcentaje que es tres veces superior al calculado para Norteamérica (7\%; Qian, 1999), pero hay que tener en cuenta que determinados hábitats muy extendidos cuando no exclusivos de las costas (principalmente saladares y humedales) son particularmente favorables para la presencia de géneros cosmopolitas como Agrostis, Calystegia, Carex, Deschampsia, Schoenoplectus, Spartina, Suaeda, Typha y muchos otros. El porcentaje de especies cosmopolitas es muy inferior al de géneros, porque éstos están representados por especies de distribución más restringida. Por ejemplo, el género cosmopolita Atriplex está representado en la zona de estudio por especies de distribución cosmopolita $(A$. patula), continental (A. canescens subsp. canescens), regional $(A$. polycarpa) e incluso por endémicas locales (A. alaskensis, $A$. julacea).

Los principales tipos de vegetación de las regiones Boreal-Norteamericana, Rocosiana y Californiana están dominados o codominados por géneros de distribución holártica tales como Alnus, Arctostapbylos, Armeria, Betula, Calamagrostis, Fragaria, Glaux, Leymus, Picea, Puccinellia o Salix. El número de especies holárticas representa sólo el 4,8\% del total de la flora, pero asciende hasta el $23 \%$ en la región Boreal Norteamericana. El porcentaje de estos elementos va descendiendo conforme lo hace la latitud, hasta ser nulo en los subgrupos californiano-meridionales y xerofítico-mexicanos. Una de las características más distintivas del elemento Holártico en el área de estudio es la abundancia de árboles. Se han inventariado 31 géneros arbóreos, 14 de los cuales (45\%) pertenecen a ese elemento. De hecho, muchos de estos géneros dominan la vegetación forestal boreo-norteamericana ( $\mathrm{P} i$ cea, Betula) y rocosiana (Picea, Salix). La abundancia de nanofanerófitos y de megaforbias nemorales es también una destacada característica del elemento 
Tabla 7. Resultados de la clasificación por ALC: diferencias florísticas más significativas entre las localidades boreales continentales de la provincia Hudsoniana (subgrupo BOR-1) y las localidades boreales oceánicas de la provincia Sitchense (subgrupo BOR-2). Las cifras son porcentajes redondeados de presencia.

\begin{tabular}{|c|c|c|}
\hline Subgrupos & $\begin{array}{l}\overline{\dot{c}} \\
\text { Oัٌ }\end{array}$ & $\begin{array}{l}N \\
\text { Õ } \\
\text { Õ }\end{array}$ \\
\hline Número de especies & 68 & 73 \\
\hline Número de localidades & 11 & 12 \\
\hline Media de especies por localidad & 29 & 26 \\
\hline \multicolumn{3}{|l|}{ Plantas exclusivas de la zona Boreal } \\
\hline Betula papyrifera var. kenaica & 100 & 75 \\
\hline Puccinellia hultenii & 55 & 67 \\
\hline Senecio pseudoarnica & 55 & 67 \\
\hline Conioselinum gmelinii & 64 & 67 \\
\hline Ligusticum scoticum subsp. hultenii & 55 & 50 \\
\hline Stellaria humifusa & 55 & 50 \\
\hline Poa eminens & 64 & 42 \\
\hline Lathyrus palustris & 55 & 42 \\
\hline Equisetum sylvaticum & 100 & 17 \\
\hline Viburnum edule & 100 & 8 \\
\hline Empetrum nigrum & 100 & - \\
\hline Geocaulon lividum & 100 & - \\
\hline Linnaea borealis subsp. americana & 100 & - \\
\hline Picea glauca & 100 & - \\
\hline Rosa acicularis subsp. acicularis & 100 & - \\
\hline Shepherdia canadensis & 100 & - \\
\hline Vaccinium uliginosum & 100 & - \\
\hline Dendranthema arcticum subsp. arcticum & 55 & - \\
\hline Atriplex alaskensis & 36 & - \\
\hline Athyrium filix-femina subsp. cyclosurum & - & 83 \\
\hline Lycopodium annotinum & - & 83 \\
\hline Menziesia ferruginea & - & 83 \\
\hline Oplopanax horridum & - & 83 \\
\hline Orthilia secunda & - & 83 \\
\hline Sorbus sitchensis & - & 83 \\
\hline Tiarella trifoliata & - & 83 \\
\hline Vaccinium membranaceum & - & 83 \\
\hline Mertensia maritima & - & 58 \\
\hline \multicolumn{3}{|l|}{ Plantas de distribución boreo-templada } \\
\hline Carex lyngbyei & 91 & 83 \\
\hline Picea sitchensis & - & 92 \\
\hline Deschampsia cespitosa subsp. beringensis & 36 & 33 \\
\hline Festuca rubra subsp. rubra & 55 & 50 \\
\hline $\begin{array}{l}\text { Hordeum brachyantherum subsp. } \\
\text { brachyantherum }\end{array}$ & 64 & 58 \\
\hline Lathyrus japonicus var. maritimus & 55 & 67 \\
\hline Honkenya peploides subsp. major & 45 & 67 \\
\hline Plantago maritima var. juncoides & 73 & 67 \\
\hline \multicolumn{3}{|l|}{ Plantas de amplia distribución costera } \\
\hline Argentina egedii subsp. egedii & 91 & 67 \\
\hline Leymus mollis subsp. mollis & 91 & 92 \\
\hline Achillea millefolium & 73 & 33 \\
\hline Triglochin maritimum & 64 & 33 \\
\hline
\end{tabular}

holártico, lo que incluye a géneros tales comos Arctostaphylos, Corallorbiza, Cornus, Fritillaria, Linnaea, Listera, Lonicera, Maianthemum, Mertensia, Pyrola, Rhammus, Rosa, Scrophularia y Vaccinium. Algunos táxones holárticos dominan sus respectivos hábitats como en el caso de Carex lyngbyei, Leymus mollis subsp. mollis, Picea glauca, Puccinellia phryganodes o Senecio pseudoarnica.

En el elemento disyunto (sensu Good, 1974) se incluye un grupo de géneros principalmente de ambientes salinos y áridos: Arthrocnemum, Distichlis, Frankenia, Limonium, Sarcocornia, Spergularia, Suaeda y Triglochin. Otros géneros disyuntos son Angelica (holártico y Australasia), Adenocaulon y Armeria (holártico y Sudamérica), Arbutus y Antirrbinum (cuenca mediterránea y Norteamérica), Empetrum (principalmente holártico pero también presente en Suramérica y en las islas Tristán da Cunha), Gaultheria y Lilaeopsis (América y Australia-Nueva Zelanda), Honkenya (holártico y costas de Patagonia), Myosurus (zonas templadas de ambos hemisferios), Nicotiana (América y Australasia), Oligomeris (holártico y Sudáfrica) y Pinus (holártico y Australasia).

De los 17 géneros pertenecientes al elemento Norteamericano-Asiático Oriental, cuatro son árboles (Lithocarpus, Pseudotsuga, Thuja y Tsuga); los dos primeros son especialmente importantes en los bosques de la zona de transición mediterráneo-templada, y los dos últimos son dominantes de los bosques templados. Ninguno de los géneros de este elemento alcanza la zona tropical, mientras que el mayor número de ellos se concentra en las zonas templada y boreal. Sólo 13 especies pueden ser consideradas dentro de este elemento debido a que la mayoría de los géneros tienen pares de especies vicariantes en uno u otro continente, y éstas son en buena medida endémicas de pequeñas zonas geográficas. La mayoría de esas especies son anfiberingianas (cf. Peinado \& al., 2005b) como sucede con Argentina egedii subsp. egedii, Deschampsia cespitosa subsp. beringensis (el taxon de esta categoría con más amplia distribución: desde Alaska hasta el sur de Oregón), Carex macrocephala (restringido al zonobioma Templado), Conioselinum gmelinii y Honkenya peploides subsp. major (zonobiomas Boreal y Templado) y Dendranthema arcticum subsp. arcticum, Saussurea nuda y Senecio pseudoarnica, las tres exclusivas del zonobioma Boreal. Otras cuatro especies (Angelica lucida, Cornus canadensis, Leymus mollis subsp. mollis y Listera convallarioides) alcanzan la costa atlántica norteamericana.

Hay cuarenta géneros en la flora del área de estudio que caen dentro del elemento Norte-Suramericano, 
que incluye a aquellos cuya distribución está en ambos semicontinentes americanos. El número es comparativamente muy alto porque representa casi el $61 \%$ de los géneros de este elemento presentes en la flora de Norteamérica (Qian, 1999). La mayoría de ellos (por ejemplo: Agave, Amblyopappus, Asclepias, Brickellia, Camissonia, Chorizanthe, Condalia o Errazurizia) están restringidos a las localidades sureñas de la región Californiana y a las xerofítico-mexicanas, mientras que sólo diez (Agoseris, Argentina, Baccharis, Camissonia, Cardionema, Grindelia, Holodiscus, Jaumea, Oenothera y Phacelia) alcanzan el sur del zonobioma Templado, y únicamente el género Argentina alcanza la costa de Alaska. Diecisiete especies pertenecen al elemento Norte-Suramericano; dos de ellas son dominantes o codominantes en las dunas de la costa del Pacífico desde el sur de la región Californiana hasta British Columbia: Ambrosia chamissonis (también presente en el norte de la zona tropical de Baja California) y Fragaria chiloensis subsp. pacifica. Esta última y Lathyrus japonicus var. maritimus son los únicos táxones de este elemento que alcanzan las costas de Alaska.

Sólo se han inventariado nueve géneros endémicos de Norteamérica, pero algunos como Ceanothus y Eriogonum son de gran importancia fitogeográfica por presentar varias especies endémicas. Dentro del elemento Norteamericano-Occidental hay 23 géneros, alguno de los cuales es de importancia en la vegetación costera como dominante en comunidades dunares: Abronia (dos de cuyas especies se cuentan entre las principales formadoras de dunas primarias en los zonobiomas Tropical, Mediterráneo y Templado), Corethrogyne, Ericameria y Eriophyllum (dunas mediterráneas) y Wislizenia (dunas tropicales).

No hay géneros endémicos en el elemento Boreopacífico Occidental. Las plantas incluidas en este elemento son endémicas de la costa boreal de Alaska, aunque algunas pueden alcanzar el extremo norte de British Columbia. Algunas son exclusivas de hábitats costeros, como ocurre con Atriplex alaskensis, A. drymarioides o Puccinellia bultenii, que aparecen en los halobiomas, y con Ligusticum scoticum subsp. bultenii y Poa eminens, muy característicos de psammobiomas. Por el contrario, otras presentan una distribución esencialmente costera aunque pueden penetrar ligeramente hacia el interior, como es el caso de Hippuris tetraphylla y Juncus arcticus subsp. alaskanus (anfibiomas) o el de Betula papyrifera var. kenaica, Castilleja unalaschcensis y Geranium erianthum (bosques costeros zonales).

Tampoco hay géneros endémicos en el elemento Templado Pacífico Noroccidental, en el cual solamen- te se incluyen dos especies: Grindelia integrifolia y Scrophularia oregana, ambas extendidas desde el sur de Oregón a British Columbia, la primera común en playas, costas rocosas y saladares, y la segunda en altifruticedas y microbosques de Salix hookeriana. Otras especies de hábitats costeros tales como Carex pluriflora, Fritillaria camschatcensis, Gaultheria shallon, Juncus falcatus, J. supiniformis, Lupinus littoralis, Pinus contorta var. contorta, Poa confinis, P. macrantha, Puccinellia nutkaensis, Salix hookeriana, Senecio bolanderi, Stachys mexicana, Tanacetum camphoratum o Vaccinium ovatum tienen su área de distribución fundamentalmente rocosiana, pero penetran ligeramente en las regiones adyacentes.

La región Madreana incluye una gran parte del sudoeste de los Estados Unidos y del norte y centro de México (Takhtajan, 1986), incluyendo las zonas climáticas mediterráneas y tropicales (provincias Californiana y Sonorense sensu Takhtajan, respectivamente). Teniendo en cuenta la enorme extensión de la región $\mathrm{Ma}$ dreana y su riqueza florística, cuando se examinan los mapas de distribución de los táxones madreanos muchos de ellos se extienden sólo en la zona mediterránea, mientras que otros lo hacen sólo sobre el zonobioma Tropical. Por ello, para el análisis de la flora costera hemos distinguido varios elementos: Madreano, Californiano o Mediterráneo, Sonorense, Bajocaliforniano, Transicional (Californiano-Bajocaliforniano) y Tropical, aunque como se comenta más adelante este último puede separarse en varios subelementos.

Los géneros del elemento Madreano son aquellos que se presentan simultáneamente en los zonobiomas Mediterráneo y Tropical, aunque muchos de ellos se presentan en zonas de ecotono. Entre los géneros madreanos más típicos están Dithyrea, Dudleya, Echinocereus, Ferocactus, Isomeris, Nolina, Pterostegia y Simmondsia. Las especies de este elemento se concentran casi exclusivamente en las zonas mediterráneas y tropicales, y los porcentajes más altos se alcanzan en los grupos fronterizos TRA-2, CAL-7 y XER-1.

Catorce géneros son endémicos de la región Californiana. Entre los más destacados están Adenostoma, Chamaebatia, Ericameria, Sequoia, Umbellularia, Bergerocactus, Cneoridium, Ornitostaphylos y Xylococcus, los cuatro últimos endémicos del noroeste de $\mathrm{Baja} \mathrm{Ca}$ lifornia. Sólo dos de ellos, Sequoia y Umbellularia, penetran ligeramente en los grupos fronterizos ROC-5 y ROC-6, mientras Aphanisma lo hace ligeramente en el grupo XER-1. El elemento Californiano es también el más sobresaliente en número de especies endémicas (19,8\% del total de la flora). Este porcentaje se eleva hasta el $40 \%$ en el subgrupo CAL-3, donde se con- 
centra el mayor número de endemismos de toda la costa del Pacífico, incluyendo los cuatro géneros endémicos de Baja California antes mencionados. Once especies del elemento Californiano aparecen en el grupo tropical, pero todas ellas están registradas en el norte de la península de El Vizcaíno, en el límite entre las zonas de clima Mediterráneo y Tropical.

El elemento endémico Sonorense, centrado sobre las zonas desérticas del sureste de Norteamérica, incluye nueve géneros de amplia distribución territorial en la región Xerofítico-Mexicana. Un género endémico Sonorense (Peucephyllum) se ha inventariado puntualmente en el grupo californiano sureño CAL-7, y dos (Pachycereus y Peucephyllum) en el grupo transicional TRA-2. El número de especies de distribución Sonorense es relativamente pequeño y está concentrado en la zona tropical, aunque ocho especies (por ejemplo Ambrosia chenopodiifolia, A. dumosa, Nolina parryi, Ferocactus cylindraceus), penetran ligeramente en las zonas meridionales mediterráneas de los grupos fronterizos CAL-6, CAL-7 y TRA-2.

El elemento endémico Bajocaliforniano incluye cuatro géneros monoespecíficos y 78 especies endémicas de la provincia fitogeográfica Bajocaliforniana (sensu Peinado \& al., 1994b). La mayoría de ellas están restringidas en la zona de clima tropical, aunque algunas (Aesculus parryi, Cuscuta veatchii, Cynanchum peninsulare, Echinocereus maritimus, Harfordia macroptera, Myrtillocactus cochal, Rosa minutifolia y Sarcostemma arenarium) han sido registradas ocasionalmente en localidades del zonobioma Mediterráneo del noroeste de Baja California.

Entre las plantas de distribución esencialmente tropical se incluyen 48 géneros que se encuentran en cualquiera de las tres zonas tropicales (África, América y Asia-Australasia). Cuando sus respectivas áreas de distribución se analizan con mayor precisión, pueden separarse hasta seis elementos: (1) Pantropical, que incluye 16 géneros (Acalypha, Amaranthus, Avicennia, Croton, Cynanchum, Ipomoea y Justicia, entre otros) que prosperan en las tres zonas tropicales; (2) Anfi-Pacífico Tropical y (3) Anfi-Atlántico Tropical, dos elementos en los que se incluyen aquellos géneros distribuidos en las costas tropicales del Pacífico (Batis) y del Atlántico (Laguncularia y Sphaeralcea), respectivamente; (4) Neotropical, al que pertenecen diez géneros (Ditaxis, Phaseolus, Stenocereus, Bursera, Jatropha, etc.) cuya distribución geográfica está principalmente restringida a América Tropical, excluyendo Baja California, cuyos táxones endémicos han sido incluidos en el elemento Bajocaliforniano. De los diez géneros neotropicales sólo dos, Ditaxis y Phaseolus, se encuentran fuera de la península de Baja California. Algunos géneros tropicales llegan hasta las zonas de clima Mediterráneo y un genero pantropical, Lilaeopsis, tiene su límite septentrional en los humedales costeros de British Columbia.

En el elemento "Introducidas" hemos incluido los táxones alóctonos para la zona de estudio. El número de géneros y especies introducidos decrece hacia los extremos climáticos del área de estudio, alcanzando los mayores valores en las zonas templadas y mediterráneas, que son las que tienen una mayor presión humana. En algunos casos, sucede con Ammophila arenaria, Carpobrotus edulis, Spartina alterniflora, de varias especies del género Bromus, o con Mesembryanthemum crystallinum y M. nodiflorum; la importancia de las especies introducidas es extraordinaria por la intensa modificación que han producido o están produciendo en algunos ecosistemas costeros del Pacífico septentrional. Veinte géneros, entre los que se cuentan Agrostis, Atriplex, Bromus, Cakile, Plantago, Rumex o Spartina, tienen especies introducidas y especies nativas. En esos casos, se ha considerado al género como nativo (Tabla 2) y se han contabilizado las especies como introducidas o nativas en la correspondiente categoría de la Tabla 3. Eso explica que para el grupo boreal, por ejemplo, no aparezca ningún género introducido, mientras que en la Tabla 3 aparezcan cuatro especies introducidas. Las cuatro especies introducidas (Atriplex patula, Polygonum aviculare, Rumex acetosella y Trifolium repens) pertenecen a cuatro géneros que tienen representación nativa en la zona boreal.

Existe, además, una estrecha relación entre la distribución climática de las especies introducidas con la de sus centros de origen. Especies de los géneros Bromus, Carpobrotus, Cytisus o Mesembryanthemum, procedentes de otras zonas de clima Mediterráneo del mundo, se han introducido preferente o exclusivamente en el zonobioma Mediterráneo. En los casos de los géneros Aira, Ammophila, Cakile, Holcus, Hypochoeris o Ulex, cuyo origen está en las zonas templadas y mediterráneas de Europa, se han naturalizado en los mismos zonobiomas de Norteamérica.

\section{Elementos fitogeográficos, orígenes y relaciones de la flora del Pacífico septentrional}

En la zona de estudio se han registrado 354 géneros nativos, de los cuales el 79,6\% (282) son géneros compartidos con las floras de otros continentes. De esos 282 géneros, 191 (67,7\%) se comparten con EurasiaÁfrica y 189 (67\%) con Suramérica. Aunque en algunos casos no pueden descartarse modelos de disper- 
sión ligados a corrientes de agua, aire o a las migraciones de las aves (Raven, 1963), resulta claro que la mayor parte de estas relaciones intercontinentales hay que buscarlas en el pasado, ligándolas a acontecimientos paleoclimáticos y paleogeológicos.

Norteamérica nunca ha estado aislada completamente del resto del mundo en los últimos 300 millones de años $(\mathrm{Ma})$, aunque la separación en continentes individuales tuviera lugar en diferentes épocas geológicas (Qian, 1999). Dado que la mayoría de las familias de angiospermas y una buena parte de los géneros surgieron y se diversificaron en el tránsito Cretácico/Terciario (Crane \& Lidgard, 1989), las conexiones intercontinentales que permitieron el intercambio de flora angiospérmica debían existir en aquel tiempo o haber surgido con posterioridad.

En el Cretácico tardío, el hemisferio norte estaba colonizado por dos floras: Pacifis, que se extendía desde el este de Asia hasta el oeste de Norteamérica, y Atlantis, que cubría el área que va desde el este de Norteamérica a Europa (Budantsev, 1992). La conexión intercontinental estaba asegurada por dos puentes terrestres: Noratlántico, entre el oriente de Norteamérica y Europa, y Bering, entre Asia oriental y el occidente de Norteamérica (Tiffney, 1985a, b). Ambos puentes permitieron un amplio intercambio de plantas entre los continentes, aunque Norteamérica estaba escindida en dos semicontinentes debido al brazo oceánico Centrocontinental, que se extendía desde el golfo de México hasta el Ártico al menos hasta comienzos del Terciario, cuando su retirada hacia el norte y hacia el sur abrió el camino a la migración intracontinental (Hallam, 1994; Graham, 1999).

Desde el Terciario temprano, y durante 40 millones de años, un clima cálido uniforme se extendía por todo el hemisferio norte (Latham \& Ricklefs, 1993), permitiendo la existencia en todo él de la llamada Geoflora Artoterciaria (Axelrod, 1958) o Boreotropical (Wolfe, 1975), que formaba un cinturón más o menos continuo alrededor del actual Ártico y cubría las latitudes actuales de la práctica totalidad de Eurasia y Norteamérica (Latham \& Ricklefs, 1993). Algunas evidencias fósiles muestran que muchos géneros de árboles de la flora costera moderna (por ejemplo Alnus, Betula, Fraxinus, Quercus o Rbus) también se presentaron en la flora Boreotropical de Norteamérica y Eurasia (Muller, 1981; Axelrod, 1988; Taylor, 1990; Graham, 1999). Por tanto, parece claro que la flora Boreotropical o Artoterciaria explica el origen de las conexiones intercontinentales entre Eurasia y Norteamérica, las cuales pudieron continuarse sin mayores dificultades bien hasta el Eoceno, cuando se rompió el puente noratlántico (Tiffney, 1985b), bien hasta hace tan sólo 10000 años, cuando definitivamente desapareció el puente terrestre beringiano (Yurtsev, 1974). Las relaciones con África son menos significativas y, al margen de la antigua conexión del supercontinente Pangea (c. $245 \mathrm{Ma}$ ), se explicarían por dos vías: una, gracias al desecamiento del mar Mediterráneo durante el Mioceno (Peinado \& al., 1992), que permitió un amplio intercambio de especies entre África y Eurasia, y desde esta última hasta Norteamérica. La segunda vía migratoria es más antigua, puesto que hay que remontarse hasta el Cretácico tardío, cuando se produjo la definitiva separación de América y África (Parrish, 1993), aunque pudo existir una relativamente fácil migración posterior a través de cadenas de islas o a través del puente terrestre Brasil-Nigeria que se mantuvo hasta el final del Cretácico (Goldblatt, 1993).

A pesar de su actual conexión a través del istmo de Panamá, las migraciones entre Norteamérica y Sudamérica tienen un origen más reciente. Norteamérica y Sudamérica estuvieron unidas desde finales del Carbonífero (c. $300 \mathrm{Ma}$ ) hasta el Cretácico temprano (c. $120 \mathrm{Ma}$; Emery \& Uchupi, 1984), es decir, antes de la diversificación de las angiospermas. Desde entonces, y hasta el levantamiento del istmo de Panamá durante el Plioceno medio (3 Ma; Darlington, 1957; Coates, 1996), Norteamérica y Sudamérica estuvieron separadas por un brazo oceánico que llegó a medir 3000 km (Raven \& Axelrod, 1974). La formación del istmo permitió la apertura del bien conocido corredor migratorio de Panamá, a través del cual se ha producido una fluida migración de plantas de origen tropical desde Sudamérica a Norteamérica y de origen templado en sentido inverso. Eso explica tanto la presencia en Sudamérica de algunos táxones de origen holártico (Empetrum, Pyrola o Vaccinium) que han migrado siguiendo las cumbres de las montañas tras los movimientos orogénicos de finales del Plioceno que levantaron las Cordilleras (Axelrod, 1948; Raven \& Axelrod, 1974; Gentry, 1982), como la presencia en la costa del Pacífico septentrional de táxones fundamentalmente tropicales, lo que incluye familias tales como Cactaceae, Fabaceae (Mimosoideae), Nyctaginaceae o Zygophyllaceae, y géneros como Agave, Asclepias, Errazurizia, Gaultheria, Phoradendron, etc. Sin embargo, considerando los millones de aves que vuelan entre Norteamérica y Sudamérica cada año, es probable que se haya producido algún transporte de semillas, sobre todo en hábitats costeros (playas, dunas, acantilados, humedales), que son frecuentados por aves migratorias. Esa dispersión ornitócora podría ex- 
plicar la distribución a lo largo de todo el litoral del Pacífico de algunas plantas costeras que presumiblemente son auto-compatibles y autógamas: Amblyopappus pusillus, Ambrosia chamissonis, Crassula connata, Cardionema ramosissimum, Juncus leseurii, Limonium californicum o Sanicula crassicaulis (cf. Raven, 1963). La mayor concentración de flora tropical se produce en la costa de Baja California, una península que se separó del continente durante el Terciario tardío, hace unos 3,6 Ma (Minch \& al., 2003), tiempo durante el cual se ha producido una fuerte especialización de su flora, que alberga 751 táxones endémicos, incluyendo 22 géneros (Delgadillo, 1995).

De los 354 géneros autóctonos norteamericanos nativos inventariados, 73 son endémicos de Norteamérica. Sólo nueve de ellos se extienden desde la costa atlántica a la pacífica, mientras que 64 lo hacen en la mitad occidental de Norteamérica, fundamentalmente desde las Montañas Rocosas hasta el Pacífico. De esos 64 géneros, 41 son endémicos de la zona mediterránea de California y de Baja California, incluyendo géneros que son endemismos locales de área muy pequeña y casi restringida a la costa: Aphanisma, Bergerocactus, Cneoridium, Harfordia, Ornitostapbylos, Sequoia y Xylococcus. A nivel de especies, de los 521 endemismos norteamericanos encontrados en el área de estudio 251 se presentan en el área de clima mediterráneo incluyendo 142 endemismos de California y Baja California. La zona mediterránea es la que presenta el nivel endémico más elevado de toda la zona de estudio, lo que concuerda con el nivel endémico global, porque California mediterránea y Baja California han sido reconocidas desde hace mucho como las dos zonas más importantes de diferenciación florística a escala continental. Tanto en California como en la porción noroccidental de Baja California que está sujeta a condiciones mediterráneas existe una interacción entre los elementos mésicos derivados de la geoflora Artoterciaria con elementos xéricos derivados de la geoflora Madroterciaria. El conjunto de táxones endémicos restringidos al suroeste (los pertenecientes a los elementos Madreano, Bajocaliforniano y Mediterráneo) están relacionados con la geoflora Madroterciaria (Axelrod, 1958), cuya existencia está ligada al aislamiento climático, habida cuenta de que el clima Mediterráneo del suroeste de Norteamérica evolucionó sólo durante el Terciario tardío (Axelrod, 1973) y nunca ha estado en contacto directo con otra región de parecidas características climáticas.

Para los géneros de amplia distribución en Norteamérica (elementos Norteamericano y Norteamericano Occidental), la explicación de su existencia es la misma a la ya apuntada para los elementos compartidos con Eurasia: su origen en la flora Boreotropical o Artoterciaria. A partir del Oligoceno el clima cálido que caracterizó el hemisferio norte durante los $40 \mathrm{Ma}$ anteriores evolucionó a más frío durante el Plioceno y se volvió extremadamente frío en el Pleistoceno (Tiffney, 1985b), lo que trajo consigo modificaciones profundas en la flora Artoterciaria, que sufrió extinciones masivas o migraciones hacia refugios meridionales.

Las glaciaciones del Wisconsiano, que fueron determinantes en la configuración de la escaparda costa septentrional del área de estudio, desde Alaska al norte de Washington, afectaron a las zonas Boreal y Templada, diezmando la flora de las llanuras, cuya vegetación fue reemplazada en lugares favorables por un bosque abierto de tipo subalpino que albergaba árboles que hoy se encuentran en zonas bajas pero también en la media y alta montaña, como es el caso del picea sitchense (Picea sitchensis) y del pino marítimo Pinus contorta var. contorta (Delcourt \& Delcourt, 1993), ambas dominantes en los bosques costeros boreales y templados actuales. Ese tipo de flora se encontraba en pequeños enclaves no afectados directamente por las glaciaciones, como sucedió en las islas Queen Charlotte y otros refugios costeros (Mathews \& al., 1989). El número relativamente alto (13) de especies endémicas de las zonas costeras boreales contrasta con el reducido número de especies endémicas (2) de la costa templada. Durante las condiciones totalmente glaciares del Wisconsiano de hace 18000 años, grandes casquetes de hielo continental dominaron una buena parte de las tierras ocupadas actualmente por la vegetación boreal y templada (Delcourt \& Delcourt, 1993). Sin embargo, habida cuenta de que sólo hubo glaciares locales entre los ríos Tanana y Yukon en el Yukon Central (Gjærevoll, 1980), esa zona debió actuar como un gran refugio que pudo ser crucial para preservar un número relativamente alto de especies endémicas en zonas boreales.

California es una de las áreas más importantes de supervivencia de relictos derivados de la flora Boreotropical (Abrams, 1925; Wood, 1972; Wolfe, 1975), por su clima oceánico poco contrastado y porque la elevación del eje Sierra Nevada-Cascadas durante el Plioceno tardío evitó la penetración desde el interior de climas áridos y fríos (Raven, 1988). El caso de Baja California es aún más notable. Esa zona mediterránea del noroeste de México, cuya superficie apenas alcanza los $25000 \mathrm{~km}^{2}$, alberga alrededor de 1322 plantas vasculares nativas (Moran in Raven \& Axelrod, 1978), 902 de las cuales no se encuentran en el resto de la península; además, alberga 633 géneros, 292 de los cuales no 
existen en ninguna otra parte de la península. Así, esta zona, cuya superficie solo constituye el $17 \%$ del total peninsular, contiene casi la mitad de las especies (44\%) y casi un tercio o un cuarto de los géneros $(71 \%)$. Por otra parte, aproximadamente 227 especies del noroeste de Baja California no se encuentran dentro de las fronteras de California (Moran in Raven, 1988). La riqueza florística de Baja California está acumulada fundamentalmente en el noroeste mediterráneo. La clave para comprender esta acumulación de diversidad se encuentra en el origen de los elementos florísticos de Baja California. Mediante el uso de un análisis florístico, Peinado \& al. (1994b) señalaron que esta zona es un lugar de refugio tanto para los táxones de la antiguas geofloras terciarias como para los táxones xerofítico-mexicanos de afinidades neotropicales, los cuales encontraron un magnífico refugio para las oscilaciones climáticas del Wisconsiano tardío en la costa de Baja California. De acuerdo con la terminología de Stebbins \& Major (1965), la zona costera mediterránea de California y Baja California es un área con una alta concentración de paleoendemismos y neoendemismos.

\section{Macrobioclima Boreal: provincias Hudsoniana y Sitchense}

El primer tratamiento fitogeográfico de la zona boreal es el de Dice (1943), y el más reciente, el de RivasMartínez \& al. (1999). Dice consideró dos provincias, una con clima Boreal Continental (Hudsoniana) y otra con clima Boreal Oceánico (Sitchense). El tratamiento de Rivas-Martínez y colaboradores es similar cuando reconocen dos provincias, la provincia de Alasko-Yukonense (que equivale a la parte más occidental de la provincia Hudsoniana), y la provincia Alaskeña-Boreal-Oceánica, cuyos límites coinciden exactamente con los de la provincia Sitchense. La clasificación de Takhtajan (1986) no considera la provincia Sitchense, sino que incluye toda la costa del Pacífico, desde la bahía de San Francisco hasta la islas Kodiak, en su provincia Vancouveriana, en la cual expresamente incluye las provincias Oregoniana y Sitchense, y la porción septentrional de la región Californiana (Takhtajan, 1986: 108). Según esta clasificación, la provincia Vancouveriana se extendería en los zonobiomas Boreal, Templado y Mediterráneo. La primera cuestión a dilucidar es si en la franja de $25^{\circ}$ de latitud sobre la que se extiende tal provincia existe una sola unidad fitogeográfica o, si como sostienen el resto de las clasificaciones, existen hasta tres.

La mayoría de las clasificaciones coinciden en considerar al conjunto de la zona mediterránea de Cali- fornia dentro de una unidad fitogeográfica bien caracterizada desde el punto de vista florístico y climático. Thorne (1993: 143), aunque básicamente sigue la clasificación de Takhtajan, ha rechazado expresamente la inclusión del noroeste de California en la provincia Vancouveriana. La individualidad florística de la porción mediterránea de California ha sido subrayada repetidamente desde los primeros trabajos fitogeográficos de Abrams (1925). El origen de la flora de California y el aislamiento de la zona de clima mediterráneo del suroeste de Norteamérica desde el Terciario (Raven \& Axelrod, 1978; Axelrod, 1988; Raven, 1988) refuerzan también la individualidad fitogeográfica de la California mediterránea. Nuestro análisis por elementos también apoya la separación de los grupos californianos con respecto a los boreales y rocosianos (Tablas 2, 3). El índice de similitud entre los grupos BOR y ROC es menor que el que se obtiene al comparar este último con el californiano (Tabla 8). Los valores más altos de similitud a nivel genérico se obtienen cuando comparamos los subgrupos BOR con los subgrupos templados ROC-1 y ROC-2 (Tabla 9). Esta acusada similitud se debe a que en esos subgrupos templados hay un nutrido grupo de géneros ligados a hábitats muy extendidos como saladares, marismas, estuarios y playas. Cuando se compara a nivel específico, los índices de similitud disminuyen drásticamente (Tabla 10).

La separación entre las unidades fitogeográficas boreales y rocosianas parece también clara, tanto a nivel climático como florístico o ecológico. El índice de

Tabla 8. Índices de Similitud de Sørensen (cifras decimales en la derecha del cuadro) y número de táxones compartidos (dígitos enteros a la izquierda) resultantes de comparar entre sí pares de agrupamientos de los obtenidos en el ALC. En cada grupo la fila superior corresponde a los géneros, y la inferior, a las especies.

\begin{tabular}{|c|c|c|c|c|c|c|c|}
\hline \multicolumn{2}{|c|}{ Agrupamientos } & 1 & 2 & 3 & 4 & 5 & 6 \\
\hline \multirow{2}{*}{\multicolumn{2}{|c|}{1 BOR }} & & 0,45 & 0,33 & 0,23 & 0,08 & 0,04 \\
\hline & & & 0,31 & 0,16 & 0,04 & 0,0 & 0,0 \\
\hline & ROC & 56 & & 0,52 & 0,55 & 0,23 & 0,12 \\
\hline & & 52 & & 0,34 & 0,36 & 0,04 & 0,01 \\
\hline \multirow[t]{2}{*}{3} & TRA-1 & 24 & 62 & & 0,38 & 0,19 & 0,07 \\
\hline & & 16 & 69 & & 0,32 & 0,10 & 0,03 \\
\hline & CAL & 34 & 105 & 53 & & 0,49 & 0,31 \\
\hline & & 21 & 110 & 76 & & 0,42 & 0,23 \\
\hline & TRA-II & 7 & 30 & 15 & 73 & & 0,43 \\
\hline & & 0 & 8 & 10 & 109 & & 0,37 \\
\hline & XER & 5 & 20 & 10 & 55 & 50 & \\
\hline & & 0 & 4 & 6 & 74 & 65 & \\
\hline
\end{tabular}




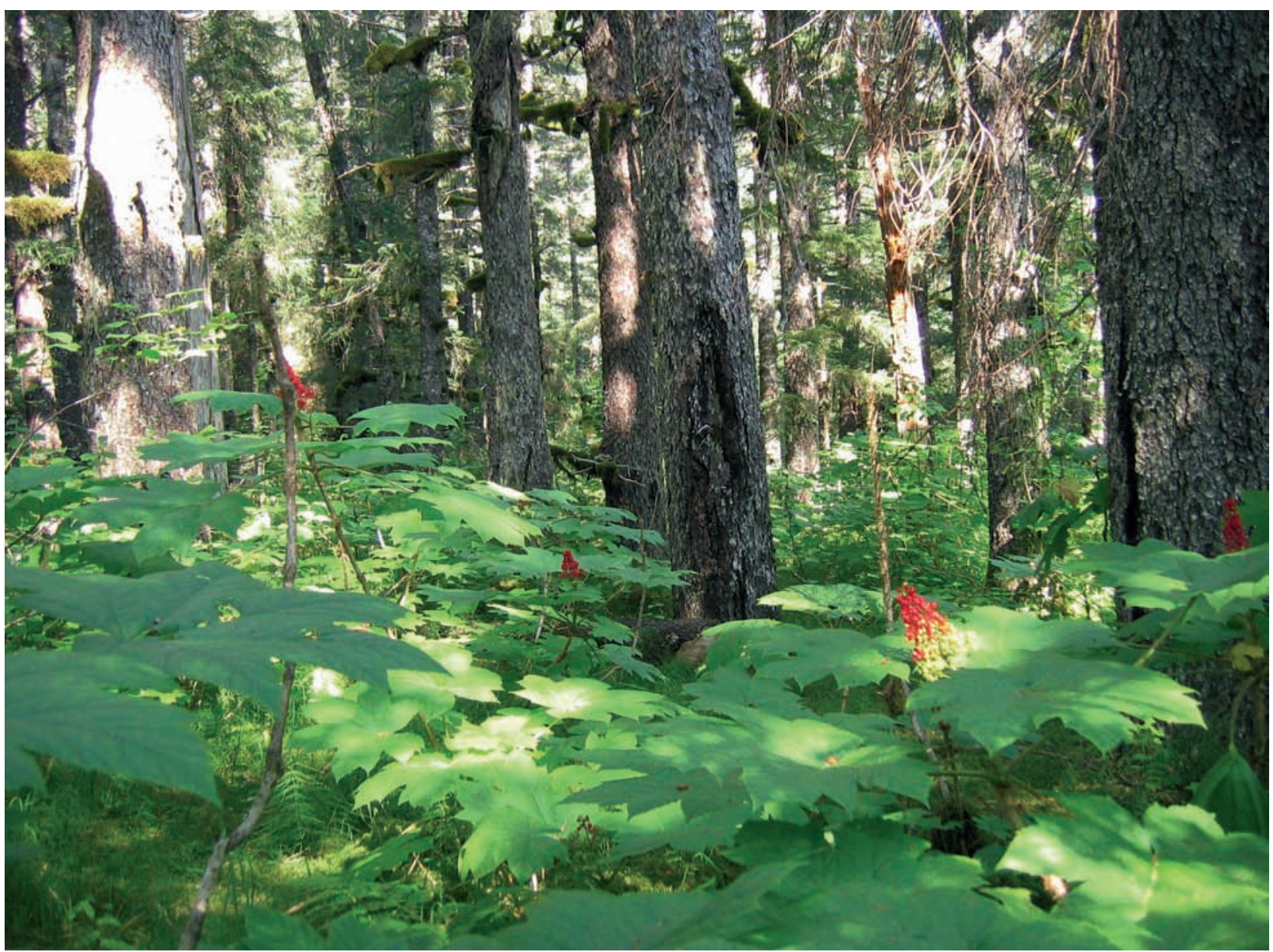

Fig. 4. Vegetación de la provincia Sitchense. Interior de un bosque boreal costero de Picea sitchensis (Tsugo mertensianae-Piceetum sitchensis). El sotobosque está dominado por una megaforbia, Oplopanax horridus. Isla de Kodiak, Alaska.

similitud entre el grupo boreal BOR y el templado ROC es inferior al que se obtiene cuando se comparan entre sí los grupos y subgrupos CAL y ROC (Tablas 9, 10), y los elementos fitogeográficos boreales y rocosianos son también muy diferentes sobre todo cuando se consideran elementos fitogeográficos tales como COS, INT, HOL, OES, BOR y TEM (Tablas 2,3). El índice de similitud entre los grupos BOR y CAL es de tan sólo 0,23 a nivel de género y prácticamente despreciable a nivel específico (Tabla 8). El análisis de los elementos fitogeográficos subraya también la separación de los grupos mediterráneos frente a los templados y boreales (Tablas 2, 3).

Los índices más altos de similitud aparecen cuando se compara el subgrupo boreal oceánico BOR-2 con los subgrupos rocosianos que contienen Picea sitchensis, que es el árbol dominante a lo largo de la costa boreotemplada, desde el golfo de Alaska hacia el sur, hasta el extremo hiperoceánico noroccidental de California. Los bosques de P. sitchensis prosperan en las cos- tas más lluviosas y afectadas por las nieblas de las provincias Sitchense y Oregoniana, en las áreas con los registros más altos de precipitación en el occidente de Norteamérica. A pesar del fondo florístico común de estos bosques costeros desde Alaska hasta Oregón, también hay diferencias significativas entre los bosques del subgrupo BOR-2 y los bosques templados del subgrupo ROC-2. Los primeros se incluyen en la asociación Tsugo mertensianae-Piceetum sitchensis, y los segundos en la asociación Vaccinio ovati-Piceetum sitchensis (para la sintaxonomía, cf. Rivas-Martínez \& al., 1999). Por último, mientras que la ausencia de bosques costeros de pino marítimo en áreas boreales es una de las diferencias entre los zonobiomas Boreal y Templado, los bosques de Picea glauca y P. mariana, y su flora asociada, son característicos del zonobioma Boreal (Peinado \& al., 2007).

Excepción hecha de la clasificación de Takhtajan, todas las demás clasificaciones coinciden en distinguir sendas unidades fitogeográficas que se sustituyen en 


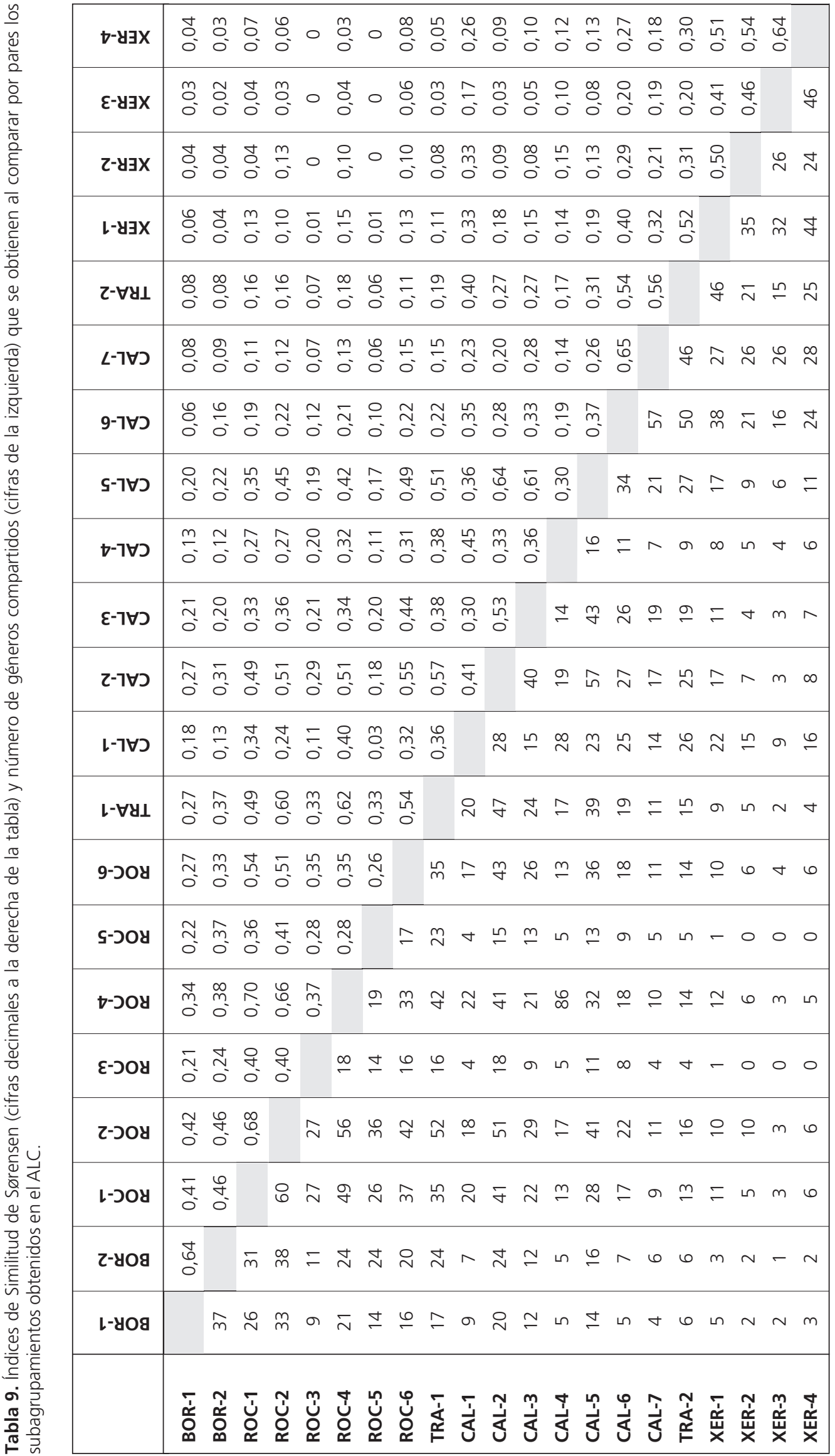




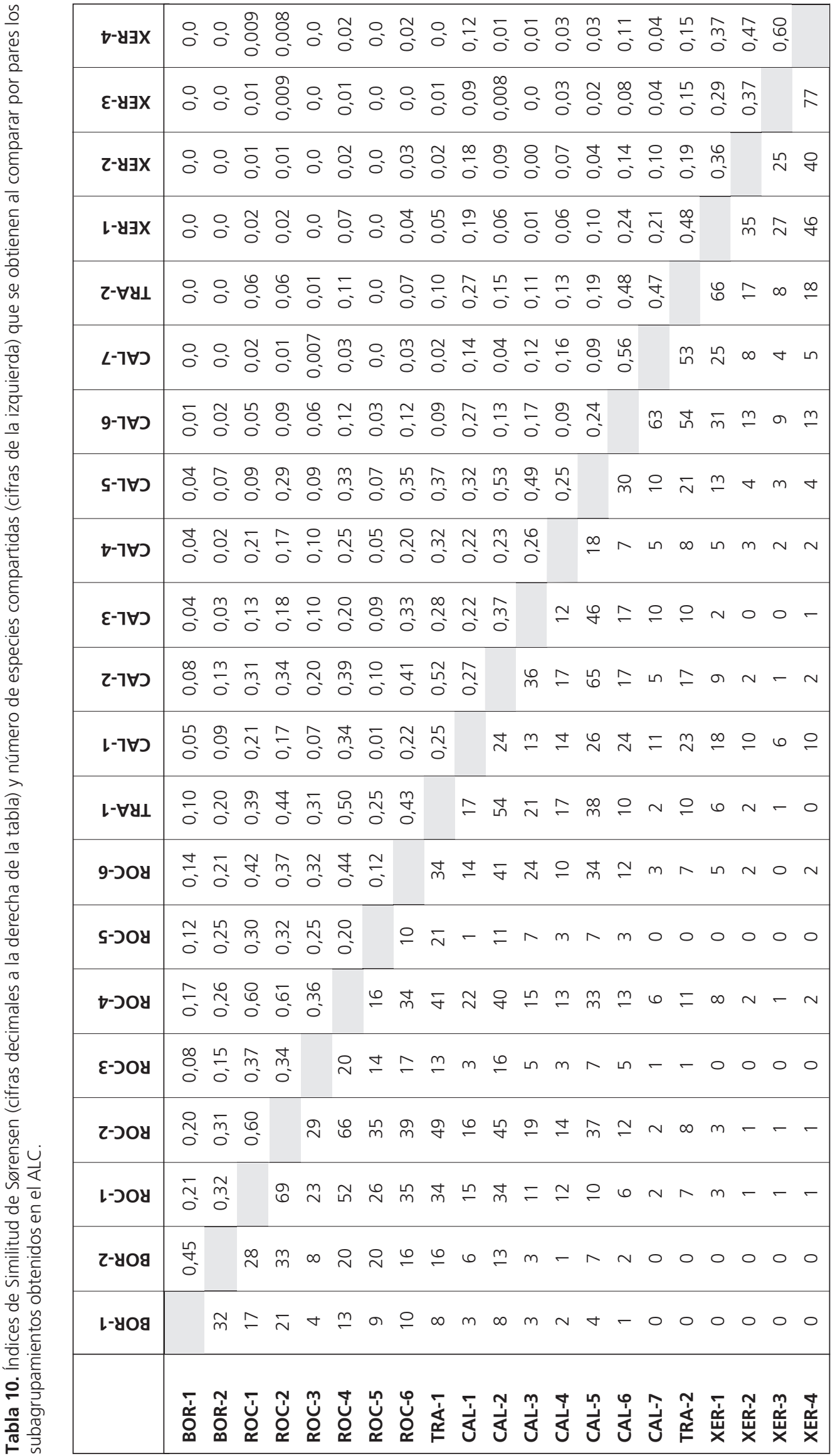


la latitud de Dixon Entrance, justo al norte de las islas Queen Charlotte, donde Dice situó la frontera entre las provincias boreal Sitchense y la templada Oregoniana, una frontera refrendada en publicaciones posteriores (Udvardy, 1975a, b; Walter, 1985; Bailey, 1995; Peinado \& al., 1997a, b, 2005, 2007; Brown \& al., 1998; Rivas-Martínez \& al., 1999).

Establecidas estas diferencias que apoyan la existencia de varias unidades fitogeográficas con base zonobioclimática, veamos ahora las existentes dentro de la zona boreal. El grupo BOR reunió todos los inventarios de Alaska. Cuando se proyectan las localidades del subgrupo BOR-1 en un mapa, se sitúan claramente a lo largo de Cook Inlet, la única zona de Norteamérica donde la provincia Hudsoniana y la taiga boreal alcanzan el oceánico Pacífico (Peinado \& al., 1998). El clima boreal está allí continentalizado y existen plantas endémicas o exclusivas de este subgrupo que no se presentan en el subgrupo BOR-2 (Tabla 7). Las localidades del subgrupo BOR-2 se extienden en la costa abierta del Pacífico bajo condiciones boreales oceánicas, unas condiciones que favorecen que los bosques de Picea sitchensis dominen las costas. Estos bosques son inexistentes en las localidades del subgrupo BOR-1, porque en Cook Inlet son sustituidos por los bosques hudsonianos dominados por Picea glauca. La flora asociada a ambos tipos de bosques costeros marca también notables diferencias florísticas entre los subgrupos BOR-1 (provincia Hudsoniana) y BOR -2 (provincia Sitchense).

\section{Macrobioclima Templado: provincia Oregoniana}

Las localidades templadas situadas entre British Columbia y el sur de Oregón se unieron en un solo agrupamiento. La zona templada del oeste norteamericano ha sido reconocida como una zona natural por los biogeógrafos, cuyo nombre más antiguo es de provincia Oregoniana otorgado por Dice (1943), quien también estableció su límite septentrional alrededor de los 54 $20^{\circ}$, donde se encuentra la frontera entre los zonobiomas Templado y Boreal (Peinado \& al., 2007). Las diferencias y similitudes florísticas entre las provincias boreales norteamericanas del zonobioma Boreal y las oregonianas del zonobioma Templado se resumen en la Tabla 11.

El límite meridional, esto es, la frontera entre la provincia Oregoniana y los territorios del zonobioma Mediterráneo (región Californiana), ha sido más discutido. Howell (1957) localizó el límite norte para su provincia florística Californiana a los $43^{\circ} 30^{\prime}$, mientras que Dice (1943) y Takhtajan (1986) situaron los límites costeros californianos mucho más al sur, justo al norte de la bahía de San Francisco (3750'), lo que implica una diferencia de casi seis grados de latitud que merece ser discutida.

De acuerdo con los climogramas de Walter \& Lieth (1967) uno de los rasgos que definen un clima como Mediterráneo es que al menos en dos meses consecutivos de los tres de verano se cumple que $\mathrm{P}<2 \mathrm{~T}$, siendo P la precipitación anual $(\mathrm{mm})$ y $\mathrm{T}$ la temperatura media anual $\left({ }^{\circ} \mathrm{C}\right)$. Si atendemos exclusivamente a este criterio, la zona de clima Mediterráneo llegaría hasta Vancouver, a los $49^{\circ} 11^{\prime}$, cuyo climograma es típicamente mediterráneo (Walter \& Lieth, 1967; Walter, 1985), como también sucedería con las estaciones meteorológicas situadas al oeste del estrecho de Georgia y en el interior de Puget Sound, coincidiendo con la zona bioclimática "Coastal Douglas-Fir" de Meidinger \& Pojar (1991) y con el clima templado mesotermal de veranos secos de Klinka \& al. (1995). A pesar de esta apariencia mediterránea, la influencia de la sequía de verano parece tener poco efecto florístico hasta aproximadamente $42^{\circ}$, porque la falta de precipitación estival es compensada por la abundancia de agua primaveral que se retiene en el suelo, por las criptoprecipitaciones de nieblas de verano que suplen una cantidad adicional de agua no registrada por encima de los $200 \mathrm{~mm}$ (Azevedo \& Morgan, 1974), y por un periodo prolongado de nubosidad y niebla que reducen grandemente la evaporación. Esta observación también fue indicada por Galán de Mera \& Vicente Orellana (2007).

Los datos florísticos avalan la existencia de una amplia zona de transición entre las provincias Oregoniana y Californiana, que fue reconocida como la transición entre los zonobiomas Templado y Mediterráneo (Walter, 1985; Peinado \& al. 1997b). La transición es señalada por la presencia de algunos elementos californianos y madreanos en el grupo ROC y, sobre todo, por la penetración del elemento Templado Pacífico Noroccidental en los grupos septentrionales y más húmedos CAL-1 y CAL-2 (Tabla 3).

El límite sur de la provincia Oregoniana puede ser establecido en función de algunos cambios florísticos significativos en la vegetación costera. Mientras que diversas especies rizomatosas como Leymus mollis subsp. mollis forman dunas primarias longitudinales como crestas continuas en las playas templadas, las de la región Californiana presentan dunas embrionarias constituidas por montículos individuales cónicos de hasta $2 \mathrm{~m}$ de alto construidos por hemicriptófitos xilopódicos almacenadores de agua (Abronia maritima y A. latifolia). Barbour \& Johnson (1988) documentaron estos montículos a lo largo de toda la costa de California, y Peinado \& al. (2008), en Baja California y Sonora. Al sur de Morro Bay no se presentan los hemicriptófitos 
Tabla 11. Resumen de los táxones compartidos y diferenciales para las provincias boreales (BOR: incluye las provincias Hudsoniana y Sitchense) y Oregoniana (ORE). Los datos aparecen en porcentajes de presencia (redondeados) para el total de localidades; el número de éstas, ajustado tras la reubicación derivada de la discusión. Las especies marcadas con un asterisco son táxones diferenciales de la provincia Oregoniana frente a la región Californiana (véase también la Tabla 12).

\begin{tabular}{|c|c|c|c|c|c|}
\hline & BOR & ORE & & BOR & ORE \\
\hline Número de localidades & 21 & 70 & & 21 & 70 \\
\hline \multicolumn{3}{|l|}{ Diferenciales boreales } & \multicolumn{3}{|l|}{ Diferenciales oregonianas } \\
\hline Betula papyrifera var. kenaica & 87 & - & Polygonum paronychia & - & 17 \\
\hline Puccinellia hultenii & 61 & - & Veronica scutellata & - & 16 \\
\hline Senecio pseudoarnica & 61 & - & Pteridium aquilinum var. pubescens & - & 16 \\
\hline Equisetum sylvaticum & 56 & - & Maianthemum dilatatum & - & 16 \\
\hline Ligusticum scoticum subsp. hultenii & 52 & - & Schoenoplectus americanus & - & 14 \\
\hline Poa eminens & 52 & - & Carex pansa & - & 14 \\
\hline Stellaria humifusa & 52 & - & Trifolium wormskjoldii & - & 14 \\
\hline Empetrum nigrum & 48 & - & Tsuga heterophylla & - & 13 \\
\hline Geocaulon lividum & 48 & - & Agrostis pallens & - & 13 \\
\hline Linnaea borealis subsp. americana & 48 & - & Vicia nigricans subsp. gigantea & - & 13 \\
\hline Picea glauca & 48 & - & Cuscuta salina & - & 13 \\
\hline Rosa acicularis subsp. acicularis & 48 & - & Spiranthes romanzoffiana & - & 13 \\
\hline Shepherdia canadensis & 48 & - & Pseudotsuga menziesii var. menziesii & - & 11 \\
\hline Lathyrus palustris & 43 & - & Thuja plicata & - & 11 \\
\hline Lycopodium annotinum & 43 & - & Grindelia integrifolia & - & 11 \\
\hline Orthilia secunda & 43 & - & Poa confinis & - & 11 \\
\hline Sorbus sitchensis & 43 & - & Lilaeopsis occidentalis & - & 11 \\
\hline Angelica lucida & 30 & - & Lathyrus littoralis & - & 10 \\
\hline Dendranthema arcticum subsp. arcticum & 26 & - & Baccharis pilularis & - & 8 \\
\hline Poa macrocalyx & 22 & - & Armeria maritima subsp. californica & - & 7 \\
\hline Artemisia campestris subsp. borealis & 17 & - & \multirow{2}{*}{\multicolumn{3}{|c|}{ Táxones compartidos }} \\
\hline Atriplex alaskensis & 17 & - & & & \\
\hline Salicornia maritima & 17 & - & Leymus mollis subsp. mollis & 91 & 50 \\
\hline Carex ramenskii & 14 & - & Carex lyngbyei & 87 & 39 \\
\hline Epilobium ciliatum subsp. glandulosum & 14 & - & Argentina egedii subsp. egedii & 78 & 50 \\
\hline Parnassia palustris var. palustris & 14 & - & Plantago maritima var. juncoides & 70 & 24 \\
\hline Puccinellia nutkaensis & 13 & - & Picea sitchensis & 48 & 69 \\
\hline Puccinellia phryganodes subsp. phryganodes & 13 & - & Hordeum brachyantherum subsp. brachyantherum* & 61 & 11 \\
\hline Rhinanthus minor subsp. groenlandicus & 13 & - & Lathyrus japonicus var. maritimus & 61 & 50 \\
\hline \multirow{2}{*}{\multicolumn{3}{|c|}{ Diferenciales oregonianas }} & Honkenya peploides subsp. major* & 56 & 11 \\
\hline & & & Conioselinum gmelinii & 56 & 3 \\
\hline Gaultheria shallon & _ & 60 & Viburnum edule* & 52 & 1 \\
\hline Vaccinium ovatum & - & 50 & Festuca rubra subsp. rubra & 52 & 26 \\
\hline Lonicera involucrata var. involucrata & - & 43 & Achillea millefolium & 52 & 26 \\
\hline Salix hookeriana & - & 41 & Vaccinium uliginosum* & 48 & 1 \\
\hline Ammophila arenaria & - & 41 & Triglochin maritimum & 48 & 33 \\
\hline Pinus contorta var. contorta & - & 39 & Dryopteris expansa & 48 & 4 \\
\hline Myrica californica & - & 37 & Oplopanax horridus* & 43 & 4 \\
\hline Carex obnupta & - & 36 & Menziesia ferruginea* & 43 & 3 \\
\hline Juncus lesueurii & - & 33 & Tiarella trifoliata* & 43 & 3 \\
\hline Polystichum munitum & - & 33 & Vaccinium membranaceum* & 43 & 3 \\
\hline Hypochaeris radicata & - & 27 & Athyrium filix-femina subsp. cyclosurum & 43 & 1 \\
\hline Sarcocornia perennis* & - & 26 & Deschampsia cespitosa subsp. beringensis & 35 & 37 \\
\hline Juncus falcatus & - & 26 & Mertensia maritima* & 35 & 1 \\
\hline Distichlis spicata & - & 24 & Calamagrostis canadensis* & 22 & 7 \\
\hline Jaumea carnosa & - & 24 & Chamerion angustifolium subsp. circumvagum* & 22 & 1 \\
\hline Arctostaphylos uva-ursi & - & 24 & Galium aparine & 22 & 3 \\
\hline Anaphalis margaritacea & - & 23 & Equisetum telmateia var. braunii* & 13 & 8 \\
\hline Cakile maritima & - & 23 & Glaux maritima* & 13 & 20 \\
\hline Cytisus scoparius & - & 23 & Ranunculus cymbalaria* & 13 & 1 \\
\hline Lupinus littoralis & - & 23 & Atriplex patula & 9 & 21 \\
\hline Alnus rubra & - & 20 & Fragaria chiloensis subsp. pacifica & 9 & 34 \\
\hline Tanacetum camphoratum & - & 20 & Juncus balticus & 9 & 17 \\
\hline Cardionema ramosissimum & - & 17 & Cakile edentula subsp. edentula var. edentula & 4 & 29 \\
\hline
\end{tabular}




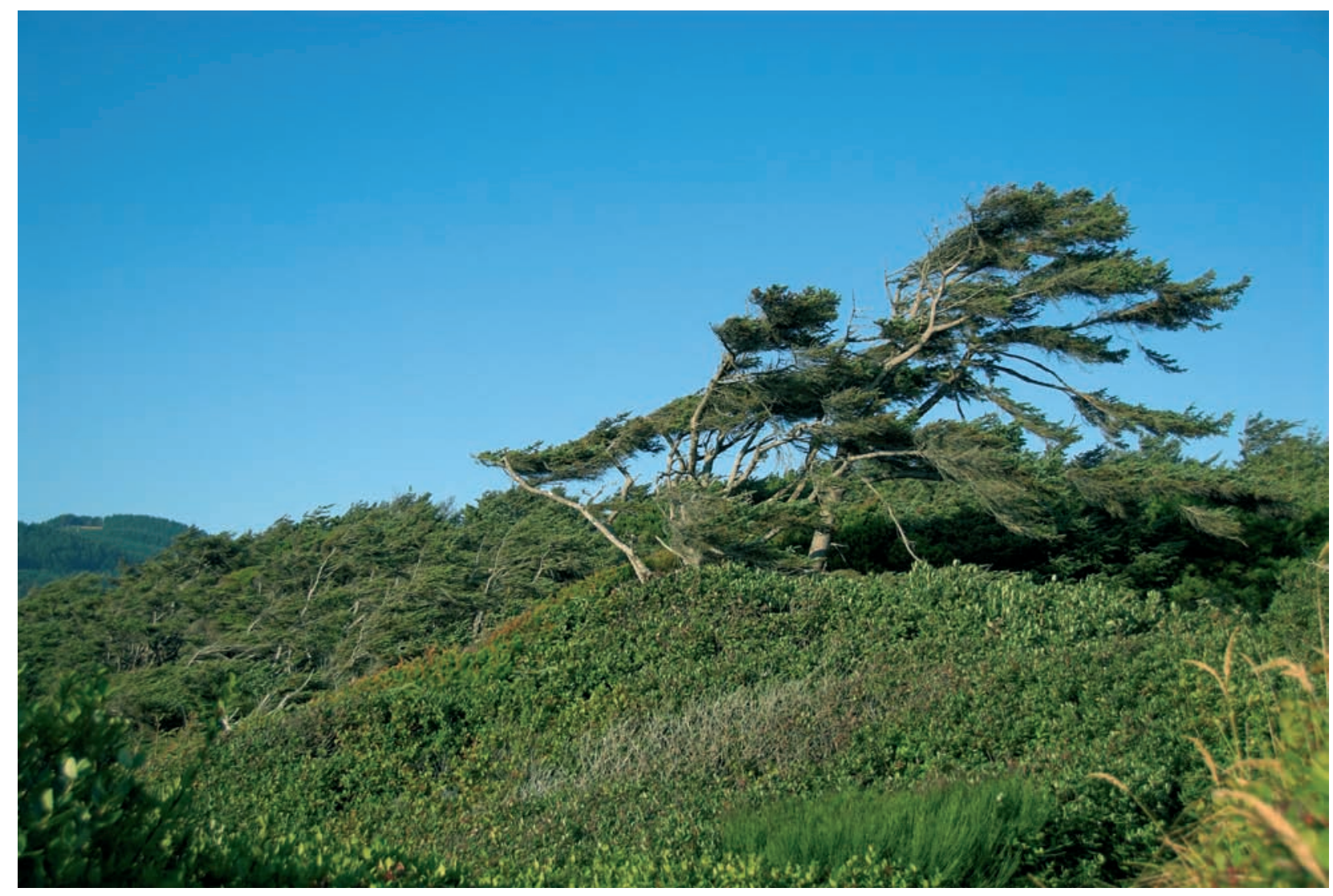

Fig. 5. Vegetación de la provincia Oregoniana. Acantilado costero colonizado por un bosque abanderado correspondiente a una faciación aerohalófila de la asociación Vaccinio ovati-Piceetum sitchensis. Los árboles emergentes son Picea sitchensis. El sotobosque está dominado por una arbusteda densa de P. sitchensis, Pinus contorta var. contorta y Gaultheria shallon. Sur de la desembocadura del río Columbia, Washington.

rizomatosos septentrionales, excepto donde se plantó Ammophila arenaria para fijar dunas. Aproximadamente desde Morro Bay hacia el norte Leymus mollis subsp. mollis crece protegido de la maresía a sotavento de los montículos de Abronia, un modelo de duna primaria muy diferente del que se produce en las playas templadas, en las cuales, a falta de los montículos de Abronia, L. mollis subsp. mollis edifica dunas primarias a barlovento, enfrentadas directamente a los fuertes vientos del noroeste.

La presencia de bosques de dunas dominados por piceas sitchenses (Picea sitchensis) y pinos marítimos (Pinus contorta var. contorta) es una característica sobresaliente de las dunas costeras templadas cuando se comparan con las dunas mediterráneas. Como ocurre en las dunas del Mediterráneo ibérico, las dunas semifijas de la zona mediterránea de California están cubiertas por arbustos característicos, incluyendo un gran número de edafoendemismos locales. Los primeros ejemplares de piceas sitchenses y de pinos marítimos con formas rastreras y de matorral abanderado empiezan a aparecer en los acantilados justo al norte de Bodega Bay (c. 38 30'), pero no hay verdaderos bosques de dunas hasta alcanzar los sistemas de dunas de Samoa-Arcata-Eureka (40 47'), situados justo al norte de cabo Mendocino en la subzona de clima mediterráneo con más lluvia y niebla, i.e., en el zonoecotono mediterráneo-templado. La última localidad con dunas extensas al sur de cabo Mendocino se encuentra en el sistema de dunas de Tenmile River (McKerringer State Park, 39 29'), en los cuales no hay bosques de dunas. Desde este punto hasta el norte de cabo Mendocino $P$. sitchensis y $P$. contorta comienzan a aparecer más frecuentemente, pero como krummbolzs de acantilados, sin formar bosques. En el primer sistema de dunas encontrado al norte de cabo Mendocino (Samoa), las dunas estabilizadas presentan una edafoclímax de coníferas dominada por pinos marítimos y piceas sitchenses, cuya composición florística es muy similar a los bosques de ambos árboles en las dunas templadas, aunque la talla de los árboles dominantes es notablemente menor. 
En ese extremo noroccidental de California se produce un cambio fitogeográfico significativo en los corrales húmedos interdunares: las saucedas de Salix lasiolepis, dominantes bajo macrobioclima Mediterráneo desde Baja California hacia el norte, son reemplazadas por saucedas de $S$. hookeriana, las cuales dominan en las mismas posiciones ecológicas desde allí a través de toda la provincia Oregoniana hasta el sur de las Islas Queen Charlotte, su límite septentrional (Klinkenberg, 2008). La aparición de bosques dunares de pino litoral y piceas sitchenses, y el reemplazamiento de ambas especies de sauces se acompaña también con otros cambios latitudinales en la vegetación costera de acantilados, saladares y bosques climácicos, que presentan cambios florísticos muy significativos entre el norte de cabo Mendocino y el sur de Oregón. La Tabla 12 resume las similitudes y diferencias florísticas más significativas entre la región Californiana y la provincia Oregoniana.

Los acantilados marinos de la región Californiana son ricos en especies, muchas de ellas endémicas de la región, que forman una vegetación característica cuya posición ecológica es similar a la clase Crithmo-Staticetea Br.-Bl. in Br.-Bl., Roussine \& Nègre 1952. En la zona transicional del noroeste de California un arbusto nemoral típicamente templado, la ericácea laurifolia Gaultheria shallon, empieza a incorporarse en los acantilados marinos, en el seno de comunidades arbustivas todavía mediterráneas. En la costa oregoniana tales arbustedas aerohalófilas no existen porque los acantilados expuestos a la maresía están directamente colonizados por los bosques costeros climácicos de pinos marítimos y piceas sitchenses.

Los cambios florísticos en los saladares también marcan el zonoecotono entre la región Californiana y la provincia Oregoniana. La composición florística de los saladares mediterráneos refleja variaciones climáticas latitudinales. Entre el norte de Baja California y el sur de Oregón, las halófitas mediterráneas van desapareciendo progresivamente. Batis mariti$m a$, un elemento de origen tropical, no se extiende más allá de Point Conception. Un poco más al norte, entre Point Conception y San Luis Obispo, coincidiendo con el cambio del ombroclima semiárido al seco que se comenta más adelante, desaparecen Amblyopappus pusillus, Artbrocnemum subterminale, Atriplex watsonii, Monanthochloe littoralis y Salicornia bigelowii, todas ellas comunes en los saladares meridionales bajo ombroclima semiárido. Spartina foliosa, pionera desde Baja California hacia el norte a lo largo de toda la costa californiana, alcanza en Humboldt County, al norte de cabo Mendocino, su límite septentrional. Desde este punto hacia el norte comienzan los cambios florísticos más notables en los saladares. Junto con S. foliosa, también comienzan a desaparecer algunos de los táxones comunes en los saladares californianos (Cordylanthus maritimus, Frankenia grandifolia, Limonium californicum, Sarcocornia pacifica), para dar paso a plantas características de los saladares oregonianos como Glaux maritima, Plantago maritima var. juncoides, Deschampsia cespitosa subsp. beringensis, Puccinellia kurilensis, Sarcocornia perennis y Triglochin maritimum. Estos significativos cambios en los saladares están sustentados por cambios climáticos que modifican la temperatura del agua y la salinidad (Macdonald \& Barbour, 1974; Macdonald, 1988).

Dado que el límite norte de Sequoia sempervirens está en el valle del río Chetco $\left(42^{\circ} 05^{\prime} \mathrm{N}\right)$, en una publicación anterior situamos el límite fitogeográfico californiano en ese punto del sur de Oregón (Peinado \& al., 1997b). Tal límite fitogeográfico se sustenta también en el análisis florístico de la vegetación de playas y dunas costeras. El último sistema de dunas del sur del río Chetco es el de Point St. George (Kellog Beach, $\left.41^{\circ} 52^{\prime}\right)$, mientras que el primer sistema de dunas significante al norte del río Chetco aparece en Bullard Beach State Park $\left(43^{\circ} 08^{\prime}\right)$, ya en pleno zonobioma Templado. En Point St. George las playas y dunas sostienen una flora y vegetación mediterránea propia de la región Californiana: Lupinus variicolor, Artemisia pycnocephala, Erigeron glaucum, Eriopbyllum staechadifolium, y Eriogonum latifolium, los cuales -aparecidos en Monterey o más hacia el sur- tienen en Point St. George su límite septentrional. En Bullard Beach no hay matorrales de dunas dominados por A. pycnocephala, ni ninguno de los arbustos anteriormente mencionados. Lupinus littoralis -un elemento Oregoniano- reemplaza a L. variicolor, mientras las playas y las dunas traseras, aunque alteradas por la influencia antrópica, sustentan comunidades en recuperación dominadas por piceas sitchenses y pinos marítimos, cuya composición florística es idéntica a la que aparece en toda la provincia Oregoniana. Mientras los saladares inmediatamente al sur de Point St. George muestran una zonación mediterránea, incluyendo las bandas de Spartina foliosa y Sarcoconia pacifica, los saladares de Bullard Beach y los excelentemente preservados de South Slough Nacional Estuarine Reserve $\left(43^{\circ} 18^{\prime} \mathrm{N}\right)$ muestran una zonación típica del norte, con Sarcornia perennis, Triglochin maritimum y Plantago maritima var. juncoides formando poblaciones densas en los bordes más bajos intermareales. Densas comunidades de Carex lyngbyei, ausentes de toda la región 
Tabla 12. Resumen de los táxones compartidos y diferenciales para la provincia Oregoniana (ORE) y la región Californiana (CAL). Los datos aparecen en porcentajes de presencia (redondeados) para el total de localidades; el número de éstas, ajustado tras la reubicación derivada de la discusión. Véanse las Tablas 11 y 13 para ver más táxones diferenciales de ambas. Las especies marcadas con un asterisco en la Tabla 11 son diferenciales de la provincia Oregoniana frente a la región Californiana y las marcadas en la Tabla 13 son diferenciales de la región Californiana frente a la Oregoniana.

\begin{tabular}{|c|c|c|c|c|c|}
\hline Número de localidades & $\begin{array}{c}\text { CAL } \\
94\end{array}$ & $\begin{array}{c}\text { ORE } \\
70\end{array}$ & & $\begin{array}{c}\text { CAL } \\
94\end{array}$ & $\begin{array}{l}\text { ORE } \\
70\end{array}$ \\
\hline Diferenciales californianas & & & Táxones compartidos & & \\
\hline Eriophyllum stoechadifolium* & 31 & _ & Ambrosia chamissonis & 40 & 4 \\
\hline Sarcocornia pacifica & 34 & & Cakile maritima & 35 & 23 \\
\hline Carpobrotus chilensis & 30 & _- & Baccharis pilularis* & 35 & 9 \\
\hline Erigeron glaucus* & 25 & - & Distichlis spicata & 35 & 24 \\
\hline Artemisia californica* & 24 & - & Camissonia cheiranthifolia subsp. cheiranthifolia* & 27 & 3 \\
\hline Artemisia pycnocephala* & 20 & - & Abronia latifolia* & 23 & 4 \\
\hline Eriogonum latifolium* & 20 & - & Achillea millefolium* & 29 & 26 \\
\hline Lotus scoparius var. scoparius* & 20 & - & Jaumea carnosa & 21 & 24 \\
\hline Eriogonum parvifolium* & 17 & - & Ammophila arenaria* & 21 & 41 \\
\hline Corethrogyne californica var. californica* & 16 & - & Cuscuta salina & 19 & 13 \\
\hline Agave shawii subsp. shawii & 16 & - & Armeria maritima subsp. californica* & 15 & 7 \\
\hline Bergerocactus emoryi & 16 & - & Rubus ursinus subsp. ursinus* & 14 & 3 \\
\hline Rhus integrifolia & 15 & - & Calystegia soldanella* & 13 & 7 \\
\hline Ericameria ericoides* & 15 & - & Polygonum paronychia* & 12 & 17 \\
\hline Eriogonum fasciculatum var. fasciculatum & 14 & - & Leymus mollis subsp. mollis & 12 & 50 \\
\hline Nassella lepida* & 14 & - & Lupinus arboreus* & 11 & 3 \\
\hline Eschscholzia californica & 13 & - & Argentina egedii subsp. egedii * & 8 & 50 \\
\hline Salix lasiolepis* & 13 & - & Lathyrus littoralis & 5 & 10 \\
\hline Amblyopappus pusillus & 13 & - & Pseudotsuga menziesii v. menziesii & 3 & 11 \\
\hline Encelia californica var. californica & 11 & - & Picea sitchensis & 3 & 69 \\
\hline Mirabilis californica & 11 & - & Gaultheria shallon & 3 & 60 \\
\hline Dudleya cultrata & 10 & - & Vaccinium ovatum & 1 & 50 \\
\hline Diferenciales oregonianas & & & Lathyrus japonicus var. maritimus & 1 & 50 \\
\hline Carex lyngbyei & - & 39 & Salix hookeriana & 3 & 41 \\
\hline Deschampsia cespitosa subsp. beringensis & - & 37 & Pinus contorta var. contorta & 2 & 39 \\
\hline Cakile edentula subsp. edentula var. edentula & - & 29 & Myrica californica & 8 & 37 \\
\hline Sarcocornia perennis & - & 26 & Carex obnupta & 6 & 36 \\
\hline Arctostaphylos uva-ursi & - & 24 & Triglochin maritimum & 8 & 33 \\
\hline Plantago maritima var. juncoides & - & 24 & Atriplex patula & 8 & 21 \\
\hline Cytisus scoparius & - & 23 & Fragaria chiloensis subsp. pacifica* & 15 & 34 \\
\hline Lupinus littoralis & - & 23 & Juncus lesueurii* & 14 & 33 \\
\hline Glaux maritima & - & 20 & Polystichum munitum & 5 & 33 \\
\hline Veronica scutellata & - & 16 & Hypochaeris radicata & 2 & 27 \\
\hline Trifolium wormskjoldii & - & 14 & Festuca rubra subsp. rubra & 1 & 26 \\
\hline Tsuga heterophylla & - & 13 & Juncus falcatus & 4 & 26 \\
\hline Agrostis pallens & - & 13 & Anaphalis margaritacea & 1 & 23 \\
\hline Vicia nigricans subsp. gigantea & - & 13 & Alnus rubra & 3 & 20 \\
\hline Spiranthes romanzoffiana & - & 13 & Tanacetum camphoratum & 3 & 20 \\
\hline Thuja plicata & - & 11 & Juncus balticus & 3 & 17 \\
\hline Grindelia integrifolia & - & 11 & Cardionema ramosissimum & 4 & 17 \\
\hline Poa confinis & - & 11 & Pteridium aquilinum var. pubescens & 4 & 16 \\
\hline Lilaeopsis occidentalis & - & 11 & Maianthemum dilatatum & 2 & 16 \\
\hline
\end{tabular}

Californiana, prosperan en las zonas de estuarios a lo largo de toda la costa templada y boreal del Pacífico desde este punto hasta Alaska.

Por tanto, si interpretamos los bosques de dunas con piceas sitchenses y pinos marítimos como característicos de las dunas costeras templadas, la frontera meridional de la provincia Oregoniana debería situar- se en las dunas de Samoa ( $\left.40^{\circ} 47^{\prime}\right)$. En nuestro análisis ALC, estos bosques de dunas fueron decisivos para la inclusión de cinco localidades del noroeste californiano dentro del grupo ROC. Si además de este criterio usamos los cambios florísticos en la vegetación de playas, dunas, acantilados costeros, saladares y bosques clímatófilos como los factores discriminantes, enton- 
ces la frontera florística entre las provincias Oregoniana y Californiana tendría que ser dibujada algo más al norte, por encima del río Chetco $\left(42^{\circ} 05^{\prime} \mathrm{N}\right)$, coincidiendo con el límite norte de los bosques de sequoias. Stebbins \& Major (1965) situaron el límite costero de la provincia florística Californiana en la boca de río Rogue en Oregón, aproximadamente a los $42^{\circ} 30^{\prime} \mathrm{N}$, un límite también establecido por Raven (1988), Thorne (1993) y Rivas-Martínez \& al. (1999). Nuestros resultados apoyan este último límite.

Habida cuenta de que el macrobioclima Templado se extiende de forma continua a través de Norteamérica al sur de la zona climática boreal, permitiendo el intenso intercambio de especies a escala continental, el número de endemismos norteamericanos y norteamericano-occidentales en la provincia Oregoniana es el más elevado de todas las zonas muestreadas (Tablas $2,3)$. Además, las condiciones climáticas hiperoceánicas de la costa templada favorecen la penetración de plantas de distribución esencialmente boreal o distribución mediterránea dentro de territorios templados (ver los táxones comunes en las Tablas 12,13). Como consecuencia, sólo hay dos especies endémicas de la costa templada, Grindelia integrifolia y Scropbularia oregana.

En resumen, excepción hecha de las localidades más septentrionales de California, que pueden ser consideradas como transicionales o ecotónicas templado-mediterráneas aunque dotadas de un componente florístico original de afinidades mediterráneas, las localidades incluidas en el grupo ROC se sustentan en una base florística que permite deducir relaciones ecológicas o dinámicas pero no diferencias fitogeográficas significativas. Toda la zona de macrobioclima Templado situada al oeste del Pacific Border System debe considerarse como una provincia, Oregoniana, perteneciente a la región Rocosiana, que se se extiende desde la cuenca baja del río Chetco, Oregón, hacia el norte, hasta Dixon Entrance, British Columbia.

\section{Macrobioclima Mediterráneo: provincias Californiano-Septentrional, Californiano-Meridional y Martirense}

La mayoría de las localidades situadas en los dominios del zonobioma Mediterráneo se reunieron en el grupo CAL, que es el grupo florísticamente mejor diferenciado. Raven (1988) calculó que California mediterránea alberga 2133 plantas vasculares endémicas (48\% de toda la flora del Estado). El número de endémicas californianas registradas en la estrecha banda de vegetación litoral del grupo CAL alcanza el 40,8\% y llega hasta el 50\% en CAL-3 (Tabla 3), y el número de géneros endémicos es también muy eleva- do (Tabla 2). Más del 50\% de los endemismos californianos registrados son "endemismos costeros", es decir, su área de distribución se restringe a hábitats litorales y, salvo raras excepciones, el resto penetra ligeramente tierra adentro.

Peinado \& al. (1994b) sugirieron que la región Californiana podría dividirse en tres provincias fitogeográficas (Fig. 1): Californiana-Septentrional (desde la frontera entre California y Oregón hasta Point Conception), Californiana-Meridional (desde este último punto hasta el límite meridional del condado de San Diego, junto a la frontera internacional) y Martirense (desde San Diego a El Rosario, Baja California). Esas divisiones provinciales resultan sustentadas por los datos de las Tablas 5, 13 y 14 .

El grupo CAL presenta tres subgrupos sostenidos por una base florística (Tabla 5) que guardan relación con los cambios en el clima que tienen lugar a lo largo de la costa de California (Major, 1988) y del noroeste de Baja California (Delgadillo, 1995), un tramo en el que, en función del descenso latitudinal de las precipitaciones, se pueden distinguir cuatro zonas: (a) la zona mediterránea en la que predominan los ombroclimas húmedo y subhúmedo, que se extiende desde el río Chetco hasta Point Arena, una franja costera en la cual, a medida que nos desplazamos hacia el sur, la precipitación media anual se reduce hasta alcanzar la cuarta parte al norte de la bahía de San Francisco; (b) la zona mediterránea de ombroclima seco, que se extiende en dirección sur desde dicha bahía hasta Point Conception; (c) doblado el cabo de Point Conception comienza la zona mediterránea semiárida, que se extiende hasta el sur de cabo Colonet; y (d) la zona árida mediterránea, en la cual el clima mediterráneo continúa, pero con un progresivo incremento en la aridez hasta que, a partir de Guerrero Negro, en la península de El Vizcaíno, comienza la transición hacia la zona de macrobioclima Tropical. Las localidades de la subzona árida se reunieron en el grupo TRA-2, mientras que los subgrupos CAL están relacionados con las otras tres zonas climáticas.

Dejando a un lado el subgrupo CAL-1, que reúne a todas las localidades mediterráneas con saladares, los restantes subgrupos se pueden dividir en tres apartados. Los subgrupos TRA-1, CAL-2, CAL-3 y CAL-4, que se extienden por la zona húmeda de California noroccidental, presentan una flora de distribución septentrional que incluye tanto táxones exclusivos (Tabla 5: "Plantas de distribución californiana septentrional") como otros compartidos con la zona templada (Tabla 5: "Plantas de distribución rocosiana y californiana septentrional”). Esta zona húmeda del norte de California, con sus elevadas precipitaciones y con abundantes nieblas estivales que compensan la se- 
quía, permite que muchas plantas de óptimo templado penetren hacia el sur por la costa californiana a lo largo de un estrecho corredor que apenas supera los $30 \mathrm{~km}$ de anchura desde la línea de costa (Zinke, 1988). McLaughlin (1989) cartografió una elevada presencia de táxones templados de distribución esencialmente oregoniana en el noroeste de California, una presencia que va decreciendo progresivamente hacia el sur hasta desaparecer cerca de la bahía de Monterey. Los subgrupos CAL-6, CAL-7 y TRA-2 (que corresponden a las localidades situadas en las zonas menos lluviosas y más cálidas del sur de California y en la porción semiárida-árida del noroeste de Baja California) se caracterizan por una falta de plantas de los subgrupos septentrionales y por la presencia de plantas de distribución esencialmente meridional (Tabla 5: "Plantas de distribución californiana meridional"). En el subgrupo CAL-5, los táxones de distribución californiana septentrional alcanzan su límite meridional y coexisten por primera vez con los táxones de distribución californiana meridional. En los subgrupos CAL-6 y CAL-7, los táxones mediterráneotropicales experimentan un aumento presencial hasta que llegan a ser dominantes en el subgrupo transicional TRA-2 (para la composición florística de éste véase la Tabla 4).

Un análisis de la distribución de los endemismos mediterráneos es muy útil para la clasificación fitogeográfica (Tabla 14). Hay dos grandes áreas de distribución de los endemismos mediterráneos: la costa de California (dividida asimismo en dos subáreas) y la costa del noroeste de Baja California. Noventa y seis endemismos del elemento Californiano tienen su área de distribución dentro del estado de California. Veintiuno de ellos penetran ligeramente dentro del sur de Oregón y 42 lo hacen dentro del noroeste de Baja California. De esos 96 endemismos registrados en la costa de la región Californiana, 42 son endémicos del sur de California, porque su área de distribución termina en la bahía de Monterey, de modo que pueden considerarse como plantas diferenciales de la provincia $\mathrm{Ca}$ liforniana-Meridional frente a la Californiana-Septentrional. Catorce de los 96 endemismos californianos son especies septentrionales cuyo límite meridional está en el norte de la bahía de Monterey, por lo que pueden considerarse como endémicas de la provincia Californiano-Septentrional. De los 42 táxones distribuidos por el sur de la región Californiana, 16 alcanzan su límite sur en el condado de San Diego, es decir, no penetran en Baja California, de modo que son endemismos de la provincia Californiano-Meridional y, por tanto, diferenciales con respecto a la colindante provincia Martirense.

El subgrupo CAL-5 (inventarios procedentes de Point Conception y de sus aledaños) ocupa una posición intermedia porque encierra especies tanto de distribución septentrional como meridional. Point Conception está en una zona de cambio de clima reconocida por Thornthwaite (1941) y por Barbour \& Johnson (1988), que se refleja en cambios en la flora y en la vegetación costera. Breckon \& Barbour (1974), Barbour \& al. (1975) y Raven (1988) situaron el ecotono entre dos zonas ecoflorísticas litorales en Point Conception. Entre ese promontorio costero y San Diego se encuentran los gigantescos desarrollos urbanísticos del sur de California que han traído como consecuen-

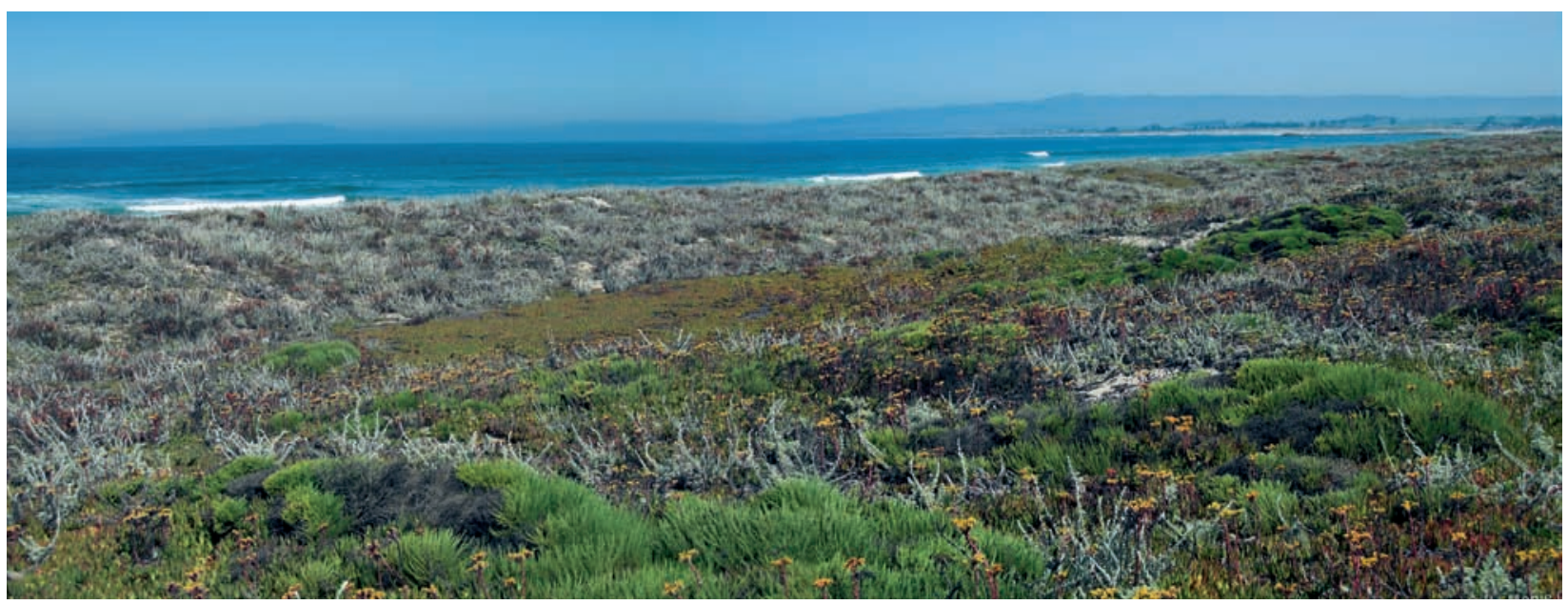

Fig. 6. Vegetación costera de la región Californiana. Cordones dunares semifijos colonizados por matorrales camefíticos de Ericameria ericoides y Artemisia pycnocephala, esta útima, de aspecto blanquecino, domina en la primera banda dunar, más cerca del océano. Cerca de la desembocadura del río Salinas en Monterey, California. 
cia la práctica desaparición de los antiguos ecosistemas dunares, pero algunas publicaciones de la primera mitad del siglo pasado indican una gran afinidad de flora y vegetación con los complejos dunares de Point Conception ( $c f$. Barbour \& Johnson, 1988; Pickart \& Barbour, 2007), de modo que esa área ecotónica debe ser considerada como perteneciente a la provincia $\mathrm{Ca}$ liforniana-Meridional.

Los subgrupos CAL-6 y CAL-7 agrupan a las localidades del extremo suroccidental de California y los del noroeste de Baja California, es decir a las situadas en la subzona semiárida de la región Californiana, cuya flora se caracteriza por el denominado elemento florístico Peninsular (McLaughlin, 1989), que corresponde a la provincia fitogeográfica Martirense de Peinado \& al. (1994b). La zona de clima Mediterráneo semiárido del noroeste de Baja California presenta 41 táxones endémicos, lo que significa que en esta pequeña zona que se extiende sobre poco más de dos grados de latitud desde San Diego a El Rosario existen 83 endemismos californianos, el $49 \%$ de los cuales son endemismos locales. Seis géneros monoespecíficos, Aphanisma, Bergerocactus, Cneoridium, Harfordia, Ornitostaphylos y Xylococcus, son endemismos locales. De los 12 géneros endémicos de California, todos ellos, salvo Ericameria y Sequoia, están también en el noroccidente de Baja California.

El grupo TRA-2 incluyó 14 localidades situadas entre los 29 y los $30^{\circ} 30^{\prime} \mathrm{N}$, en el área de transición entre las zonas de macrobioclima Mediterráneo y Tropical. Los límites meridionales de la provincia florística Californiana de Howell (1957), de la provincia biótica de California de Dice (1943), y de la zona faunística Californiana de Van Dyke (1919) aparecen alrededor de los $30^{\circ} 30^{\prime}$; la flora y la vegetación de esta área han sido consideradas "transicionales" (Shreve, 1936; Shreve \& Wiggins, 1964; Peinado \& al., 1995a). Breckon \& Barbour (1974) demostraron que la vegetación de las playas de Baja California sufre un cambio florístico cerca de los 30³0', mientras Johnson (1977) describió esa zona como un área de reemplazamiento de especies herbáceas dunares mediterráneas y tropicales.

La flora del grupo transicional TRA-2 presenta características intermedias entre las de las zonas climáticas mediterránea y tropical. El índice de similitud del grupo TRA-2 es muy semejante cuando se compara con los grupos CAL y XER (Tabla 8), pero cuando se comparan subgrupos la similitud es mayor con los subgrupos CAL (Tablas 9, 10) sobre todo con los subgrupos meridionales CAL-6 y CAL-7. Las características climáticas de ese zonoecotono son mediterráneas (Delgadillo, 1995), y el porcentaje de táxones infragenéricos relacionados con la zona mediterránea es mucho mayor que el que lo relaciona con la zona tropical en su conjunto (Tabla 3). Peinado \& al. (1995a) analizaron la flora del interior de ese territorio y la incluyeron en la provincia Martirense (región Californiana). La flora litoral apoya esa conclusión y las localidades del grupo TRA-2 deben ser consideradas dentro de la provincia fitogeográfica Martirense.

\section{Macrobioclima Tropical: provincias Bajocaliforniana y Sanlucana}

Cuarenta y cinco localidades estaban ligadas inicialmente al macrobioclima Tropical. En el ALC, 37 de ellas se agruparon en el grupo tropical XER, y tres dentro del grupo TRA-2. Otras cinco localidades tropicales, que sólo tenían saladares, se distribuyeron por los grupos ROC y CAL. El grupo XER se caracteriza a nivel de género por el predominio de los elementos fitogeográficos de distribución tropical, Norte-Suramericana y Madreana, que en total representan más del 60\% de los géneros (Tabla 2). Los subgrupos XER-1 y XER3 muestran un índice de similitud infragenérico de 0,68 (Tabla 11) y sólo se diferencian porque la inclusión en XER-3 de algunas localidades con saladares. De los tres subgrupos tropicales, XER-2 es el que presenta menos elementos Madreanos, Mediterráneos y Transicionales Mediterráneo-Bajocalifornianos, lo que indica su menor relación con la flora septentrional. Por el contrario, el porcentaje de táxones con relaciones tropicales (elementos Bajocaliforniano, Sonorense y Tropical) es con diferencia el más alto de todos los grupos (Tabla 3).

Entre los táxones pertenecientes al elemento tropical que no se presentan en XER-1 y XER-3 se encuentran plantas dominantes en algunas comunidades costeras como los manglares (Avicennia germinans, Laguncularia racemosa, Maytenus phyllanthoides, Rhizophora mangle) y de playas y dunas primarias (Ipomoea pes-caprae, Jouvea pilosa, Sporobolus virginicus). Desde el extremo sur de la península, los manglares tropicales se extienden hacia el norte hasta Punta Abreojos en la costa Pacífica y hasta Bahía de los Ángeles en la costa cálida del golfo (Peinado \& al., 1995c). Punta Abreojos es una zona de cambio de clima y de zonas ecoflorísticas: la zona árida cálida del sur es remplazada por la zona árida del norte (Breckon \& Barbour, 1974). Esa región sur de Baja California, cuyas localidades fueron incluidas en el subgrupo XER-2, corresponde a la provincia fitogeográfica termotropical Sanlucana (Peinado \& al., 1994b) y al grupo florístico Región del Cabo identificado por Johnson (1977) en su análisis florístico de las dunas de Baja California.

Los subgrupos XER-3 y XER-1 agruparon localidades muestreadas al norte de Punta Abreojos, den- 
Tabla 13. Resumen de los táxones compartidos y diferenciales para la la región Californiana (CAL) y las provincias tropicales Bajocaliforniana y Sanlucana (XER). Los datos aparecen en porcentajes de presencia (redondeados) para el total de localidades; el número de éstas, ajustado tras la reubicación derivada de la discusión. Véase la Tabla 12 para ver más táxones diferenciales de ambas. Las especies marcadas con un asterisco en la Tabla 12 son táxones diferenciales de la provincia Californiana.

\begin{tabular}{|c|c|c|c|c|c|}
\hline & XER & CAL & & XER & CAL \\
\hline Número de localidades & 91 & 94 & & 91 & 94 \\
\hline Diferenciales tropicales & & & Táxones compartidos & & \\
\hline Betula papyrifera var. kenaica & 87 & - & Polygonum paronychia & & 17 \\
\hline Cenchrus palmeri & 64 & - & Allenrolfea occidentalis * & 50 & 1 \\
\hline Maytenus phyllantoides & 49 & - & Abronia maritima * & 35 & 16 \\
\hline Jouvea pilosa & 29 & - & Frankenia palmeri * & 33 & 6 \\
\hline Sporobolus virginicus & 29 & - & Batis maritima * & 32 & 11 \\
\hline Euphorbia leucophylla & 27 & - & Atriplex julacea * & 30 & 10 \\
\hline Proboscidea althaefolia & 25 & - & Monanthochloe littoralis & 27 & 15 \\
\hline Cyrtocarpa edulis & 22 & - & Camissonia crassifolia & 22 & 4 \\
\hline Ipomoea pes-caprae & 22 & - & Lycium californicum * & 19 & 15 \\
\hline Rhizophora mangle & 22 & - & Euphorbia misera * & 19 & 16 \\
\hline Oenothera drummondii var. thalassaphila & 20 & - & Arthrocnemum subterminale * & 19 & 13 \\
\hline Fouquieria diguetii & 20 & - & Sarcocornia pacifica & 19 & 34 \\
\hline Avicennia germinans & 20 & - & Lycium brevipes * & 18 & 15 \\
\hline Laguncularia racemosa & 20 & - & Suaeda taxifolia * & 16 & 4 \\
\hline Phaseolus acutifolius var. latifolius & 20 & - & Croton californicus & 16 & 6 \\
\hline Lycium fremontii var. congestum & 19 & - & Stenocereus gummosus & 15 & 12 \\
\hline Opuntia cholla & 19 & - & Mesembryanthemum crystallinum * & 15 & 16 \\
\hline Encelia ventorum & 18 & - & Atriplex canescens subsp. canescens & 14 & 8 \\
\hline Froelichia interrupta & 18 & - & Suaeda moquinii & 14 & 4 \\
\hline Dalea divaricata subsp. anthonyi & 16 & - & Lycium andersonii & 12 & 5 \\
\hline Asclepias subulata & 15 & - & Spartina foliosa * & 12 & 28 \\
\hline Atriplex magdalenae & 15 & - & Abronia umbellata & 10 & 10 \\
\hline Porophyllum maritimum & 15 & - & Atriplex barclayana subsp. barclayana & 9 & 1 \\
\hline Jatropha cinerea & 14 & - & Suaeda esteroa * & 7 & 14 \\
\hline Antigonon leptopus & 13 & - & Frankenia salina * & 5 & 27 \\
\hline Portulaca pilosa & 13 & - & Ambrosia dumosa & 5 & 1 \\
\hline Euphorbia micromera & 13 & - & Sarcostemma arenarium & 5 & 2 \\
\hline Condaliopsis rigida & 13 & - & Cryptantha maritima var. maritima & 5 & 3 \\
\hline Jatropha cuneata & 12 & - & Stillingia linearifolia & 4 & 1 \\
\hline Bursera microphylla & 12 & - & Atriplex leucophylla * & 4 & 14 \\
\hline Chaenactis lacera & 10 & - & Distichlis spicata & 4 & 24 \\
\hline Pachycereus pringlei & 10 & - & Helianthus niveus subsp. niveus & 4 & 13 \\
\hline Jatropha cordata & 10 & - & Isocoma menziesii var. vernonioides & 3 & 8 \\
\hline Castela peninsularis & 10 & - & Limonium californicum & 3 & 19 \\
\hline Drymaria holosteoides var. crassifolia & 9 & - & Dudleya cultrata & 2 & 10 \\
\hline Physalis glabra & 9 & - & Mirabilis californica & 2 & 11 \\
\hline Achyronychia cooperi & 8 & - & Salicornia bigelovii & 2 & 10 \\
\hline Encelia farinosa var. phenocodonta & 8 & - & Camissonia cheiranthifolia subsp. suffruticosa & 1 & 7 \\
\hline Sphaeralcea fulva & 8 & - & Cuscuta salina & 1 & 19 \\
\hline Trianthema portulacastrum & 8 & - & Echinocereus maritimus & 1 & 11 \\
\hline Atriplex polycarpa & 7 & - & Lepidium nitidum & 1 & 4 \\
\hline Dyssodia anthemidifolia & 7 & - & Rhus integrifolia & 1 & 15 \\
\hline Perityle emoryi & 7 & - & Ribes speciosum & 1 & 6 \\
\hline Coulterella capitata & 7 & - & Rosa minutifolia & 1 & 7 \\
\hline Dalea tinctoria var. tinctoria & 7 & - & Pentagramma triangularis var. viscosa & 1 & 5 \\
\hline Hofmeisteria fasciculata var. fasciculata & 7 & - & Malosma laurina & 1 & 8 \\
\hline Triteleiopsis palmeri & 7 & - & Isomeris arborea & 1 & 3 \\
\hline
\end{tabular}

tro o alrededor de la Reserva de la Biosfera El Vizcaíno. La frontera costera entre las subdivisiones El Vizcaíno y Magdalena se presenta aproximadamente a los 20' al sur de Punta Abreojos, en Bahía de San Juanico (Shreve \& Wiggins, 1964). Las planicies de El
Vizcaíno presentan características climáticas diferentes a las de otras zonas áridas de Baja California en donde constituyen una unidad florística fitogeográfica claramente definida (Shreve \& Wiggins, 1964; Wiggins, 1969; Turner \& Brown, 1982; Peinado \& al., 


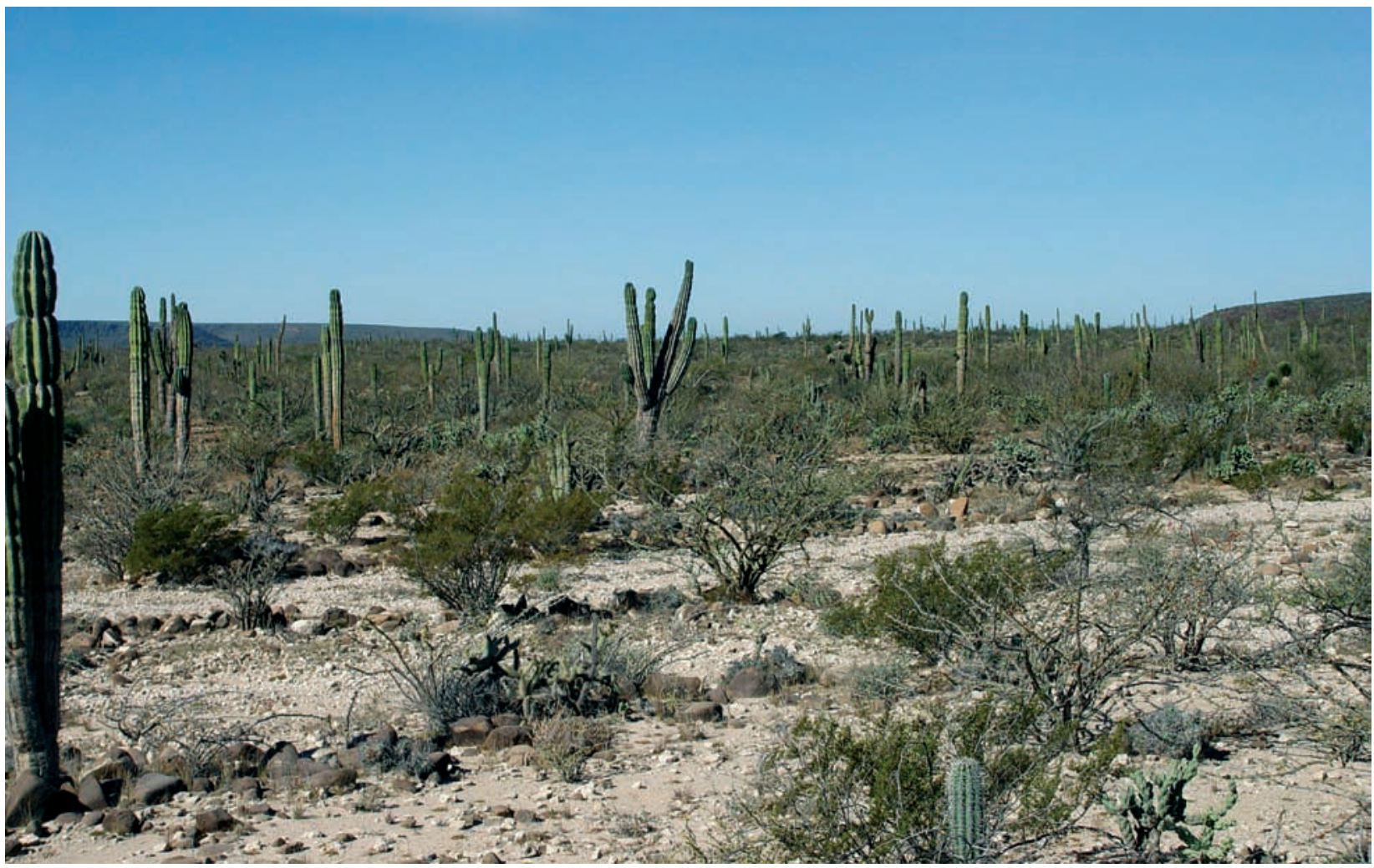

Fig. 7. Vegetación de la provincia Bajocaliforniana. Desierto costero con matorral crasicaule y micrófilo de la asociación Opuntio invictae-Burseretum microphyllae. Cerca de la laguna de San Ignacio, Baja California Sur.

2005a). Las comunidades vegetales de esta unidad son muy características e inexistentes fuera de esta área, tales como las comunidades de saladares interiores arreicos dominadas por Atriplex polycarpa que prosperan en las extensas planicies costeras, muy ricas en especies endémicas de Baja California (Turner \& Brown, 1982), y los matorrales de dunas eólicas. Las dunas en forma de barchán de El Vizcaíno son exclusivas de Norteamérica debido tanto a sus características geomorfológicas como a la riqueza de su flora (Wiggins, 1980). De ahí que el sistema de dunas de El Vizcaíno y sus planicies alcalinas postdunares alberguen 183 plantas endémicas de Baja California, 89 de las cuales no existen en otros lugares de la península (Peinado \& al., 2005a). Los táxones que diferencian a ambos subgrupos con respecto al subgrupo XER-2 son elementos característicos de la provincia florística Bajocaliforniana, dentro de la cual El Vizcaíno forma un sector fitogeográfico (Peinado \& al., 1994b; Delgadillo, 1995), del que debe excluirse la franja más costera al norte de Punta Abreojos, cuyas localidades presentan un bioclima Mediterráneo Desértico-Oceánico (Peinado \& al., 2008), por lo que deben considerarse fitogeográficamente como martirenses.

\section{Conclusiones}

A lo largo de la costa del Pacífico norteamericano existen ocho provincias fitogeográficas, cada una con una combinación característica de clima, flora y vegetación. Dos provincias, Hudsoniana y Sitchense, se extienden en la zona de macrobioclima Boreal, la primera bajo clima Boreal Continental y la segunda con clima Boreal Oceánico. Las áreas de clima Templado corresponden a la provincia Oregoniana. Los territorios bajo macroclima Mediterráneo se dividen en tres provincias: Californiano-Septentrional, CalifornianoMeridional y Martirense. Las provincias Bajocaliforniana y Sanlucana se extienden en las zonas con macrobioclima Tropical.

Florísticamente, las provincias se caracterizan por la presencia de especies endémicas, por la presencia o ausencia de determinados elementos fitogeográficos y por variaciones en los porcentajes de éstos en cada una de ellas. Las diferencias florísticas entre provincias están relacionadas con eventos paleoclimáticos y paleogeográficos. La flora de la zona de estudio presenta tanto elementos endémicos como otros de distribución más amplia que permiten establecer relaciones con las floras de Eurasia, África y Sudamérica. 

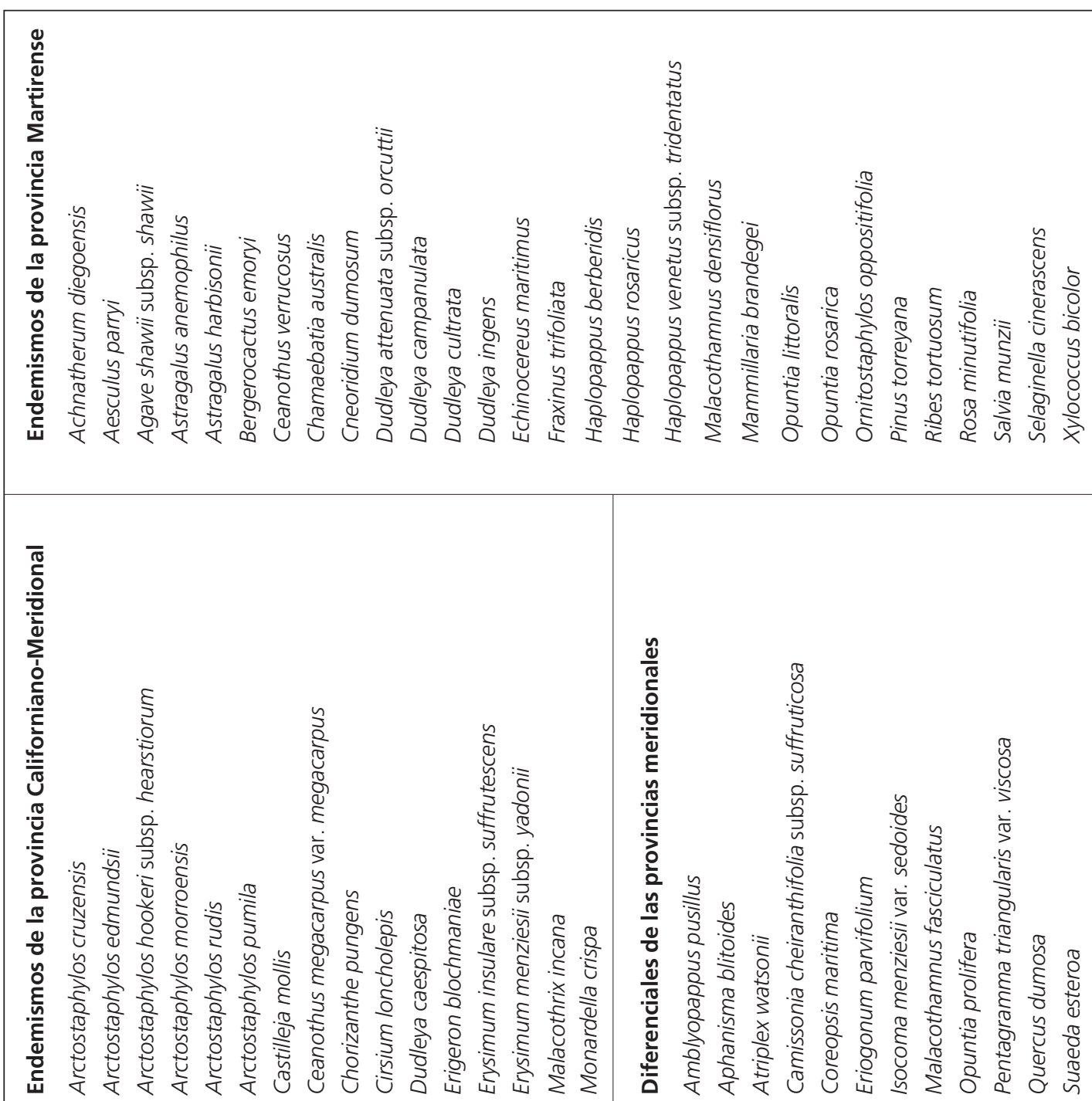

हू

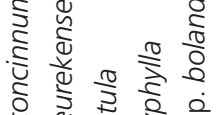

व. वे क्षे

政

$\frac{\pi}{2}$

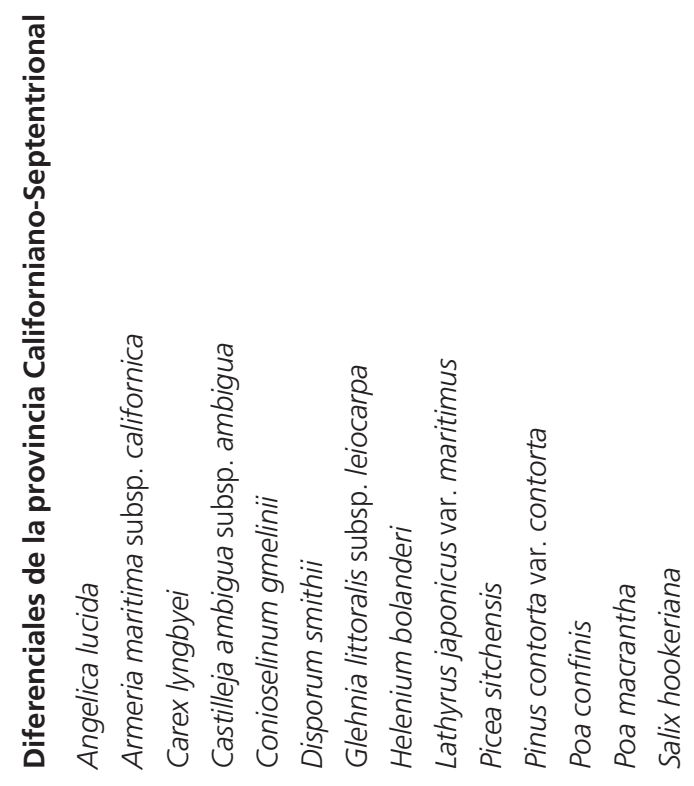


Las provincias septentrionales Hudsoniana, Sitchense y Oregoniana presentan un elevado porcentaje de elementos de amplia distribución cuyos orígenes están en la geoflora Boreotropical o Artoterciaria que dominó todo el hemisferio norte durante el Terciario. Los macrobioclimas Templado y Boreal que caracterizan esas áreas septentrionales están ampliamente distribuidos a nivel continental e intercontinental, lo que ha permitido un intenso intercambio migratorio de especies, por lo que las provincias Hudsoniana, Sitchense y Oregoniana muestran bajas proporciones de especies endémicas locales y pocas especies exclusivas. La influencia de las glaciaciones del Pleistoceno es también apreciable en esas provincias, aunque la falta de los efectos de las glaciaciones en Alaska-Yukon ha llevado a la supervivencia de algunos endemismos hudsonianos.

Las provincias que presentan una mayor riqueza florística basada en su elevado número de táxones endémicos son las tres existentes en la zona de clima Mediterráneo porque en ellas se reúnen elementos de las geofloras Artoterciaria y Madroterciaria. Además, la costa mediterránea ha servido de refugio frente a los acontecimientos climáticos del Terciario tardío y del Cuaternario que diezmaron la flora de las provincias más septentrionales.

La flora de Baja California, excepto en su extremo noroccidental mediterráneo, está caracterizada por un elevado número de táxones relacionados con las floras tropicales, en especial con las que permiten establecer relaciones con Sudamérica.

Cada provincia presenta unos tipos característicos de vegetación. Las provincias boreales comparten algunos tipos de vegetación como los de playas y marismas, pero difieren por los bosques climácicos costeros, dominados por Picea glauca en la provincia Hudsoniana y por $P$. sitchensis en la provincia Sitchense. Grandes complejos dunares, con extensivas áreas de deflación colonizadas por comunidades de herbáceas y estabilizados por bosques psammófilos dominados por Pinus contorta var. contorta y P. sitchensis, caracterizan a la provincia Oregoniana. Los saladares costeros presentan algunas similitudes florísticas con los mediterráneos, pero difieren profundamente por la existencia y la dominancia de táxones de distribución templado-boreal tales como Carex lyngbyei, Plantago maritima var. juncoides, Sarcocornia perennis o Triglochin maritimum. La vegetación más característica de las provincias mediterráneas son las comunidades formadoras de dunas en montículo de las playas, los saladares, los matorrales de dunas y la vegetación de los acantilados marinos. En la provincia Martirense la vegetación de los acantilados marinos está dominada por el matorral costero suculento, un matorral extraordinariamente rico en especies endémicas. Entre los tipos de vegetación que caracterizan a las provincias tropicales se encuentran los manglares (provincia Sanlucana) y las comunidades de planicies alcalinas (provincia Bajocaliforniana).

\section{Agradecimientos}

Este estudio ha sido llevado a cabo gracias a un convenio de colaboración suscrito entre la Universidad de Alcalá y la Universidad Autónoma de Baja California, y financiado con fondos de la Dirección General de Universidades (PR2004-0176) y de la Agencia Española de Cooperación Internacional y Desarrollo (A/16146/08).

\section{Referencias bibliográficas}

Abrams, L. 1925. The origin and geographical affinities of the flora of California. Ecology 6: 1-6.

Abrams, L. \& Ferris, R.S. 1980. Illustrated Flora of the Pacific States, Washington, Oregon, and California. Vol. I-IV. Stanford University Press. Stanford.

Axelrod. D.I. 1948. Climate and vegetation in western North America during middle Pliocene time. Evolution 2: 127-144.

Axelrod, D.I. 1958. Evolution of the Madro-Tertiary Geoflora. The Botanical Review 24: 433-509.

Axelrod, D.I. 1973. History of the Mediterranean ecosystems in California. In: Di Castri, F. \& Mooney, H.A. (eds.), Mediterranean type ecosystems: origin and structure: 225-227. SpringerVerlag. Nueva York.

Axelrod, D.I. 1988. Outline history of California vegetation. In: Barbour, M.G. \& Major, J. (eds.), Terrestrial vegetation of California: 139-194. California Native Plant Society. Davis.

Azevedo, J. \& Morgan, D.L. 1974. Fog precipitation in coastal Californian forests. Ecology 55: 1135-1141.

Bailey, R.G. 1995. Description of the ecoregions of the United States. $2^{\text {nd }}$ ed. USDA Forest Service. Washington DC.

Barbour, M.G., De Jong, T.M. \& Johnson, A.F. 1975. Additions and corrections to a review of North American Pacific Coast beach vegetation. Madroño 23: 130-134.

Barbour, M.G. \& Johnson, A.F. 1988. Beach and dune. In: Barbour, M.G. \& Major, J. (eds.), Terrestrial vegetation of California: 223-262. California Native Plant Society. Davis.

Braun-Blanquet, J. 1979. Fitosociología. Bases para el estudio de las comunidades vegetales. Blume. Madrid.

Breckon, G.J. \& Barbour, M.G. 1974. Review of North American Pacific Coast beach vegetation. Madroño 22: 333-360.

Brouillet, L. \& Whetstone, R.D. 1993. Climate and Physiography. In: Flora of North America Editorial Committee (eds.), Flora of North America: North of Mexico 1: 15-46. Oxford University Press. Nueva York.

Brown, D.E., Reichenbacher, F. \& Franson, S.E. 1998. A classification of North American Biotic Communities. University of Utah Press. Salt Lake City.

Budantsev, L.Y. 1992. Early stages of formation and dispersal of the temperate flora in the boreal region. The Botanical Review 58: $1-48$.

Calder, J.A. \& Taylor, R.L. 1968. Flora of the Queen Charlotte Islands, I. Systematics of the vascular plants. Canada Dept. Agriculture. Ottawa.

Coates, A.G. 1996. The geologic evolution of the Central American isthmus. In: Obando, J.A. (ed.), Evolution and environment in tropical America: 21-56. University of Chicago Press. Chicago. 
Cooper, W.S. 1936. The strand and dune flora of the Pacific Coast of North America: a geographic study. In: Goodspeed, T.H. (ed.), Essays in Geobotany: 141-187. University of California Press. Berkeley.

Crane, P.R. \& Lidgard, S. 1989. Angiosperm diversification and paleolatitudinal gradients in Cretaceous floristic diversity. Science 246: 675-678

Darlington, P.J. 1957. Zoogeography: the Geographical distributions of Animals. John Wiley \& Sons. Nueva York.

Daubenmire, R. 1978. Plant Geography with special reference to North America. Academic Press. Londres.

Delcourt, P.A. \& Delcourt, H.R. 1993. Paleoclimates, paleovegetation, and paleofloras during the Late Quaternary. In: Flora of North America Editorial Committee (eds.), Flora of North America: North of Mexico 1: 71-96. Oxford University Press. Nueva York.

Delgadillo, J. 1995. Introducción al conocimiento bioclimático, fitogeográfico y fitosociológico del Suroeste de Norteamérica (Estados Unidos y México). Ensenada.

Dice, L.R. 1943. The biotic provinces of North America. University of Michigan. Ann Arbor.

Dice, L.R. 1945. Measures of ecologic association between species. Ecology 26(3): 297-302.

Digby, P.G.N. \& Kempton, R.A. 1987. Multivariate Analysis of Ecological Communities. Chapman and Hall. Londres.

Emery, K.O. \& Uchupi, E. 1984. The geology of the Atlantic Ocean. Springer-Verlag. Nueva York.

Flora of North America Editorial Committee. 1993-2008. Flora of North America: North of Mexico. Oxford University Press. Nueva York.

Franklin, J.F. \& Dyrness, C.T. 1988. Natural vegetation of Oregon and Washington. $2^{\text {nd }}$ ed. Oregon State University Press. Corvallis.

Galán de Mera, A. \& Vicente Orellana, J.A. (2007): Cronosequences of vegetation- a bioclimatic theory for interpreting the patterns of relic vegetation types. Phytocoenologia 37: 471-494.

Gentry, A.H. 1982. Neotropical floristic diversity. Annals of the Missouri Botanical Gardens 69: 557-593.

Gentry, S.H. 1978. The agaves of Baja California. Occasional Papers of the California Academy of Science 130: 1-123.

Gjærevoll, O. 1980, A comparison between the alpine plant communities of Alaska and Scandinavia. Acta Phytogeographyca Suecica 68: 83-88.

Gleason, H.A. \& Cronquist, A. 1964. The natural geography of plants. Columbia University Press. Nueva York.

Goldblatt, P. 1993. Biological relations between Africa and South America. Yale University Press. New Haven.

Good, R. 1974. The geography of the flowering plants, $4^{\text {th }}$ ed. Longman. Londres.

Graham, A. 1999. Late Cretaceous and Cenozoic history of North American vegetation north of Mexico. Oxford University Press. Nueva York.

Grewell B.J., Callaway J.C. \& Ferren W.R. 2007. Estuarine Wetlands. In: Barbour, M.G. \& al. (eds.), Terrestrial Vegetation of California, $3^{a}$ ed.: 124-179. University of California Press. Berkeley.

Hagen, J.B. 1986. Ecologists and taxonomists: divergent traditions in twentieth-century plant geography. Journal Historical Biology 19: 197-214.

Hallam, A. 1994. An outline of Phanerozoic Biogeography. Oxford University Press. Oxford.

Heiser, C.B., Smith, D.M., Clevenger, S.B. \& Martin, W.C. 1966. The North American Sunflowers (Helianthus). Memoirs of the Torrey Botanical Club 22(3): 1-218.

Hickman, J.C. 1993. The Jepson Manual. Higher Plants of California. University of California Press. Berkeley.

Howell, J.T. 1957. The California flora and its province. Leaflets Western Botany 8: 133-138.
Hultén, E. 1968. Flora of Alaska and neighbouring territories. Stanford University Press. Stanford.

Johnson, A.F. 1977. A survey of the strand and dune vegetation along the Pacific and southern coasts of Baja California, Mexico. Journal of Biogeography 7: 83-99.

Keeler-Wolf, T. 2007. The History of Vegetation Classification and Mapping in California.. In: Barbour, M.G. \& al. (eds.), Terrestrial Vegetation of California, $3^{a}$ ed.: 1-42. California Native Plant Society. Davis.

Kent, M. \& Coker, P. 1992. Vegetation Description and Analysis. A Practical Approach. Belhaven Press. Londres.

Klinka, K., Krajina, V.J., Ceska, A. \& Scagel, A.M. 1995. Indicator Plants of British Columbia, $2^{\text {nd }}$ ed. University of British Columbia Press. Vancouver.

Klinkenberg, B. (ed.). 2008. E-Flora BC: Electronic Atlas of the Plants of British Columbia. www.eflora.bc.ca

Kumler, M.L. 1969. Plant succession on the sand dunes of the Oregon coast. Ecology 50(4): 695-704.

Latham, R.E. \& Ricklefs, R.E. 1993. Continental comparisons of temperate-zone tree species diversity. In: Ricklefs, R.E. \& Schluter, D. (eds.), Species diversity in ecological communities: historical and geographical perspectives: 294-314. Chicago University Press. Chicago.

Legendre, P. \& Legendre, L. 1987. Developments in Numerical Ecology. NATO ASI Series G14. Springer-Verlag. Berlín.

Mabberley, D.J. 2002. The plant-book: a portable dictionary of the vascular plants, $2^{\mathrm{a}}$ ed. rev. Cambridge University Press. Cambridge.

Macdonald, K.B. 1988. Coastal salt marsh. In: Barbour, M.G. \& Major, J. (eds.), Terrestrial vegetation of California: 263-294. California Native Plant Society. Davis.

Macdonald, K.B. \& Barbour M.G. 1974. Beach and salt marsh vegetation of the North American Pacific Coast. In: Reimold, R.J. \& Queen, W.H. (eds.), Ecology of halophytes: 175-233. Academic Press. Nueva York.

MacKinnon, A., Pojar J. \& Coupé, R. 1994. Plants of northern British Columbia. Lone Pine Publishers. Vancouver.

Major, J. 1988. California climate in relation to vegetation In: Barbour, M.G. \& Major, J. (eds.), Terrestrial vegetation of California: 11-74. California Native Plant Society. Davis.

Matthews, J.V., Anderson, T.W., Boyko-Diakonow, M., Mathewes, R.W., McAndrews, J.H., Mott, R.J., Richard, P.J.H., Ritchie, J.C. \& Schweger, C.E. 1989. Quaternary environments in Canada as documented by paleobotanical case histories. In: Fulton, R.J. (ed.), Quaternary Geology of Canada and Greenland: 481-539. Otawa.

McLaughlin, S.P. 1989. Natural floristic areas of the western United States. Journal of Biogeography 16: 239-248.

Meidinger, D. \& Pojar, J. 1991. Ecosystems of British Columbia. BC Ministry of Forests, Special Report Series 6. Victoria.

Merriam, C.H. 1890. Results of a Biological Survey of the San Francisco Mountains Region and Desert of the Little Colorado in Arizona. USDA, North American Fauna, 3. Washington DC.

Merriam, C.H. 1898. Life-zones and Crop-zones of the United States. USDA, Division of Biological Survey, Bulletin 10. Washington DC.

Minch, J., Minch, E., Minch, J. \& Ledesma Vázquez, J. 2003. Caminos de Baja California. John Minch \& Associates. Mission Viejo.

Muller J. 1981. Fossil pollen records of extant angiosperms. The Botanical Review 47: 1-142.

Munz, P.A. \& Keck, D.D. 1973. A California Flora and Supplement. University of California Press. Berkeley.

Nesom, G.L. 1991. Taxonomy of Isocoma (Compositae: Astereae). Phytologia 70(2): 69-114.

Parrish, J.T. 1993. The palaeogeography of the opening South Atlantic. In: George, W. \& Lavocat R., R. (eds.), The Africa-South America connection: 8-27. Clarendon Press. Oxford. 
Peck, M.E. 1941. A Manual of the higher plants of Oregon. Binfords \& Mort. Portland.

Peinado, M., Alcaraz, F. \& Martínez-Parras, J.M. 1992. Vegetation of Southeastern Spain. J. Cramer. Berlín.

Peinado, M., Alcaraz, F., Aguirre, J.L. \& Álvarez, J. 1994a. Vegetation formations and associations of the zonobiomes along the North American Pacific coast. Vegetatio 114: 123-135.

Peinado, M., Alcaraz, F., Delgadillo, J. \& Aguado, I. 1994b. Fitogeografía de la península de Baja California, México. Anales del Jardín Botánico de Madrid 51(2): 255-277.

Peinado, M., Alcaraz, F., Aguirre, J.L., Delgadillo, J. \& Álvarez, J. 1995a. Similarity of zonation within Californian-Baja Californian and Mediterranean salt marshes. The Southwestern $\mathrm{Na}$ turalist 40: 388-405.

Peinado, M., Alcaraz, F., Delgadillo, J., Aguirre, J.L. \& Aguado, I. 1995b. Shrubland formations and associations in Mediterranean-desert transitional zones of northwestern Baja California. Vegetatio 117: 165-179.

Peinado, M, Alcaraz F, Delgadillo J. 1995c. Syntaxonomy of some halophilous communities of North and Central America. Phytocoenologia 25: 23-31.

Peinado, M., Aguirre, J.L. \& Delgadillo, J. 1997a. Phytosociological, bioclimatic and biogeographical classification of woody climax communities of western North America. Journal of Vegetation Science 8: 505-528.

Peinado, M., Alcaraz, F., Aguirre, J.L. \& Martínez-Parras, J.M. 1997b.Vegetation formations and associations of the zonobiomes along the North American Pacific coast: from Northern California to Alaska. Plant Ecology 137: 151-202.

Peinado, M., Aguirre, J.L. \& de la Cruz, M. 1998. A phytosociological survey of the boreal forest (Vaccinio-Piceetea) in North America. Plant Ecology 129: 29-47.

Peinado, M., Delgadillo, J. \& Aguirre, J.L. 2005a. Plant associations of the El Vizcaíno Biosphere Reserve (Baja California Sur, México). The Southwestern Naturalist 50(2): 129-149.

Peinado, M., Aguirre, J.L. \& Martínez-Parras, J.M. 2005b. A phytosociological survey of the chionophilous communities of Western North America. Part I: temperate and Mediterranean associations. Plant Ecology 180: 187-241.

Peinado, M., Aguirre, J.L., Delgadillo, J. \& Macías, MA. 2007. Zonobiomes, zonoecotones and azonal vegetation along the $\mathrm{Pa}$ cific coast of North America. Plant Ecology 191: 221-252.

Peinado, M., Aguirre, J.L., Delgadillo, J. \& Macías, M.A. 2008. A phytosociological and phytogeographical survey of the coastal vegetation of western North America. Part I: plant communities of Baja California, Mexico. Plant Ecology 196: 27-60.

Pickart, A.J. \& Barbour, M.G. 2007. Beach and Dune. In: Barbour, M.G. \& al. (eds.), Terrestrial Vegetation of California, 3 . ed.: 155-173. California Native Plant Society. Davis.

Pojar, J. \& MacKinnon, A. 1994. Plants of coastal British Columbia. Lone Pine Publ. Vancouver.

Purer, E.A. 1936. Studies of certain coastal sand dune plants of southern California. Ecological Monographs 6: 4-85.

Qian, H. 1999. Floristic analysis of vascular plant genera of North America north of Mexico: characteristics of phytogeography. Journal of Biogeography 26: 1307-1321.

Raven, P.H. 1963. Amphitropical relationships in the flora of North and South America. Quarterly Review of Biology 38: 151-177.

Raven, P.H. 1988. The California flora. In: Barbour, M.G. \& Major, J. (eds.), Terrestrial vegetation of California: 109-138. California Native Plant Society. Davis.

Raven, P.H. \& Axelrod, D.I. 1974. Angiosperm biogeography and past continental movements. Annals Missouri Botanical Gardens 61: 539-673.

Raven, P.H., \& Axelrod, D.I. 1978. Origins and relationships of the California flora. University of California Publications in Botany 72: 1-134.
Rivas-Martínez, S. 2007. Mapa de series, geoseries y geopermaseries de vegetación de España (Memoria del Mapa de Vegetación Potencial de España), Parte I. Itinera Geobotanica 17: 5-436.

Rivas-Martínez, S., Sánchez-Mata, D. \& Costa, M. 1999. North American boreal and western temperate forest vegetation. Itinera Geobotanica 12:5-316.

Rzedowski, J. 1978. Vegetación de México. Limusa, México D.F.

Shreve, F. 1936. The transition from desert to chaparral in Baja California. Madroño 3: 257-264.

Shreve, F. \& Wiggins, I.L. 1964. Vegetation and flora of the Sonoran Desert. Stanford University Press. Stanford.

Sørensen, T. 1948. A method of establishing groups of equal amplitude in plant sociology based on similarity of species content. Biologiske Scrifter Copenhagen 5: 1-34.

Stebbins, G.L. \& Major, D. 1965. Endemism and speciation in the California flora. Ecological Monographs 35: 1-35.

Stott, P. 1981. Historical plant geography. George Allen \& Unwin. Londres.

Takhtajan, A. 1986. Floristic regions of the world. University of California Press. Berkeley.

Taylor, D.W. 1990, Paleobiogeographic relationships of angiosperms from the Cretaceous and early Tertiary of the North American Area. Biological Review 56: 279-417.

Thorne, R.F. 1993. Phytogeography. In: Flora of North America Editorial Committee. (eds.), Flora of North America: North of Mexico 1: 132-153. Oxford University Press. Nueva York.

Thornthwaite, C.W. 1941. USDA atlas of climatic types of the United States, 1900-1939. Misc. Pub. US Government Printing Office, Washington DC.

Tiffney, B.H. 1985a. Perspectives on the origin of the floristic similarity between eastern Asia and eastern North America. Journal of the Arnold Arboretum 66: 73-94.

Tiffney, B.H. 1985b. The Eocene North Atlantic land bridge: its importance in Tertiary and modern phytogeography of the Northern Hemisphere. Journal of the Arnold Arboretum 66: 243-273.

Turner, R.M. \& Brown, D.E. 1982. Sonoran Desert scrub. Desert Plants 4: 181-222.

Udvardy, M.D.F. 1975a. World biogeographical provinces. Map scale 1:39,629,000. Coevolution Quarterly. Sausalito.

Udvardy, M.D.F. 1975b. A classification of the fitogeographical provinces of the world. International Union for Conservation of Nature and Natural Resources. Morges.

USDA NRCS. 2008. The PLANTS Database, Version 3.5. Data compiled from various sources by Mark W. Skinner. National Plant Data Center. Baton Rouge. www.plants.usda.gov

Van Dyke, E.C. 1919. The distribution of insects in western North America. Annals of the Entomological Society of America 12:1-12.

Viereck, L.A. \& Little, E.L. 1991. Alaska trees and shrubs, $3^{\mathrm{a}} \mathrm{ed}$. University of Alaska Press. Fairbanks.

Walter, H. 1985. Vegetation of the Earth and Ecological Systems of the Geobiosphere. $3^{\text {a }}$ ed. Springer-Verlag. Berlín.

Walter, H. \& Lieth, H. 1967. Klimadiagramm-Welatlas. VEB Gustav Fischer. Jena.

Westhoff, V. \& van der Maarel, E. 1973. The Braun-Blanquet approach. In: Whittaker, R.H. (ed.), Ordination and classification of communities: 617-626. Dr. W Junk. La Haya.

Whittaker, R.H. \& Niering, W.A. 1964. Vegetation of the Santa Catalina Mountains, Arizona. I. Ecological classification and distribution of species. Journal of the Arizona-Nevada Academy of Science 3: 9-34

Wiedemann, A.M. 1966. Contributions to the Plant Ecology of the Oregon coastal sand dunes. Ph. D. Thesis, Oregon State University, Corvallis.

Wielgorskaya, T. 1995. Dictionary of generic names of seed plants. Columbia University Press. Nueva York. 
Wiggins, I.L. 1969. Observations on the Vizcaíno Desert and its biota. Proceedings of the California Academy of Sciences, 36: 317-346.

Wiggins, I.L. 1980. Flora of Baja California. Stanford University Press. Stanford.

Williams, W.T. \& Potter, J.R. 1972. The coastal strand community at Morro Bay State Park. Bulletin Torrey Botanical Club 99: 163-171.

Wolfe, J.A. 1975. Some aspects of plant geography of the Northern Hemisphere during the Late Cretaceous and Tertiary. Annals Missouri Botanical Gardens 62: 264-279.

Wood, C.E. 1972. Morphology and phytogeography: the classical approach to the study of disjunctions. Annals Missouri Botanical Gardens 59: 107-124.

Yurtsev, B.A. 1974. Problems of the botanical geography of Northeastern Asia. Nauka. Leningrado.

Zinke, P.J. 1988. The redwood forest and associated north coast forests. In: Barbour, M.G. \& Major, J. (eds.), Terrestrial vegetation of California: 679-698. California Native Plant Society. Davis.

\section{Apéndice 1: Elementos fitogeográficos (abreviaturas según la Tabla 1)}

\section{Géneros}

Abies (HOL), Abronia (OES), Abutilon (PAN), Acacia (PAN), Acalypha (PAN), Acer (HOL), Achillea (HOL), Achnatherum (COS), Achyronychia (SON), Acourtia (OES), Adenocaulon (DIS), Adenostoma (CAL), Aeschynomene (PAN), Aesculus (HOL), Agave (NEO), Ageratina (NAS), Agoseris (NAS), Agrostis (COS), Aira (INT), Allenrolfea (MAD), Allium (HOL), Alnus (HOL), Amarantbus (COS), Amblyopappus (NAS), Ambrosia (COS), Ammophila (INT), Anagallis (INT), Anaphalis (HOL), Angelica (DIS), Antigonon (NEO), Antirrbinum (DIS), Aphanisma (CAL), Arbutus (DIS), Arctostapbylos (HOL), Argentina (NAS), Armeria (DIS), Artemisia (HOL), Arthrocnemum (DIS), Asclepias (AAT), Astragalus (HOL), Atbyrium (COS), Atriplex (COS), Avicennia (PAN), Baccharis (NAS), Bassia (COS), Batis (APT), Bergerocactus (CAL), Betula (HOL), Blechnum (COS), Brickellia (NAS), Briza (INT), Bromus (COS), Bursera (NEO), Caesalpinia (PAN), Cakile (HOL), Calamagrostis (HOL), Calliandra (PAN), Calochortus (OES), Calystegia (COS), Camissonia (NAS), Cardionema (NAS), Cardiospermum (PAN), Carex (COS), Carpobrotus (INT), Castela (NEO), Castilleja (NAE), Ceanothus (NOA), Cenchrus (PAN), Centaurium (INT), Cerastium (COS), Cercocarpus (MAD), Chaenactis (OES), Chamaebatia (CAL), Chamerion (CAL), Chorizanthe (NAS), Cirsium (HOL), Claytonia (NAE), Clematis (COS), Clintonia (NAE), Cneoridium (CAL), Comarum (HOL), Commelina (PAN), Condalia (NAS), Condaliopsis (NAS), Conicosia (INT), Conioselinum (HOL), Conium (INT), Corallorbiza (HOL), Cordylanthus (OES), Coreocarpus (SON), Coreopsis (DIS), Corethrogyne (OES), Cornus (HOL), Cotula (INT), Coulterella (BAJ), Crassula (COS), Cressa (COS), Croton (PAN), Cryptantha (OES), Cupressus (HOL), Cuscuta (COS), Cynanchum (DIS), Cyrtocarpa (NEO), Cytisus (INT), Dalea (NAS), Dendranthema (HOL), Deschampsia (COS), Dichelostemma (OES), Disporum (NAE), Distichlis (DIS), Ditaxis (NEO), Dithyrea (MAD), Dodecatheon (NAE), Drymaria (NAS), Dryopteris (COS), Dudleya (MAD), Dyssodia (NAS), Echinocereus (MAD), Echinopepon (NAS), Eleocharis (COS), Empetrum (DIS), Encelia (NAS), Ephedra (COS), Epilobium (CAL), Equisetum (COS), Eragrostis (COS), Erechtites (INT), Ericameria (OES), Erigeron (COS), Eriodictyon (MAD), Eriogonum (NOA), Eriophyllum (OES), Errazurizia (NAS), Erysimum (HOL), Eschscholzia (OES), Euphorbia (COS), Fagonia (PAN), Ferocactus (MAD), Festuca (COS), Filago (HOL), Foeniculum (INT), Fouquieria (SON), Fragaria (HOL), Frankenia (DIS), Fraxinus
(HOL), Fritillaria (HOL), Froelichia (NEO), Galium (COS), Gaultheria (DIS), Geocaulon (NOA), Geranium (COS), Glaux (HOL), Glebnia (NAE), Gnaphalium (COS), Goodyera (COS), Grindelia (NAS), Haplopappus (NAS), Harfordia (BAJ), Hazardia (OES), Hedera (INT), Helenium (NAS), Helianthus (NOA), Heliotropium (COS), Hemizonia (NOA), Heracleum (HOL), Heteromeles (CAL), Heterotheca (NAS), Heuchera (NOA), Hieracium (HOL), Hierochloe (COS), Hippuris (HOL), Hofmeisteria (NEO), Holcus (INT), Holodiscus. (NAS), Honkenya (DIS), Hordeum (COS), Horsfordia (OES), Houstonia (PAN), Hymenoclea (OES), Hypericum (COS), Hypochaeris (INT), Hyptis (NEO), Ibervillea (OES), Ipomoea (NEO), Iris (HOL), Isocoma (MAD), Isolepis (COS), Isomeris (MAD), Jathropha (AAT), Jaumea (NAS), Jouvea (NAS), Juglans (HOL), Juncus (COS), Justicia (PAN), Keckiella (CAL), Krameria (NAS), Laguncularia (AAT), Larrea (NAS), Latbyrus (HOL), Leontondon (INT), Lepidium (COS), Leymus (HOL), Ligusticum (HOL), Lilaeopsis (DIS), Limonium (DIS), Linnaea (HOL), Listera (HOL), Lithocarpus (NAE), Lomatogonium (HOL), Lonicera (HOL), Lotus (HOL), Lupinus (DIS), Luzula (COS), Lycium (COS), Lycopodium (COS), Lysichiton (NAE), Maba (PAN), Madia (NAS), Maianthemum (HOL), Malacothamnus (NAS), Malacothrix (OES), Malosma (CAL), Malus (HOL), Malvastrum (MAD), Mammillaria (NAS), Marab (OES), Maytenus (PAN), Melica (COS), Melilotus (INT), Mentha (COS), Menziesia (NAE), Mertensia (HOL), Mesembryanthemum (INT), Mimulus (DIS), Mirabilis (NAE), Momordica (PAN), Monanthochloe (NAS), Monardella (OES), Myosurus (DIS), Myrica (COS), Myrtillocactus (NEO), Nassella (NAS), Nemacaulis (MAD), Nicotiana (DIS), Nolina (MAD), Oenanthe (COS), Oenothera (NAS), Oligomeris (DIS), Olneya (SON), Oplopanax (NAE), Opuntia (NAS), Ornitostaphylos (CAL), Orthilia (HOL), Osmorbiza (NAE), Oxalis (COS), Pachycereus (SON), Pachycormus (BAJ), Palafoxia (SON), Parentucellia (INT), Parkinsonia (SON), Parnassia (HOL), Passiflora (APT), Pedilanthus (NEO), Pentagramma (OES), Perityle (MAD), Peucepbyllum (SON), Phacelia (NAS), Phaseolus (NEO), Phoradendron (NAS), Phrygilanthus (NEO), Physalis (COS), Picea (HOL), Pinus (DIS), Pithecellobium (PAN), Plantago (COS), Pleuraphis (NAS), Poa (COS), Polycarpon (COS), Polygonum (HOL), Polypodium (COS), Polypogon (INT), Polystichum (COS), Populus (HOL), Poropbyllum (NAS), Portulaca (COS), Potentilla (HOL), Proboscidea (NAS), Prosopis (PAN), Prunus (COS), Pseudotsuga (NAE), Pteridium (COS), Puccinellia (HOL), Pyrola (HOL), Quercus (HOL), Ranunculus (COS), Raphanus (INT), Rhamnus (HOL), Rbinanthus (HOL), Rbizophora (PAN), Rhododendron (COS), Rhus (COS), Ribes (DIS), Rorippa (COS), Rosa (HOL), Rubus (COS), Rumex (COS), Sagina (COS), Salicornia (COS), Salix (HOL), Salsola (DIS), Salvia (COS), Sambucus (COS), Sanicula (COS), Sapindus (APT), Sarcocornia. (DIS), Sarcostemma (PAN), Saussurea (DIS), Scaevola (PAN), Schismus (INT), Schoenoplectus (COS), Scrophularia (HOL), Selaginella (COS), Senecio (COS), Sequoia (CAL), Sesuvium (COS), Setaria (COS), Shepherdia (NOA), Silene (HOL), Simmondsia (MAD), Sisyrinchium (NAS), Solanum (COS), Solidago (HOL), Sonchus (INT), Sorbus (HOL), Spartina (HOL), Spergularia (DIS), Sphaeralcea (AAT), Spiraea (HOL), Spiranthes (COS), Sporobolus (COS), Stachys (COS), Stegnosperma (MAD), Stellaria (COS), Stenocereus (NEO), Stephanomeria (OES), Stillingia (PAN), Suaeda (DIS), Symphyotrichum (NOA), Tamarix (INT), Tanacetum (HOL), Tetragonia (INT), Thuja (NAE), Tiarella (NAE), Tillaea (COS), Tiquilia (NEO), Toxicodendron (NAE), Trianthema (PAN), Trientalis (HOL), Trifolium (COS), Triglochin (DIS), Triphysaria (OES), Triteleiopsis (SON), Trixis (NAS), Tsuga (NAE), Typha (COS), Ulex (INT), Umbellularia (CAL), Urtica (COS), Vaccinium (HOL), Vallesia (NEO), Veronica (COS), Viburnum (COS), Vicia (HOL), Viguiera (NAS), Viola (DIS), Viscainoa (BAJ), Vulpia (INT), Washingtonia (OES), Wislizenia (OES), Xeropbyllum (NOA), Xylococcus (CAL) and Yucca (MAD). 


\section{Táxones infragenéricos}

Abies grandis var. grandis (OES), Abronia latifolia (PAC), A. maritima (MAD), A. umbellata subsp. umbellata (MAD), Abutilon carterae (BAJ), Acacia peninsularis (BAJ), Acalypha californica (MAD), Acer glabrum (NOA), A. macrophyllum (OES), Achillea millefolium (HOL), Achnatherum diegoenis (CAL), Achyronychia cooperi (SON), Acourtia microcephala (CAL), Adenocaulon bicolor (NOA), Adenostoma fasciculatum (CAL), Aeschynomene nivea (BAJ), Aesculus parryi (BAJ), Agave datylio var. vexans (BAJ), A. shawii subsp. sebastiana (BAJ), A. shawii subsp. shawii (CAL), Ageratina adenophora (INT), Agoseris apargioides var. eastwoodieae (PAC), Agrostis blasdalei (CAL), A. exarata (NOA), A. pallens (OES), A. stolonifera (COS), Aira cariopbyllea (INT), Allenrolfea occidentalis (MAD), Allium baematochiton (MAD), Alnus rubra (OES), Amaranthus watsonii (SON), Amblyopappus pusillus (CAL), Ambrosia ambrosioides (SON), A. chamissonis (NAS), A. chenopodiifolia (MAD), A. dumosa (SON), Ammophila arenaria (INT), Anagallis arvensis (INT), Anaphalis margaritacea (HOL), Angelica genuflexa (PAC), A. hendersonii (PAC), A. lucida (NAE), Antigonon leptopus (SON), Antirrbinum cyathiferum (SON), A. nuttallianum subsp. subsessile (MAD), Aphanisma blitoides (CAL), Arabis blepharophylla (CAL), Arbutus menziesii (PAC), Arctostaphylos columbiana (PAC), A. cruzensis (CAL), A. edmundsii (CAL), A. hookeri subsp. hearstiorum (CAL), A. morroensis (CAL), A. pumila (CAL), A. rudis (CAL), A. uva-ursi (HOL), Argentina egedii subsp. egedii (NAE), Armeria maritima subsp. californica (PAC), Artemisia californica (CAL), A. campestris subsp. borealis (HOL), A. pycnocephala (CAL), Artbrocnemum subterminale (MAD), Asclepias albicans (SON), A. subulata (SON), Astragalus anemophilus (BAJ), A. fastidius (BAJ), A . harbisonii (BAJ), $A$. magdalenae var. magdalenae (SON), A. nuttallianus var. cedrodensis (SON), A. nuttallii (CAL), A. trichopodus (CAL), Atbyrium filixfemina subsp. cyclosurum (NOA), Atriplex alaskensis (BOR), A. barclayana subsp. barclayana (SON), A. barclayana subsp. sonorae (SON), A. canescens subsp. canescens (NOA), A canescens subsp. linearis (SON), A. drymarioides (BOR), A. bymenelytra (SON), $A$. julacea (BAJ), A. leucophylla (CAL), A. magdalenae (BAJ), A. patula (INT), A polycarpa (NOA), A. semibaccata (INT), A. watsonii (CAL), Avicennia germinans (NEO), Baccharis douglasii (CAL), B. pilularis (CAL), B. sarotbroides (MAD), Bassia byssopifolia (INT), Batis maritima (NAS), Bergerocactus emoryi (CAL), Betula papyrifera var. kenaica (BOR), Blechnum spicant (HOL), Brickellia californica (CAL), Briza maxima (INT), Bromus carinatus (OES), B. diandrus (INT), B. glabra (BAJ), B. madritensis (INT), B. vulgaris (OES), Bursera cerasifolia (BAJ), B. epinnata (BAJ), B. filicifolia (BAJ), B. bindsiana (SON), B. microphylla (SON), B. odorata (SON), Caesalpinia placida (BAJ), Cakile edentula subsp. edentula var. edentula (NOA), C. maritima (INT), Calamagrostis canadensis (NOA), Calliandra eriophylla (SON), Calochortus concolor (CAL), Calystegia macrostegia subsp. cyclostegia (CAL), C. macrostegia subsp. tenuifolia (CAL), C. occidentalis (CAL), C. sepium subsp. angulata (NOA), C. soldanella (COS), Camissonia cardiophylla subsp. cedrosensis (BAJ), C. cheiranthifolia subsp. cheiranthifolia (CAL), C. cheiran-thifolia subsp. suffruticosa (CAL), C. crassifolia (BAJ), Cardionema ramosissimum (NAS), Cardiospermum corindum (NEO), Carex aquatilis var. dives (OES), C. cusickii (OES), C. lenticularis var. limnophila (OES), C. lenticularis var. lipocarpa (OES), C. lyngbyei (HOL), C. macrocephala (NAE), C. mertensii (OES), C. obnupta (PAC), C. pansa (PAC), C. pluriflora (PAC), C. ramenskii (NAE), Carpobrotus chilensis (INT), C. edulis (INT), Castela peninsularis (BAJ), Castilleja affinis subsp. affinis (CAL), C. ambigua subsp. ambigua (PAC), C. foliolosa (CAL), C. latifolia (CAL), C. mollis (CAL), C. unalaschcensis (BOR), C. wightii (CAL), Ceanothus cuneatus var. cuneatus (CAL), C. megacarpus (CAL), C. sorediatus (CAL), C. thyrsiflorus (CAL), C. verrucosus (CAL), Cenchrus palmeri (SON), Centaurium erythraea (INT), Cerastium fontanum subsp. vulgare (INT), Cercocarpus betuloides var. betuloides (CAL), Chaenactis lacera (BAJ), Chamaebatia australis (CAL), Chamerion angustifolium subsp. circumvagum (HOL), Chorizanthe pungens (CAL), Cirsium arvense (INT), C. loncholepis (CAL), Claytonia perfoliata subsp. mexicana (NAS), C. sibirica var. sibirica (OES), Clematis lasiantha (CAL), Clintonia uniflora (OES), Cneoridium dumosum (CAL), Comarum palustre (HOL), Commelina diffusa (NOA), Condalia globosa (SON), Condaliopsis rigida (BAJ), Conicosia pugioniformis (INT), Conioselinum gmelinii (NAE), Conium maculatum (INT), Corallorbiza mertensiana (OES), Cordylanthus maritimus (CAL), Coreocarpus parthenoides var. parthenoides (SON), Coreopsis maritima (CAL), Corethrogyne californica var. californica (CAL), Cornus canadensis (NAE), Cotula coronopifolia (INT), Coulterella capitata (BAJ), Crassula connata var. eremica (CAL), Cressa truxillensis (OES), Croton californicus (MAD), Cryptantha leiocarpa (CAL), C. maritima var. maritima (MAD), Cupressus macrocarpa (CAL), C. salina (OES), C. veatchii (BAJ), Cynanchum peninsulare (BAJ), Cyrtocarpa edulis (BAJ), Cytisus scoparius (INT), C. striatus (INT), Dalea brandegeei (BAJ), D. divaricata subsp. anthonyi (BAJ), D. maritima (BAJ), D. mollis subsp. mollis (SON), D. tinctoria var. tinctoria (BAJ), Dendranthema arcticum subsp. arcticum (NAE), Deschampsia cespitosa subsp. beringensis (NAE), Dichelostemma capitatum subsp. capitatum (MAD), Disporum hookeri (NOA), D. smithii (PAC), Distichlis spicata (NOA), Ditaxis brandegeei var. intonsa (BAJ), D. neomexicana (MAD), D. serrata (SON), Dithyrea californica var. clinata (BAJ), Dodecatheon pulchellum subsp. macrocarpum (PAC), Drymaria holosteoides var. crassifolia (BAJ), Dryopteris arguta (OES), D. expansa (NOA), Dudleya attenuata subsp. orcuttii (CAL), D. caespitosa (CAL), D. campanulata (CAL), D. cultrata (BAJ), D. cymosa subsp. cymosa (CAL), D. farinosa (CAL), D. ingens (BAJ), D. lanceolata (MAD), D. pulverulenta (MAD), Dyssodia anthemidifolia (BAJ), D. speciosa (BAJ), Echinocereus brandegeei (BAJ), E. maritimus (BAJ), Echinopepon minimus (BAJ), Eleocharis palustris (COS), Empetrum nigrum (HOL), Encelia californica var. asperifolia (BAJ), E. californica var. californica (MAD), E. farinosa var. farinosa (SON), E. farinosa var. phenocodonta (SON), E. farinosa var. radians (BAJ), E. halimifolia (SON), E. laciniata (BAJ), E. ventorum (BAJ), Ephedra californica (MAD), E. trifurca (SON), Epilobium ciliatum subsp. glandulosum (NOA), E. densiflorum (OES), Equisetum byemale var. affine (NOA), E. sylvaticum (HOL), E. telmateia var. braunii (NOA), Eragrostis bypnoides (NAS), Erechtites minima (INT), Ericameria ericoides (CAL), Erigeron blochmaniae (CAL), E. glaucus (CAL), Eriodictyon crassifolium (CAL), Eriogonum fasciculatum var. fasciculatum (CAL), E. fasciculatum var. flavoviride (SON), E. latifolium (CAL), E. parvifolium (CAL), E. confertiflorum (CAL), Eriopbyllum stoechadifolium (CAL), Errazurizia megacarpa (BAJ), Erysimum franciscanum (CAL), E. insulare subsp. suffrutescens (CAL), E. menziesii subsp. concinnum (CAL), E. menziesii subsp. eurekense (CAL), E. menziesii subsp. yadonii (CAL), Eschscholzia californica (NOA), Euphorbia ceratoderma (SON), E. heteropbylla var. graminifolia (NAS), E. leucopbylla (SON), E. micromera (NEO), E. misera (MAD), E. polycarpa var. johnstonii (BAJ), Fagonia laevis (SON), F. pachyacantha (SON), Ferocactus cylindraceus var. cylindraceus (SON), F. fordii var. fordii (BAJ), Ferocactus gracilis var. coloratus (BAJ), F. towsendianus (BAJ), F. viridescens (CAL), Festuca rubra subsp. rubra (COS), Filago californica (OES), Foeniculum vulgare (INT), Fouquieria diguetii (SON), Fragaria chiloensis subsp. pacifica (NAS), Frankenia palmeri (MAD), F. salina (NAS), Fraxinus latifolia (PAC), F. trifoliata (BAJ), Fritillaria camschatcensis (PAC), Froelichia interrupta (NEO), Galium angustifolium (CAL), G. aparine (HOL), G. porrigens (CAL), G. trifidum subsp. columbianum (OES), G. triflorum (COS), Gaultheria shallon (PAC), Geocaulon lividum (NOA), Geranium erianthum (BOR), Glaux maritima (HOL), Glebnia littoralis subsp. leiocarpa (PAC), Gnaphalium purpureum (NOA), G. ramosissimum (CAL), G. stramineum (NOA), Goodyera oblongifolia (NOA), Grindelia 
birsutula var. hirsutula (CAL), G. birsutula var. maritima (CAL), G. integrifolia (SON), G. stricta subsp. platyphylla (CAL), Haplopappus berberidis (BAJ), H. rosaricus (BAJ), H. sonorensis (SON), $H$. venetus subsp. tridentatus (CAL), Harfordia macroptera (BAJ), Hazardia squarrosa var. grindelioides (CAL), Hedera belix (INT), Helenium bolanderi (CAL), Helianthus niveus subsp. niveus (MAD), Heliotropium curassavicum (NAS), H. procumbens (NAS), Hemizonia fasciculata (CAL), Heracleum maximum (NOA), Heteromeles arbutifolia (CAL), Heterotheca sessiliflora subsp. bolanderi (CAL), H. subaxillaris (NOA), Heuchera pilosissima (CAL), Hieracium albiflorum (OES), Hierochloe alpina subsp. alpina (HOL), Hippuris tetraphylla (BOR), H. vulgaris (COS), Hofmeisteria fasciculata var. fasciculata (BAJ), Holcus lanatus (INT), H. mollis (INT), Holodiscus discolor (NOA), Honkenya peploides subsp. major (NAE), Hordeum brachyantherum subsp. brachyantherum (NOA), H. marinum subsp. gussonianum (INT), Horsfordia alata (SON), Houstonia mucronata (BAJ), Hymenoclea pentalepis (SON), Hypericum anagallioides (OES), Hypochaeris glabra (INT), H. radicata (INT), Hyptis emoryi (SON), Ibervillea sonorae var. peninsularis (BAJ), Ipomoea costellata (NEO), I. pes-caprae subsp. brasiliensis (NEO), I. stolonifera (NEO), Iris douglasiana (CAL), Isocoma menziesii var. menziesii (CAL), I. menziesii var. sedoides (CAL), I. menziesii var. vernonioides (MAD), Isolepis carinata (NOA), I. cernua (COS), Isomeris arborea (MAD), Jatropha cinerea (NEO), J. cordata (BAJ), J. cuneata (SON), Jaumea carnosa (OES), Jouvea pilosa (NEO), Juglans californica (CAL), Juncus balticus (COS), J. bufonius (COS), J. falcatus (COS), J. gerardii (HOL), J. haenkey (BOR), J. lesueurii (PAC), J. phaeocephalus (OES), J. sphaerocarpus (MAD), J. supiniformis (PAC), Justicia californica (SON), Keckiella antirrbinoides var. antirrbinoides (CAL), K. cordifolia (CAL), Krameria paucifolia (SON), Laguncularia racemosa, Larrea tridentata (NEO), Lathyrus japonicus var. maritimus (NAS), L. littoralis (PAC), L. palustris (NOA), Leotondon taraxacoides (INT), Lepidium nitidum (MAD), Leymus mollis subsp. mollis (NAE), Ligusticum scoticum subsp. bultenii (BOR), Lilaeopsis occidentalis (PAC), Limonium californicum (CAL), Linnaea borealis subsp. americana (NOA), Listera convallarioides (NAE), Lithocarpus densiflorus (CAL), Lomatogonium rotatum (OES), Lonicera ciliosa (OES), L. involucrata var. involucrata (NOA), L. involucrata var. ledebourii (CAL), Lotus bryantii (BAJ), L. corniculatus (INT), L. hamatus (CAL), L. junceus var. biolettii (CAL), L. rigidus (MAD), L. salsuginosus (OES), Lotus scoparius var. scoparius (CAL), L. uliginosus (INT), Lupinus arboreus (PAC), L. chamissonis (CAL), L. concinnus (MAD), L. littoralis (PAC), L. variicolor (CAL), Luzula glabrata var. hitchcockii (OES), L. multiflora subsp. multiflora (OES), Lycium andersonii (MAD), L. berlandieri var. peninsulare (SON), L. brevipes (MAD), L. californicum (MAD), L. carolinianum (NEO), L. exsertum (SON), L. fremontii var. congestum (SON), L. megacarpum (BAJ), Lycopodium annotinum (HOL), Lysichiton americanum (OES), Maba intrincata (BAJ), Madia sativa (NAS), Maianthemum dilatatum (OES), Maianthemum racemosum subsp. amplexicaule (NOA), M. stellatum (NOA), Malacothamnus densiflorus (CAL), M. fasciculatus (CAL), Malacothrix incana (CAL), M. saxatilis (CAL), Malosma laurina (CAL), Malus fusca (PAC), Malvastrum coromendalianum (PAC), Mammillaria brandegeei (BAJ), M. dioica (MAD), Marah fabaceus (CAL), M. macrocarpus (CAL), M. oreganus (OES), Maytenus phyllantoides (NEO), Melica frutescens (MAD), M. imperfecta (CAL), Melilotus indica (INT), Mentha arvensis (HOL), Menziesia ferruginea (OES), Mertensia maritima (HOL), Mesembryan-themum crystallinum (INT), M. nodiflorum (INT), Mimulus aurantiacus (CAL), M. guttatus (NOA), Mirabilis californica (CAL), Momordica charanthia (PAC), Monanthochloe littoralis (NOA), Monardella crispa (CAL), Myosurus minimus (HOL), Myrica californica (PAC), Myrtillocactus cochal (BAJ), Nassella lepida (CAL), N. pulchra (CAL), N. speciosa (NOA), Nemacaulis denudata (MAD), Nicotiana glauca (INT), Nolina parryi (MAD), Oenanthe sarmentosa (PAC), Oenothera drummondii var. thalassaphila (BAJ), O. elata subsp. hookeri (CAL), Oligomeris linifolia (MAD), Olneya tesota (SON), Oplopanax horridus (NOA), Opuntia acanthocarpa (SON), O. cholla (BAJ), O. ganderi var. ganderi (BAJ), O. invicta (BAJ), O. littoralis (CAL), O. prolifera (CAL), O. rosarica (BAJ), O. tesajo (BAJ), Ornitostaphylos oppositifolia (CAL), Orthilia secunda (HOL), Osmorbiza berteroi (NOA), Oxalis oregana (PAC), Pachycereus pringlei (SON), P. schottii (SON), Pachycormus discolor var. veatchiana (BAJ), Palafoxia linearis var. linearis (SON), Parentucellia viscosa (INT), Parkinsonia microphylla (SON), Parnasia palustris var. palustris (HOL), Passiflora foetida var. longipedunculata (NEO), Pedilanthus macrocarpus (SON), Pentagramma triangularis var. triangularis (OES), P. triangularis var. viscosa (CAL), Perityle crassifolia var. crassifolia (BAJ), P. crassifolia var. robusta (BAJ), P. emoryi (MAD), Peucephyllum schottii (MAD), Phacelia argentea (CAL), P. bolanderi (PAC), P. distans (NOA), Phaseolus acutifolius var. latifolius (NEO), P. filiformis (SON), Phoradendron californicum (MAD), Phrygilanthus sonorae (SON), Physalis crassifolia (SON), Picea glauca (NOA), P. sitchensis (PAC), Pinus contorta var. contorta (PAC), P. torreyana (CAL), Pithecellobium confine (BAJ), Plantago coronopus (INT), P. erecta (MAD), P. lanceolata (INT), P. maritima var. juncoides (HOL), P. subnuda (CAL), Pleuraphis rigi$d a$ (SON), Poa arctica subsp. williamsii (OES), P. confinis (PAC), $P$. douglasii subsp. douglasii (CAL), $P$. eminens (BOR), P. fendleriana (OES), P. macrantha (PAC), P. macrocalyx (BOR), Polycarpon depressum (CAL), Polygonum aviculare (INT), P. bydropiperoides (NOA), P. paronychia (PAC), Polypodium glycyrrbiza (OES), P. scouleri (OES), Polypogon maritimus (INT), P. monspeliensis (INT), Polystichum munitum (OES), Populus balsamifera subsp. trichocarpa (OES), P. fremontii (MAD), Porophyllum gracile (MAD), P. maritimum (BAJ), P. porfyreum (BAJ), Portulaca pilosa (NEO), Potentilla villosa (PAC), Proboscidea altheaefolia (SON), Prosopis articulata (SON), P. glandulosa var. torreyana (SON), P. palmeri (BAJ), Prunus fasciculata var. fasciculata (MAD), P. ilicifolia (CAL), Pseudotsuga menziesii var. menziesii (OES), Pteridium aquilinum var. pubescens (OES), Puccinellia distans subsp. distans (HOL), P. bultenii (BOR), P. kurilensis (PAC), P. nutkaensis (PAC), P. nuttalliana (NOA), P. phryganodes subsp. phryganodes (HOL), P. tenella subsp. alascana (BOR), Pyrola picta (OES), Quercus agrifolia (CAL), Q. dumosa (CAL), Ranunculus cymbalaria (HOL), $R$. flammula var. ovalis (NOA), R. uncinatus (OES), Raphanus sativus (INT), Rhamnus californica subsp. californica (CAL), R. crocea (CAL), R. purshiana (OES), Rhinanthus minor subsp. groenlandicus (BOR), R. minor subsp. minor (HOL), Rbizophora mangle (NEO), Rhododendron macrophyllum (PAC), $R$. occidentale (PAC), Rhus integrifolia (CAL), Ribes lacustre (NOA), R. speciosum (CAL), R. tortuosum (BAJ), Rorippa nasturtium-aquaticum (COS), Rosa acicularis subsp. acicularis (HOL), R. minutifolia (BAJ), R. nutkana var. nutkana (OES), Rubus discolor (INT), R. lasiococcus (PAC), R. macropetalus (OES), $R$. parviflorus (NOA), $R$. ursinus subsp. ursinus (OES), Rumex acetosella (INT), $R$. arcticus (HOL), R. crispus (INT), R. salicifolius var. crassus (PAC), Sagina maxima subsp. crassicaulis (PAC), $S$. procumbens (NOA), Salicornia bigelovii (NAS), S. maritima (COS), Salix bookeriana (PAC), S. lasiolepis (MAD), Salsola tragus (INT), S. apiana (CAL), S. mellifera (CAL), S. munzii (CAL), Sambucus nigra subsp. caerulea (OES), S. racemosa (NOA), Sanicula crassicaulis (NAS), S. hoffmannii (CAL), Sapindus saponaria (NEO), Sarcocornia pacifica (PAC), $S$. perennis (HOL), Sarcostemma arenarium (BAJ), Saussurea nuda (NAE), Scaevola plumieri (PAC), Schismus barbatus (INT), Schoenoplectus americanus (NAS), S. californicus (NAS), S. maritimus (COS), S. robustus (NAS), S. tabernaemontani (COS), Scropbularia californica (CAL), S. oregana (SON), Selaginella cinerascens (CAL), S. lepidophylla (NEO), Senecio blochmaniae (CAL), S. bolanderi (PAC), S. jacobea (INT), S. pseudoarnica (NAE), Sequoia sempervirens (CAL), Sesuvium verrucosum (MAD), Setaria palmeri (BAJ), Shepherdia canadensis (NOA), Silene californica (CAL), Simmondsia chinensis 
(MAD), Sisynrinchium californicum (PAC), Solanum bindsianum (SON), Solidago occidentalis (NOA), S. spathulata subsp. spathulata (CAL), S. spectabilis var. confinis (CAL), Sonchus arvensis (INT), S. oleraceus (INT), Sorbus sitchensis (OES), Spartina alterniflora (NOA), S. foliosa (PAC), Spergularia bocconii (INT), S. canadensis var. occidentalis (PAC), S. macrotheca (PAC), S. maritima (INT), S. ambigua (MAD), Sphaeralcea fulva (BAJ), Spiraea douglasii (NOA), Spiranthes romanzoffiana (NOA), Sporobolus virginicus (NEO), Stachys ajugoides var. rigida (OES), S. bullata (CAL), S. mexicana (PAC), Stegnosperma balimifolium (NEO), Stellaria calycantha (OES), S. bumifusa (HOL), S. littoralis (CAL), Stenocereus gummosus (SON), S. thurberi var. littoralis (BAJ), Stephanomeria pauciflora (SON), Stillingia linearifolia (MAD), Suaeda calceoliformis (NOA), S. esteroa (CAL), S. maritima (INT), S. moquinii (NOA), S. taxifolia (MAD), Symphyotrichum chilense (OES), Symphyotrichum subspicatum (OES), Tamarix ramosissima (INT), Tanacetum camphoratum (PAC), Tetragonia tetragonioides (INT), Thuja plicata (OES), Tiarella trifoliata (OES), Tillaea erecta subsp. eremica (SON), Tiquilia plicata (SON), Toxicodendron diversilobum (OES), Trianthema portulacastrum (PAC), Trientalis europaea subsp. arctica (OES), Trientalis latifolia (OES), Trifolium arvense (INT), T. campestre (INT), T. repens (INT), T. wormskjoldii (OES), Triglocbin conncinna (NOA), T. maritimum (HOL), T. palustris (HOL), Triphysaria pusilla (PAC), Triteleiopsis palmeri (SON), Trixis californica (MAD), Tsuga beteropbylla (OES), T. angustifolia (COS), T. latifolia (COS), Ulex europaeus (INT), UmbeIlularia californica (CAL), Urtica bolosericea (CAL), Vaccinium membranaceum (NOA), V. ovatum (PAC), V. parvifolium (OES), V. uliginosum (HOL), Vallesia glabra (NEO), Veronica americana (NOA), V. scutellata (NOA), Viburnum edule (NOA), Vicia nigricans subsp. gigantea (PAC), Viguiera deltoidea var. chenopodina (BAJ), V. laciniata (MAD), V. microphylla (BAJ), Viola sempervirens (OES), Viscainoa geniculata (BAJ), Vulpia myuros (INT), Washingtonia filifera (SON), Wislizenia refracta var. mammillata (SON), Xeropbyllum tenax (OES), Xylococcus bicolor (CAL), Yucca schidigera (MAD) y Yucca valida (BAJ).

\section{Apéndice 2: Localidades muestreadas}

Baja California Sur: 1, Migriño $\left(23^{\circ} 02^{\prime} \mathrm{N}-110^{\circ} 06^{\prime} \mathrm{W}\right)$; 2, Bahía Tortugas $\left(23^{\circ} 06^{\prime} \mathrm{N}-109^{\circ} 32^{\prime} \mathrm{W}\right)$; 3, La Fortuna $\left(23^{\circ} 08^{\prime} \mathrm{N}\right.$ $\left.109^{\circ} 30^{\prime} \mathrm{W}\right) ; 4$, Santa Elena $\left(23^{\circ} 09^{\prime} \mathrm{N}-109^{\circ} 29^{\prime} \mathrm{W}\right) ; 5$, Punta Paredones $\left(23^{\circ} 10^{\prime} \mathrm{N}-109^{\circ} 28^{\prime} \mathrm{W}\right) ; 6$, Boca de la Vinorama $\left(23^{\circ} 13^{\prime} \mathrm{N}\right.$ -

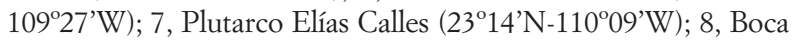
de la Ardilla $\left(23^{\circ} 15^{\prime} \mathrm{N}-109^{\circ} 26^{\prime} \mathrm{W}\right)$; 9, Boca del Salado $\left(23^{\circ} 17^{\prime} \mathrm{N}\right.$ -

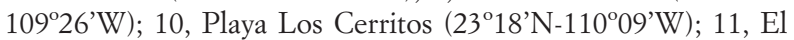

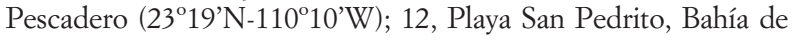
Todos Santos $\left(23^{\circ} 21^{\prime} \mathrm{N}-110^{\circ} 11^{\prime} \mathrm{W}\right) ; 13$, Bahía de los Frailes

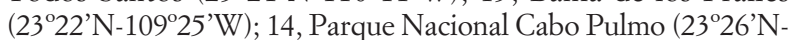
$\left.109^{\circ} 25^{\prime} \mathrm{W}\right) ; 15$, Cabo Pulmo (23⒉' N-109²6’W); 16, Las Playitas, Todos Santos $\left(23^{\circ} 29^{\prime} \mathrm{N}-110^{\circ} 16^{\prime} \mathrm{W}\right)$; 17 , Punta Las Arenas lighthouse $\left(23^{\circ} 33^{\prime} \mathrm{N}-109^{\circ} 29^{\prime} \mathrm{W}\right)$; 18 , Punta Colorada $\left(23^{\circ} 33^{\prime} \mathrm{N}\right.$ -

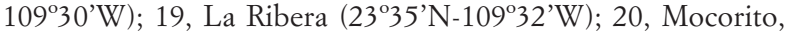
Bahía las Palmas $\left(23^{\circ} 36^{\prime} \mathrm{N}-109^{\circ} 34^{\prime} \mathrm{W}\right) ; 21$, Ejido La Conquista

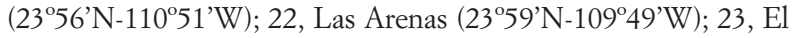
Teso, Bahía la Ventana $\left(24^{\circ} 04^{\prime} \mathrm{N}-109^{\circ} 56^{\prime} \mathrm{W}\right) ; 24$, Punta Conejo $\left(24^{\circ} 04^{\prime} \mathrm{N}-111^{\circ} 01 \mathrm{~W}\right) ; 25$, El Sargento $\left(24^{\circ} 05^{\prime} \mathrm{N}-110^{\circ} 00^{\prime} \mathrm{W}\right) ; 26$, Bahía Ventana $\left(24^{\circ} 08^{\prime} \mathrm{N}-109^{\circ} 58^{\prime} \mathrm{W}\right) ; 27$, El Cajete $\left(24^{\circ} 14^{\prime} \mathrm{N}\right.$ $\left.110^{\circ} 36^{\prime} \mathrm{W}\right) ; 28$, between $\mathrm{La} \mathrm{Paz}$ and Pichilingüe (24\%15'$\left.110^{\circ} 18^{\prime} \mathrm{W}\right) ; 29$, Bahía Pichilingue ( $\left.24^{\circ} 17^{\prime}-110^{\circ} 20^{\prime} \mathrm{W}\right) ; 30$, Bahía Balandra $\left(24^{\circ} 19^{\prime} \mathrm{N}-110^{\circ} 19^{\prime} \mathrm{W}\right) ; 31$, El Camarón $\left(24^{\circ} 20^{\prime} \mathrm{N}-110^{\circ} 39^{\prime} \mathrm{W}\right)$; 32, Playa El Tecolote ( $\left.24^{\circ} 20^{\prime} \mathrm{N}-110^{\circ} 18^{\prime} \mathrm{W}\right)$; 33, Rancho Piedras Coloradas $\left(24^{\circ} 21^{\prime} \mathrm{N}-110^{\circ} 40^{\prime} \mathrm{W}\right)$; 34 , San Juan de la Costa

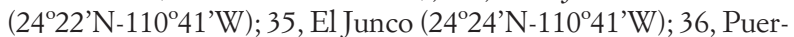
to Chale $\left(24^{\circ} 25^{\prime} \mathrm{N}-11^{\circ} 32^{\prime} \mathrm{W}\right)$; 37 , Punta Tarabillas $\left(24^{\circ} 26^{\prime} \mathrm{N}\right.$ $\left.110^{\circ} 41^{\prime} \mathrm{W}\right) ; 38$, Puerto Cancún $\left(24^{\circ} 35^{\prime} \mathrm{N}-111^{\circ} 41^{\prime} \mathrm{W}\right)$; 39, Las Áni-

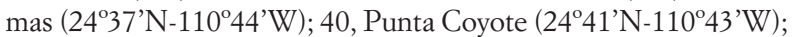

41, Puerto San Carlos ( $\left.24^{\circ} 47^{\prime} \mathrm{N}-112^{\circ} 07^{\prime} \mathrm{W}\right)$; 42, Isla Magdalena $\left(25^{\circ} 05^{\prime} \mathrm{N}-112^{\circ} 09^{\prime} \mathrm{W}\right) ; 43$, Isla Magdalena ( $\left.25^{\circ} 12^{\prime} \mathrm{N}-112^{\circ} 07^{\prime} \mathrm{W}\right) ; 44$,

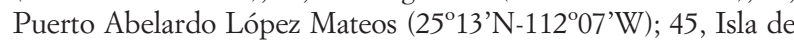
Santo Domingo $\left(25^{\circ} 17^{\prime} \mathrm{N}-112^{\circ} 07^{\prime} \mathrm{W}\right)$; 46, El Paraíso $\left(25^{\circ} 35^{\prime} \mathrm{N}\right.$ $\left.112^{\circ} 03^{\prime} \mathrm{W}\right) ; 47$, Estero el Gato $\left(25^{\circ} 39^{\prime} \mathrm{N}-112^{\circ} 03^{\prime} \mathrm{W}\right) ; 48$, La Poza Grande (25 $\left.41^{\prime} \mathrm{N}-112^{\circ} 04^{\prime} \mathrm{W}\right)$; 49, Laguna Puerto Escondido

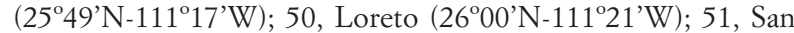
Juanico $\left(26^{\circ} 15^{\prime} \mathrm{N}-112^{\circ} 27^{\prime} \mathrm{W}\right)$; 52 , El Dátil (26⒉ $\left.26^{\prime} \mathrm{N}-112^{\circ} 47^{\prime} \mathrm{W}\right)$;

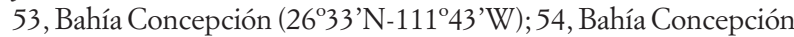

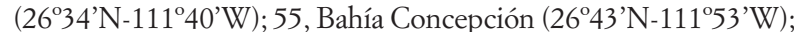
56, Bahía de Ballenas (26 $\left.44^{\prime} \mathrm{N}-113^{\circ} 32^{\prime} \mathrm{W}\right) ; 57$, Playa del Burro (26 $\left.6^{\circ} 44^{\prime} \mathrm{N}-111^{\circ} 53^{\prime} \mathrm{W}\right)$; 58, Playa Santispac (26⒋ $\left.46^{\prime} \mathrm{N}-111^{\circ} 53^{\prime} \mathrm{W}\right)$; 59, between Punta Abreojos and El Coyote (26 $\left.47^{\circ} \mathrm{N}-113^{\circ} 30^{\prime} \mathrm{W}\right)$;

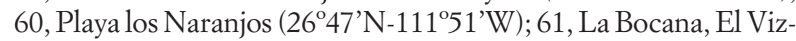
caíno Biosphere Reserve (26 $\left.49^{\prime} \mathrm{N}-113^{\circ} 43^{\prime} \mathrm{W}\right) ; 62$, Mulegé dunes

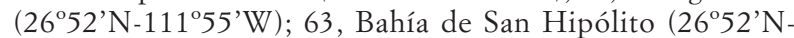
$\left.113^{\circ} 45^{\prime} \mathrm{W}\right) ; 64$, El Vizcaíno Biosphere Reserve (265 $56^{\prime} \mathrm{N}$ -

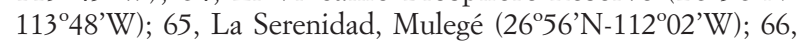
Punta Prieta $\left(27^{\circ} 01^{\prime} \mathrm{N}-114^{\circ} 01^{\prime} \mathrm{W}\right) ; 67$, Punta Chivato $\left(27^{\circ} 04^{\prime} \mathrm{N}\right.$ -

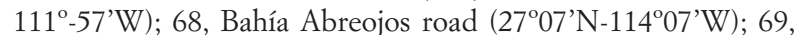
Playa Los Médanos $\left(27^{\circ} 08^{\prime} \mathrm{N}-114^{\circ} 12^{\prime} \mathrm{W}\right) ; 70$, Bahía Asunción ( $\left.27^{\circ} 09^{\prime} \mathrm{N}-114^{\circ} 18^{\prime} \mathrm{W}\right) ; 71$, Rancho El Paraíso (27 $\left.11^{\circ} \mathrm{N}-13^{\circ} 17^{\prime} \mathrm{W}\right)$; 72, Barra de San Bruno (27 $\left.12^{\circ} \mathrm{N}-112^{\circ} 11^{\prime} \mathrm{W}\right) ; 73$, Bahía Tortugas (27 $\left.7^{\circ} 41^{\prime} \mathrm{N}-114^{\circ} 53^{\prime} \mathrm{W}\right) ; 74$, Punta Caballo de Piedra, Malarrimo $\left(27^{\circ} 47^{\prime} \mathrm{N}-114^{\circ} 42^{\prime} \mathrm{W}\right) ; 75$, Estero Laguna Ojo de Liebre $\left(27^{\circ} 47^{\prime} \mathrm{N}\right.$ $\left.114^{\circ} 05^{\prime} \mathrm{W}\right) ; 76$, Malarrimo $\left(27^{\circ} 46^{\prime} \mathrm{N}-114^{\circ} 34^{\prime} \mathrm{W}\right) ; 77$, El Chevo $\left(27^{\circ} 49^{\prime} \mathrm{N}-114^{\circ} 51^{\prime} \mathrm{W}\right)$; 78 , Laguna Ojo de Liebre $\left(27^{\circ} 52^{\prime} \mathrm{N}\right.$ $\left.113^{\circ} 59^{\prime} \mathrm{W}\right) ; 79$, Guerrero Negro $\left(27^{\circ} 57^{\prime} \mathrm{N}-114^{\circ} 04^{\prime} \mathrm{W}\right) ; 80$, Guerrero Negro $\left(28^{\circ} 02^{\prime} \mathrm{N}-114^{\circ} 01^{\prime} \mathrm{W}\right)$. Baja California Norte: 81 , Jesús y María (2806'N-11400’W); 82, La Bocana de Jesús y María

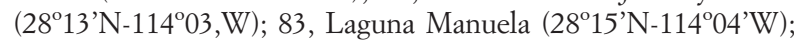
84 , Miller's Landing $\left(28^{\circ} 29^{\prime} \mathrm{N}-114^{\circ} 03^{\prime} \mathrm{W}\right) ; 85$, Santa Rosalillita $\left(28^{\circ} 41^{\prime} \mathrm{N}-114^{\circ} 14^{\prime} \mathrm{W}\right)$; 86, Bahía de los Ángeles $\left(28^{\circ} 55^{\prime} \mathrm{N}\right.$ $\left.113^{\circ} 33^{\prime} \mathrm{W}\right) ; 87$, Punta Canoas (29⒉ $\left.26^{\prime} \mathrm{N}-115^{\circ} 12^{\prime} \mathrm{W}\right) ; 88$, Puerto Catarina $\left(29^{\circ} 31^{\prime} \mathrm{N}-115^{\circ} 15^{\prime} \mathrm{W}\right) ; 89$, Punta San Carlos $\left(29^{\circ} 37^{\prime} \mathrm{N}\right.$ $\left.115^{\circ} 31^{\prime} \mathrm{W}\right)$; 90 , Punta Baja (29 $\left.58^{\prime} \mathrm{N}-115^{\circ} 47^{\prime} \mathrm{W}\right)$; 91 , Bocana del

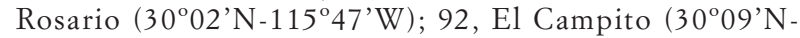
$\left.115^{\circ} 48^{\prime} \mathrm{W}\right)$; 93 , Playa El Tranquilo (306' $\left.16^{\prime} \mathrm{N}-115^{\circ} 48^{\prime} \mathrm{W}\right)$; 94 , El So-

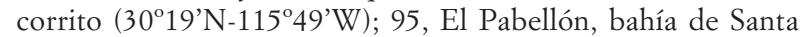

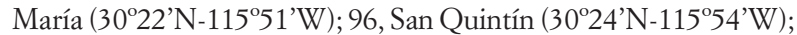
97, Los Volcanes ( $\left.30^{\circ} 27^{\prime} \mathrm{N}-116^{\circ} 02^{\prime} \mathrm{W}\right)$; 98 , El Papolote (30²7’N$\left.115^{\circ} 47^{\prime} \mathrm{W}\right)$; 99, La Chorera (30²8'N-116 $\left.02^{\prime} \mathrm{W}\right) ; 100$, La Pedrera $\left(30^{\circ} 29^{\prime} \mathrm{N}-116^{\circ} 03^{\prime} \mathrm{W}\right) ; 101$, Laguna Figueroa (3041'N-116 $\left.01^{\circ} \mathrm{W}\right)$; 102, Bahía Camalú $\left(30^{\circ} 47^{\prime} \mathrm{N}-116^{\circ} 05^{\prime} \mathrm{W}\right) ; 103$, San Felipe

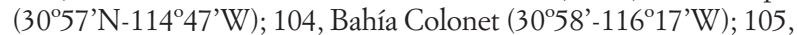
San Antonio del Mar (31 $\left.07^{\circ} \mathrm{N}-116^{\circ} 19^{\prime} \mathrm{W}\right) ; 106$, Bocana Eréndira ( $\left.31^{\circ} 16^{\prime} \mathrm{N}-116^{\circ} 23^{\prime} \mathrm{W}\right) ; 107$, Puerto San Isidro ( $\left.31^{\circ} 17^{\prime} \mathrm{N}-116^{\circ} 24^{\prime} \mathrm{W}\right)$; 108, Punta Cabras ( $\left.31^{\circ} 19^{\prime} \mathrm{N}-116^{\circ} 27^{\prime} \mathrm{W}\right) ; 109$, La Bocana de Santo Tomás $\left(31^{\circ} 33^{\prime} \mathrm{N}-116^{\circ} 41^{\prime} \mathrm{W}\right)$; 110 , Punta Banda $\left(31^{\circ} 43^{\prime} \mathrm{N}\right.$ -

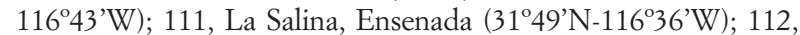
Bahía de Todos los Santos (3152'N-116 $\left.37^{\circ} \mathrm{W}\right) ; 113$, Playa Saldamando ( $\left.31^{\circ} 56^{\prime} \mathrm{N}-116^{\circ} 46^{\prime} \mathrm{W}\right)$; 114 , Salsipuedes $\left(31^{\circ} 58^{\prime} \mathrm{N}\right.$ $\left.116^{\circ} 47^{\prime} \mathrm{W}\right) ; 115$, La Salina, sur de Tijuana (32 $\left.03^{\prime} \mathrm{N}-116^{\circ} 54^{\prime} \mathrm{W}\right)$; 116, Plaza del Mar (32 $\left.07^{\prime} \mathrm{N}-116^{\circ} 55^{\prime} \mathrm{W}\right) ; 117$, El Médano ( $\left.32^{\circ} 13^{\prime} \mathrm{N}-116^{\circ} 54^{\prime} \mathrm{W}\right)$; 118 , El Rosarito ( $\left.32^{\circ} 17^{\prime} \mathrm{N}-117^{\circ} 03^{\prime} \mathrm{W}\right)$. California: 119 , Tijuana Estuary $\left(32^{\circ} 34^{\prime} \mathrm{N}-117^{\circ} 08^{\prime} \mathrm{W}\right) ; 120$, Imperial Beach (32 $\left.36^{\prime} \mathrm{N}-117^{\circ} 09^{\prime} \mathrm{W}\right) ; 121$, Mission Bay (32 $46^{\prime} \mathrm{N}$ $\left.117^{\circ} 14^{\prime} \mathrm{W}\right) ; 122$, Torrey Pines State Reserve (32 $\left.{ }^{\circ} 55^{\prime} \mathrm{N}-117^{\circ} 16^{\prime} \mathrm{W}\right)$;

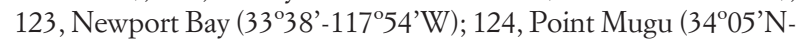

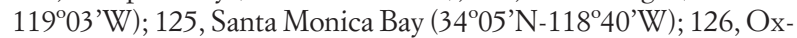
nard Beach $\left(34^{\circ} 08^{\prime} \mathrm{N}-119^{\circ} 11^{\prime} \mathrm{W}\right)$; 127 , Port Hueneme Beach $\left(34^{\circ} 09^{\prime} \mathrm{N}-119^{\circ} 11^{\prime} \mathrm{W}\right) ; 128$, Carpinteria State Beach $\left(34^{\circ} 24^{\prime} \mathrm{N}\right.$ $\left.119^{\circ} 30^{\prime} \mathrm{W}\right) ; 129$, Gaviota State Beach $\left(34^{\circ} 28^{\prime} \mathrm{N}-120^{\circ} 11^{\prime} \mathrm{W}\right) ; 130$, Jalama Beach, Point Conception (34'32'N-120'37'W); 131, Rancho Guadalupe Dune Preserve (34 $\left.{ }^{\circ} 57^{\prime} \mathrm{N}-120^{\circ} 39^{\prime} \mathrm{W}\right)$; 132, Pismo Dunes Preserve, Pismo Beach ( $\left.35^{\circ} 00^{\prime} \mathrm{N}-120^{\circ} 35^{\prime} \mathrm{W}\right) ; 133$, Oso Fla-

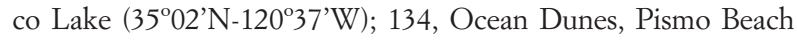


$\left(35^{\circ} 07^{\prime} \mathrm{N}-120^{\circ} 38^{\prime} \mathrm{W}\right) ; 135$, Oso Valley Sand Spit $\left(35^{\circ} 19^{\prime} \mathrm{N}-\right.$ $\left.120^{\circ} 52^{\prime} \mathrm{W}\right)$; 136 , Morro Bay $\left(35^{\circ} 22^{\prime} \mathrm{N}-120^{\circ} 51^{\prime} \mathrm{W}\right) ; 137$, San Simeón (35 $\left.35^{\circ} \mathrm{N}-121^{\circ} 07^{\prime} \mathrm{W}\right)$; 138 , Piedras Blancas $\left(35^{\circ} 40^{\prime} \mathrm{N}\right.$ $\left.121^{\circ} 15^{\prime} \mathrm{W}\right) ; 139$, Garrapata Creek (36 $\left.25^{\circ} \mathrm{N}-151^{\circ} 55^{\prime} \mathrm{W}\right) ; 140$, Seal Point, Monterey Bay (36³5’N-121-58W); 141, Scenic Drive, Monterey Bay $\left(36^{\circ} 36^{\prime} \mathrm{N}-121^{\circ} 57^{\prime} \mathrm{W}\right) ; 142$, Bay lagoon, Monterey Bay $\left(36^{\circ} 36^{\prime} \mathrm{N}-121^{\circ} 51^{\prime} \mathrm{W}\right) ; 143$, Spanish Drive, Monterey Bay (36³ $\left.36^{\prime} \mathrm{N}-121-59 \mathrm{~W}\right) ; 144$, Asilomar State Beach (36⒊'N $\left.121^{\circ} 56^{\prime} \mathrm{W}\right) ; 145$, Seaside Beach, Sand City (36 $\left.37^{\circ} \mathrm{N}-121^{\circ} 51^{\prime} \mathrm{W}\right)$; 146, Marina State Beach (36 $\left.6^{\circ} 42^{\prime} \mathrm{N}-121^{\circ} 48^{\prime} \mathrm{W}\right) ; 147$, Salinas River State Beach (36 $\left.47^{\circ} \mathrm{N}-121^{\circ} 48^{\prime} \mathrm{W}\right)$; 148 , Moss Landing State Beach (36 $\left.{ }^{\circ} 49^{\prime} \mathrm{N}-121^{\circ} 47^{\prime} \mathrm{W}\right) ; 149$, Elkorn Slough National Estuarine Preserve (36 $\left.49^{\prime} \mathrm{N}-121^{\circ} 43^{\prime} \mathrm{W}\right)$; 150, Año Nuevo State Reserve $\left(37^{\circ} 07^{\prime} \mathrm{N}-122^{\circ} 18^{\prime} \mathrm{W}\right)$; 151 , Gazos Creek (37 $\left.{ }^{\circ} 10^{\prime} \mathrm{N}-122^{\circ} 22^{\prime} \mathrm{W}\right)$; 152, Bean Hollow $\left(37^{\circ} 13^{\prime} \mathrm{N}-122^{\circ} 24^{\prime} \mathrm{W}\right) ; 153$, Pescadero Beach $\left(37^{\circ} 16^{\prime}-122^{\circ} 25^{\prime} \mathrm{W}\right) ; 154$, Pomponio State Beach $\left(37^{\circ} 18^{\prime} \mathrm{N}\right.$ $\left.122^{\circ} 21^{\prime} \mathrm{W}\right) ; 155$, Dunes Beach, Half Moon Bay $\left(37^{\circ} 29^{\prime} \mathrm{N}\right.$ $\left.122^{\circ} 27^{\prime} \mathrm{W}\right) ; 156$, San Francisco Bay $\left(37^{\circ} 32^{\prime} \mathrm{N}-122^{\circ} 12^{\prime} \mathrm{W}\right) ; 157$, Moss Beach (37 $\left.32^{\prime} \mathrm{N}-122^{\circ} 30^{\prime} \mathrm{W}\right) ; 158$, Muir Beach $\left(37^{\circ} 51^{\prime} \mathrm{N}\right.$ -

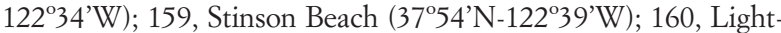

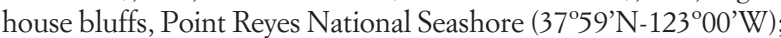
161 , Drake Beach, Point Reyes National Seashore $\left(38^{\circ} 01^{\prime} \mathrm{N}\right.$ $\left.122^{\circ} 57^{\prime} \mathrm{W}\right) ; 162$, South Beach, Point Reyes National Seashore (38 $\left.03^{\circ} \mathrm{N}-122^{\circ} 59^{\prime} \mathrm{W}\right) ; 163$, North Beach, Point Reyes National Seashore (38 $\left.04^{\prime} \mathrm{N}-122^{\circ} 58^{\prime} \mathrm{W}\right)$; 164 , Schooner Bay, Point Reyes National Seashore ( $\left.38^{\circ} 06^{\prime} \mathrm{N}-122^{\circ} 54^{\prime} \mathrm{W}\right) ; 165$, Kehoe Beach, Point Reyes National Seashore (38 $\left.09^{\prime} \mathrm{N}-122^{\circ} 56^{\prime} \mathrm{W}\right)$; 166, San Pablo

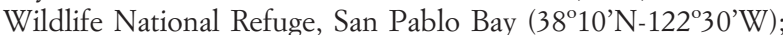
167, McClure Beach, Point Reyes National Seashore $\left(38^{\circ} 11^{\prime} \mathrm{N}\right.$ -

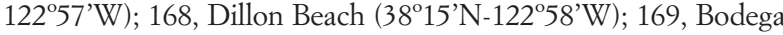
Bay $\left(38^{\circ} 20^{\prime} \mathrm{N}-123^{\circ} 04, \mathrm{~W}\right) ; 170$, Miwok Beach $\left(38^{\circ} 21^{\prime} \mathrm{N}\right.$ $\left.123^{\circ} 04^{\prime} \mathrm{W}\right) ; 171$, Goat Rock State Beach $\left(38^{\circ} 27^{\prime} \mathrm{N}-123^{\circ} 07^{\prime} \mathrm{W}\right)$; 172, Dump Beach, Point Arena State Park (38 $\left.35^{\prime} \mathrm{N}-123^{\circ} 20^{\prime} \mathrm{W}\right)$; 173, Manchester Beach State Park (38 $\left.58^{\prime} \mathrm{N}-123^{\circ} 42^{\prime} \mathrm{W}\right) ; 174$, Ten Mile River $\left(39^{\circ} 33^{\prime} \mathrm{N}-123^{\circ} 46^{\prime} \mathrm{W}\right)$; 175 , Mackerringer State Park (39 $\left.29^{\prime} \mathrm{N}-123^{\circ} 47^{\prime} \mathrm{W}\right) ; 176$, Cape Mendocino ( $\left.40^{\circ} 20^{\prime} \mathrm{N}-124^{\circ} 20^{\prime} \mathrm{W}\right)$; 177, Bear River, Capetown ( $\left.40^{\circ} 29^{\prime} \mathrm{N}-124^{\circ} 18^{\prime} \mathrm{W}\right) ; 178$, Samoa dunes, Eureka $\left(40^{\circ} 47^{\prime} \mathrm{N}-124^{\circ} 12^{\prime} \mathrm{W}\right) ; 179$, Arcata Bottoms

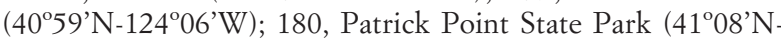
$\left.124^{\circ} 08^{\prime} \mathrm{W}\right) ; 181$, Big Lagoon Park, Humboldt $\left(41^{\circ} 09^{\prime} \mathrm{N}\right.$ -

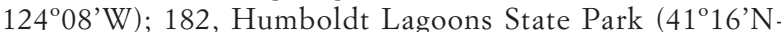
$\left.124^{\circ} 06 \mathrm{~W}\right) ; 183$, Requa $\left(41^{\circ} 35^{\prime} \mathrm{N}-124^{\circ} 05^{\prime} \mathrm{W}\right) ; 184$, Talawa Lake

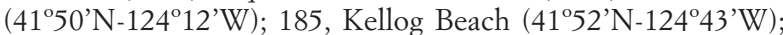
186, Talawa Lake Beach $\left(41^{\circ} 52^{\prime} \mathrm{N}-124^{\circ} 13^{\prime} \mathrm{W}\right)$. Oregón: 187 , Samuel Boardman State Park $\left(42^{\circ} 08^{\prime} \mathrm{N}-124^{\circ} 19^{\prime} \mathrm{W}\right)$; 188 , Pistol River State Park (42 $\left.{ }^{\circ} 16^{\prime} \mathrm{N}-124^{\circ} 24^{\prime} \mathrm{W}\right)$; 189 , Gold Beach $\left(42^{\circ} 24^{\prime} \mathrm{N}\right.$ $\left.124^{\circ} 25^{\prime} \mathrm{W}\right)$; 190, Cape Blanco (42 $\left.{ }^{\circ} 50^{\prime} \mathrm{N}-124^{\circ} 33^{\prime} \mathrm{W}\right)$; 191, Bullard

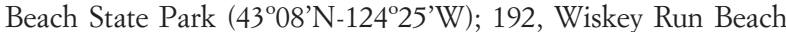
$\left(43^{\circ} 12^{\prime} \mathrm{N}-124^{\circ} 24^{\prime} \mathrm{W}\right)$; 193 , Seven Devil Beach $\left(43^{\circ} 14^{\prime} \mathrm{N}\right.$ $\left.124^{\circ} 24^{\prime} \mathrm{W}\right) ; 194$, South Slough National Estuarine Research Re-

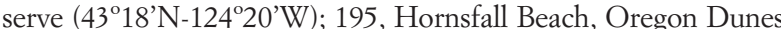

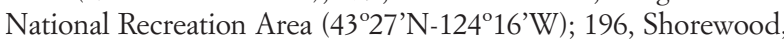
Coos Bay $\left(43^{\circ} 27^{\prime} \mathrm{N}-124^{\circ} 14^{\prime} \mathrm{W}\right) ; 197$, Bandom State Park $\left(43^{\circ} 28, \mathrm{~N}\right.$ $\left.124^{\circ} 13^{\prime} \mathrm{W}\right) ; 198$, Clear Lake (43⒊' $\left.\mathrm{N}-124^{\circ} 11^{\prime} \mathrm{W}\right) ; 199$, Umpkua

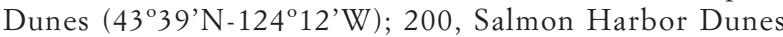

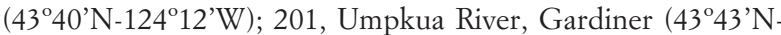
$\left.124^{\circ} 05^{\prime} \mathrm{W}\right) ; 202$, Sparrow Park, Oregon Dunes National Recreation Area $\left(43^{\circ} 44^{\prime} \mathrm{N}-124^{\circ} 11^{\prime} \mathrm{W}\right) ; 203$, Threemile Creek, Siuslaw National Forest $\left(43^{\circ} 46^{\prime} \mathrm{N}-124^{\circ} 08, \mathrm{~W}\right) ; 204$, Thakenitch, Oregon Dunes National Recreation Area $\left(43^{\circ} 50^{\prime} \mathrm{N}-124^{\circ} 09^{\prime} \mathrm{W}\right) ; 205$, South Jetty, Dunes City $\left(43^{\circ} 57^{\prime} \mathrm{N}-124^{\circ} 08^{\prime} \mathrm{W}\right) ; 206$, Heceta Beach

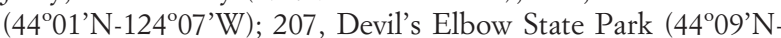
$\left.124^{\circ} 07^{\prime} \mathrm{W}\right) ; 208$, China Creek $\left(44^{\circ} 10^{\prime} \mathrm{N}-124^{\circ} 06^{\prime} \mathrm{W}\right) ; 209$, Beachside State Park $\left(44^{\circ} 23^{\prime} \mathrm{N}-124^{\circ} 05^{\prime} \mathrm{W}\right)$; 210 , Alsea Bay, Wadport

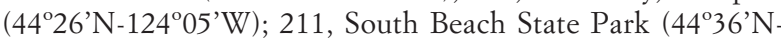

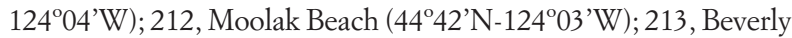
Beach State Park $\left(44^{\circ} 44^{\prime} \mathrm{N}-124^{\circ} 03^{\prime} \mathrm{W}\right) ; 214$, Gleneaden Beach

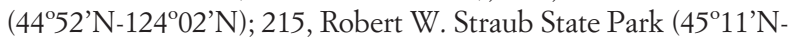

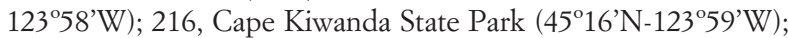
217, North Fork River, Nehalem $\left(45^{\circ} 24^{\prime} \mathrm{N}-123^{\circ} 53^{\prime} \mathrm{W}\right) ; 218$,

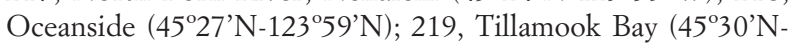

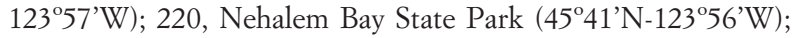

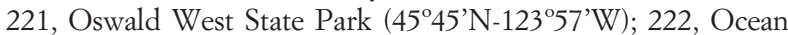
Beach, Fort Stevens State Park ( $\left.46^{\circ} 11^{\prime} \mathrm{N}-123^{\circ}{ }^{\circ} 9^{\prime} \mathrm{W}\right)$. Washington: 223 , Long Beach, Willapa Wildlife National Refuge $\left(46^{\circ} 36^{\prime} \mathrm{N}\right.$ $\left.124^{\circ} 02^{\prime} \mathrm{W}\right) ; 224$, Bay Center (46 $\left.37^{\circ} \mathrm{N}-123^{\circ} 57^{\prime} \mathrm{W}\right) ; 225$, Takeland, Willapa Bay $\left(46^{\circ} 43^{\prime} \mathrm{N}-124^{\circ} 01^{\prime} \mathrm{W}\right) ; 226$, North River $\left(46^{\circ} 44^{\prime} \mathrm{N}\right.$ $\left.123^{\circ} 53^{\prime} \mathrm{W}\right) ; 227$, Cranberry State Park ( $\left.46^{\circ} 47^{\prime} \mathrm{N}-124^{\circ} 05^{\prime} \mathrm{W}\right) ; 228$, Grayland Beach (46 $\left.48^{\prime} \mathrm{N}-124^{\circ} 05^{\prime} \mathrm{W}\right) ; 229$, Twin Harbors State Park $\left(46^{\circ} 51^{\prime} \mathrm{N}-124^{\circ} 06^{\prime} \mathrm{W}\right)$; 230 , Westport State Park Beach (46 $\left.54^{\prime} \mathrm{N}-124^{\circ} 07^{\prime} \mathrm{W}\right)$; 231, Westport State Park Wetland (46 $\left.{ }^{\circ} 54^{\prime} \mathrm{N}-124^{\circ} 06^{\prime} \mathrm{W}\right) ; 232$, Ocean City Beach $\left(47^{\circ} 04^{\prime} \mathrm{N}\right.$ $\left.124^{\circ} 10^{\prime} \mathrm{W}\right) ; 233$, Copalis Beach ( $\left.47^{\circ} 07^{\prime} \mathrm{N}-124^{\circ} 10^{\prime} \mathrm{W}\right) ; 234$, Eldon, Hood Canal (47 $\left.30^{\prime} \mathrm{N}-123^{\circ} 03^{\prime} \mathrm{W}\right)$; 235 , Kalahoch Beach ( $47^{\circ} 42^{\prime} \mathrm{N}$ $\left.124^{\circ} 25^{\prime} \mathrm{W}\right) ; 236$, La Push Beach, Olympic National Park

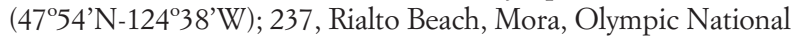
Park $\left(47^{\circ} 55^{\prime} \mathrm{N}-124^{\circ} 38^{\prime} \mathrm{W}\right)$; 238 , Durgeness Spit Wildlife Refuge Area $\left(48^{\circ} 08^{\prime} \mathrm{N}-123^{\circ} 11^{\prime} \mathrm{W}\right) ; 239$, Crescent Beach, Olympic Nation-

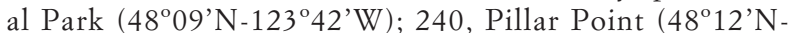
$\left.124^{\circ} 06^{\prime} \mathrm{W}\right) ; 241$, Clallam Bay ( $\left.48^{\circ} 15 \mathrm{~N}-124^{\circ} 16^{\prime} \mathrm{W}\right) ; 242$, Tsoo Yess Beach, Makah Indian Reserve (48 $\left.{ }^{\circ} 19^{\prime} \mathrm{N}-124^{\circ} 40^{\prime} \mathrm{W}\right) ; 243$, Sooa River, Makah Indian Reserve (48 $\left.20^{\prime} \mathrm{N}-124^{\circ} 39^{\prime} \mathrm{W}\right)$; 244 , Bellinghan Bay $\left(48^{\circ} 45^{\prime} \mathrm{N}-122^{\circ} 35^{\prime} \mathrm{W}\right)$. British Columbia: 245 , French

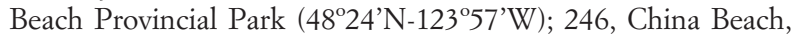
Juan de Fuca Provincial Park (48 $\left.26^{\prime} \mathrm{N}-124^{\circ} 05^{\prime} \mathrm{W}\right) ; 247$, Sombrio

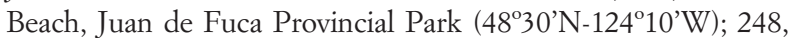
Botanical Beach, Juan de Fuca Provincial Park (4832'N$\left.124^{\circ} 27^{\prime} \mathrm{W}\right) ; 249$, Combers Beach, Pacific Rim National Park $\left(49^{\circ} 02^{\prime} \mathrm{N}-125^{\circ} 42^{\prime} \mathrm{W}\right) ; 250$, Florence Bay (49 $\left.00^{\circ} \mathrm{N}-125^{\circ} 39^{\prime} \mathrm{W}\right)$; 251, Chesterman Beach, Pacific Rim National Park $\left(49^{\circ} 07^{\prime} \mathrm{N}\right.$ $\left.125^{\circ} 53^{\prime} \mathrm{W}\right) ; 252$, Ocean Beach, Pacific Rim National Park (49 $\left.08^{\circ} \mathrm{N}-125^{\circ} 54^{\prime} \mathrm{W}\right) ; 253$, Bella Coola ( $\left.52^{\circ} 17^{\prime} \mathrm{N}-126^{\circ} 35^{\prime} \mathrm{W}\right) ; 254$, Bella Coola Valley $\left(52^{\circ} 22^{\prime}\right.$ N-126 $46^{\circ}$ 'W); 255, Log Creek, Skeena Valley, Port Essington ( $\left.54^{\circ} 12^{\prime} \mathrm{N}-129^{\circ} 40^{\prime} \mathrm{W}\right) ; 256$, Prince Rupert (54 $\left.21^{\prime} \mathrm{N}-129^{\circ} 09^{\prime} \mathrm{W}\right)$. Alaska: 257, Istmum Bay, Kodiak Island (57 $36^{\prime}$ N- $\left.152^{\circ} 24^{\prime} \mathrm{W}\right) ; 258$, Chinuak Lake, Kodiak Island

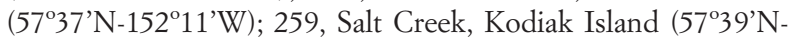

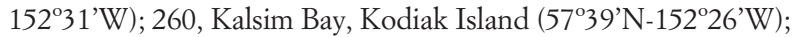

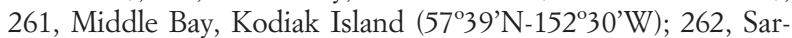
gent Creek, Women Bay, Kodiak Island (57 $\left.42^{\circ} \mathrm{N}-152^{\circ} 34^{\prime} \mathrm{W}\right) ; 263$, Pillar Creek Beach, Kodiak Island (57 $\left.{ }^{\circ} 49^{\prime} \mathrm{N}-152^{\circ} 26^{\prime} \mathrm{W}\right) ; 264$, Monashka Creek Bay, Kodiak Island (57 $\left.50^{\prime} \mathrm{N}-152^{\circ} 26^{\prime} \mathrm{W}\right) ; 265$, Anton Larsen Bay, Kodiak Island (57 $\left.50^{\circ} \mathrm{N}-152^{\circ} 38^{\prime} \mathrm{W}\right) ; 266$, Gustavus, Glacier Bay National Park (58 $\left.23^{\circ} \mathrm{N}-135^{\circ} 20^{\prime} \mathrm{W}\right) ; 267$, Taiya Inlet, Lynn Canal, Skagway (59 $29^{\prime}$ N-135 $16^{\prime}$ 'W); 268, Homer Spit (59 $\left.36^{\prime} \mathrm{N}-151^{\circ} 25^{\prime} \mathrm{W}\right) ; 269$, Ninilchik State Recreation Area, Cook Inlet $\left(60^{\circ} 02^{\prime} \mathrm{N}-151^{\circ} 40^{\prime} \mathrm{W}\right) ; 270$, Deep Creek, Ninilchick $\left(60^{\circ} 02^{\prime} \mathrm{N}\right.$ $\left.151^{\circ} 42^{\prime} \mathrm{W}\right) ; 271$, Toltsina Beach, Caines Coastal Trail, Seward $\left(60^{\circ} 04^{\prime} \mathrm{N}-149^{\circ} 26^{\prime} \mathrm{W}\right) ; 272$, Clam Gulf State Recreation Area, Cook Inlet $\left(60^{\circ} 14^{\prime} \mathrm{N}-151^{\circ} 24^{\prime} \mathrm{W}\right) ; 273$, Bishop Creek, Captain Cook State Park $\left(60^{\circ} 47^{\prime} \mathrm{N}-151^{\circ} 05^{\prime} \mathrm{W}\right) ; 274$, Turnagain Arm, Portage Glacier $\left(60^{\circ} 51^{\prime} \mathrm{N}-148^{\circ} 59^{\prime} \mathrm{W}\right)$; 275 , Turnagain Arm $\left(60^{\circ} 56^{\prime} \mathrm{N}-149^{\circ} 10^{\prime} \mathrm{W}\right)$; 276, Susitna Flats $\left(61^{\circ} 15^{\prime} \mathrm{N}-150^{\circ} 30^{\prime} \mathrm{W}\right) ; 277$, Goose Bay $\left(61^{\circ} 27^{\prime} \mathrm{N}\right.$ -

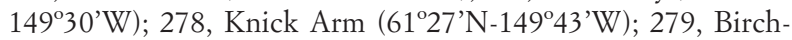
wood Lake (61'30'N-149³0'W).

Editor asociado: A. Galán de Mera Recibido: 15-I-2009 Aceptado: 4-III-2009 